Prepared for the U.S. Department of Energy under Contract DE-AC05-76RL01830

\title{
Nanocrystalline $\mathrm{SiC}$ and $\mathrm{Ti}_{3} \mathrm{SiC}_{2}$ Alloys for Reactor Materials: Annual Report
}

$\mathrm{CH}$ Henager, Jr. TJ Roosendaal BN Nguyen

W Jiang

December 2014
KJ Alvine

Y Shin

BA Borlaug

SA Arreguin

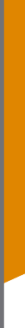

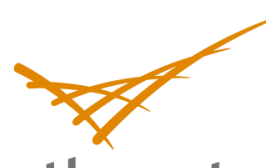

Pacific Northwest

NATIONAL LABORATORY

Proudly Operated by Battelle Since 1965 


\section{DISCLAIMER}

This report was prepared as an account of work sponsored by an agency of the United States Government. Neither the United States Government nor any agency thereof, nor Battelle Memorial Institute, nor any of their employees, makes any warranty, express or implied, or assumes any legal liability or responsibility for the accuracy, completeness, or usefulness of any information, apparatus, product, or process disclosed, or represents that its use would not infringe privately owned rights. Reference herein to any specific commercial product, process, or service by trade name, trademark, manufacturer, or otherwise does not necessarily constitute or imply its endorsement, recommendation, or favoring by the United States Government or any agency thereof, or Battelle Memorial Institute. The views and opinions of authors expressed herein do not necessarily state or reflect those of the United States Government or any agency thereof.

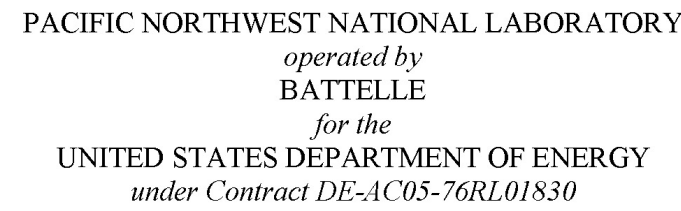

Printed in the United States of America

Available to DOE and DOE contractors from the Office of Scientific and Technical Information,

P.O. Box 62, Oak Ridge, TN 37831-0062;

ph: (865) 576-8401

fax: $(865)$ 576-5728

email: reports $\boldsymbol{a}$ adonis.osti.gov

Available to the public from the National Technical Information Service

5301 Shawnee Rd., Alexandria, VA 22312

ph: (800) 553-NTIS (6847)

email: orders@ntis.gov $<$ http://www.ntis.gov/about/form.aspx $>$

Online ordering: http://www.ntis.gov

This document was printed on recycled paper.

(8/2010) 


\title{
Nanocrystalline $\mathrm{SiC}$ and $\mathrm{Ti}_{3} \mathrm{SiC}_{2}$ Alloys for Reactor Materials: Annual Report
}

\author{
$\mathrm{CH}$ Henager, Jr. KJ Alvine \\ TJ Roosendaal Y Shin \\ BN Nguyen BA Borlaug \\ W Jiang SA Arreguin
}

December 2014

Prepared for

the U.S. Department of Energy

under Contract DE-AC05-76RL01830

Pacific Northwest National Laboratory

Richland, Washington 99352 


\begin{abstract}
A new dual-phase nanocomposite of $\mathrm{Ti}_{3} \mathrm{SiC}_{2} / \mathrm{SiC}$ is being synthesized using preceramic polymers, ceramic powders, and carbon nanotubes (CNTs) designed to be suitable for advanced nuclear reactors and perhaps as fuel cladding. The material is being designed to have superior fracture toughness compared to $\mathrm{SiC}$, adequate thermal conductivity, and higher density than $\mathrm{SiC} / \mathrm{SiC}$ composites. This annual report summarizes the progress towards this goal and reports progress in understanding certain aspects of the material behavior but some shortcomings in achieving full density or in achieving adequate incorporation of CNTs. The measured thermal conductivity is adequate and falls into an expected range based on $\mathrm{SiC}$ and $\mathrm{Ti}_{3} \mathrm{SiC}_{2}$. Part of this study makes an initial assessment for $\mathrm{Ti}_{3} \mathrm{SiC}_{2}$ as a barrier to fission product transport. Ion implantation was used to introduce fission product surrogates (Ag and $\mathrm{Cs}$ ) and a noble metal $(\mathrm{Au})$ in $\mathrm{Ti}_{3} \mathrm{SiC}_{2}, \mathrm{SiC}$, and a synthesized at PNNL. The experimental results indicate that the implanted $\mathrm{Ag}$ in $\mathrm{SiC}$ is immobile up to the highest temperature $(1273 \mathrm{~K})$ applied in this study; in contrast, significant out-diffusion of both $\mathrm{Ag}$ and $\mathrm{Au}$ in $\mathrm{MAX}$ phase $\mathrm{Ti}_{3} \mathrm{SiC}_{2}$ occurs during ion implantation at 873 $\mathrm{K}$. $\mathrm{Cs}$ in $\mathrm{Ti}_{3} \mathrm{SiC}_{2}$ is found to diffuse during post-irradiation annealing at $973 \mathrm{~K}$, and noticeable Cs release from the sample is observed. This study may suggest caution in using $\mathrm{Ti}_{3} \mathrm{SiC}_{2}$ as a fuel cladding material for advanced nuclear reactors operating at very high temperatures. Progress is reported in thermal conductivity modeling of $\mathrm{SiC}$-based materials that is relevant to this research, as is progress in modeling the effects of CNTs on fracture strength of SiC-based materials.
\end{abstract}




\section{Summary}

This annual report documents the synthesis, characterization, and modeling of SiC-based alloys with an overall structure of $\mathrm{SiC} / \mathrm{Ti}_{3} \mathrm{SiC}_{2}$ dual phase composites formed by simultaneous polycarbosilane pyrolysis that forms nanocrystalline $\mathrm{SiC}$ and $\mathrm{Si}+\mathrm{TiC}$ displacement reactions that form $\mathrm{SiC}+\mathrm{Ti}_{3} \mathrm{SiC}_{2}$ interpenetrating phase composites. To the best of our knowledge these are the first such dual phase composites made by combining these two methods. The structure and phase morphology of the composites are determined by optical microscopy, scanning electron microscopy, and X-ray diffraction methods. The general microstructural morphology is best described as a blocky, dual phase $\mathrm{SiC} / \mathrm{Ti}_{3} \mathrm{SiC}_{2}$ composite with porosity confined to the $\mathrm{SiC}$ phase. Data for thermal conductivity and fracture toughness indicate that properties of these composites are in agreement with what others have measured for similar materials but synthesized by different methods, such as spark plasma sintering, for example. The measured thermal conductivities determined using laser flash thermal diffusivity methods, while preliminary, are in the range of 40 to $60 \mathrm{~W} /(\mathrm{m} \cdot \mathrm{K})$, which is about half of that for a standard $\mathrm{SiC}$ material, such as Hexoloy SiC. This is an expected result since the thermal properties of $\mathrm{Ti}_{3} \mathrm{SiC}_{2}$ are not as good as $\mathrm{SiC}$. These values are still higher than those typically measured for $\mathrm{SiC}_{\mathrm{f}} / \mathrm{SiC}$ woven composites, which are often only $20 \mathrm{~W} /(\mathrm{m} \cdot \mathrm{K})$ or lower. However, the fracture toughness of the $\mathrm{SiC} / \mathrm{Ti}_{3} \mathrm{SiC}_{2}$ composites produced here are significantly increased relative to Hexoloy $\mathrm{SiC}$ values. This is an encouraging result and indicates that polymer pyrolysis methods can be used to continue these studies of combining in situ displacement reactions together with CNT mats to make tougher composites than can be synthesized by combining $\mathrm{SiC}$ and $\mathrm{Ti}_{3} \mathrm{SiC}_{2}$ materials alone.

This report documents important experimental results from a diffusion study of fission product surrogates (Ag and $\mathrm{Cs}$ ) and a noble metal $(\mathrm{Au})$ in MAX phase $\mathrm{Ti}_{3} \mathrm{SiC}_{2}$, cubic/hexagonal $\mathrm{SiC}$, and a dualphase nanocomposite of $\mathrm{Ti}_{3} \mathrm{SiC}_{2} / \mathrm{SiC}$. All of the implanted species were observed to be mobile in MAX phase $\mathrm{Ti}_{3} \mathrm{SiC}_{2}$ and to diffuse to the surface at moderately high temperatures (873 -973 K). However, Ag in $\mathrm{SiC}$ was observed to be immobile at the highest temperature $(1273 \mathrm{~K})$ applied in this study. The results from this study may provide an implication for caution of using $\mathrm{Ti}_{3} \mathrm{SiC}_{2}$ as a fuel cladding material for advanced nuclear reactors operating at very high temperatures.

Three significant modeling publications are highlighted that discuss new methods developed during this project to model thermal conductivity of composites, specifically multi-phase composites such as $\mathrm{SiC}_{\mathrm{f}} / \mathrm{SiC}$ composites, accounting for radiation damage degradation. The use of atomistic data is integrated into the methodology, which makes it particularly powerful. The second area of modeling is a micromechanics model of CNT toughening that emphasizes the limitations of CNTs in increasing fracture toughness of $\mathrm{SiC}$ and, therefore, suggests that other methods need to be introduced, such as a textured CNT mat as proposed here. 


\section{Acknowledgments}

A portion of the research was performed using EMSL, a national scientific user facility sponsored by the DOE's Office of Biological and Environmental Research and located at PNNL. Cesium ion implantation was conducted at the Institute of Modern Physics, Chinese Academy of Sciences. We would like to acknowledge Douglas Conner and Clyde Chamberlin for sample cutting and polishing, Chonghong Zhang and Jie Gou for Cs ion implantation, Tamas Varga for XRD, and Limin Zhang and Amila Dissanayake for assistance in performing some of the experiments. 


\section{Acronyms and Abbreviations}

\begin{tabular}{|c|c|}
\hline $\begin{array}{l}\text { PNNL } \\
\text { PNNL-23948 }\end{array}$ & Pacific Northwest National Laboratory \\
\hline CNTs & Carbon nanotubes \\
\hline CVD & Chemical Vapor Deposition \\
\hline CVI & Chemical vapor infiltration \\
\hline dpa & Displacements per Atom \\
\hline ECR & Electron Cyclotron Resonance \\
\hline EDS & Energy dispersive X-ray spectroscopy \\
\hline EMSL & Environmental Molecular Sciences Laboratory \\
\hline EMTA & Eshelby-Mori-Tanaka Approach \\
\hline FE & Finite Element \\
\hline FWHM & Full Width at Half Maximum \\
\hline GIXRD & Grazing-angle Incidence X-ray Diffraction \\
\hline HIM & Helium Ion Microscopy \\
\hline IMP & Institute of Modern Physics \\
\hline MAX & $\begin{array}{l}M_{n+1} A X_{n} \text { with } n=1,2 \text {, or } 3 \text {, where } M \text { is an early transition metal, } A \text { is mostly elements } \\
\text { in group } 13 \text { or } 14 \text {, and } X \text { is } C \text { or } N\end{array}$ \\
\hline MBL & modified boundary layer \\
\hline Micro-XRD & Micro-beam X-ray Diffraction \\
\hline MWCNT & multiwall carbon nanotube \\
\hline NEC & National Electrostatics Corporation \\
\hline NEET & Nuclear Energy Enabling Technologies \\
\hline $\mathrm{OM}$ & Optical microscopy \\
\hline
\end{tabular}




\begin{tabular}{|c|c|}
\hline $\mathrm{RBS} / \mathrm{C}$ & Rutherford Backscattering Spectrometry under Channeling condition \\
\hline SEM & Secondary Electron Microscopy \\
\hline SEVNB & single edge $\mathrm{V}$-notched beam \\
\hline SW & single wall \\
\hline $\mathrm{SiC}$ & Silicon carbide \\
\hline SRIM03 & Stopping and Range of Ions in Matter code, version 2003 \\
\hline TEM & Transmission Electron Microscopy \\
\hline TOPAS & Total Pattern Analysis Solution \\
\hline TRISO & Tristructural Isotropic \\
\hline UD & unidirectional \\
\hline $\mathrm{VE}$ & vanishing element \\
\hline XRD & X-ray Diffraction \\
\hline$\alpha_{\mathrm{a}}$ & Thermal Expansion Coefficient along $a$ Axis \\
\hline$\alpha_{\mathrm{c}}$ & Thermal Expansion Coefficient along $c$ Axis \\
\hline$\chi_{\text {min }}$ & Minimum Yield \\
\hline$\kappa_{\text {th }}$ & Thermal Conductivity \\
\hline
\end{tabular}




\section{Contents}

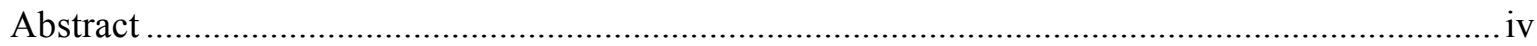

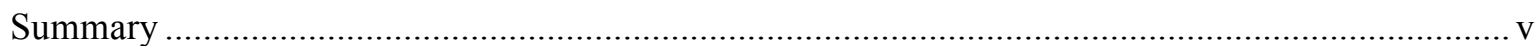

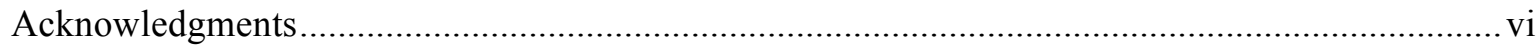

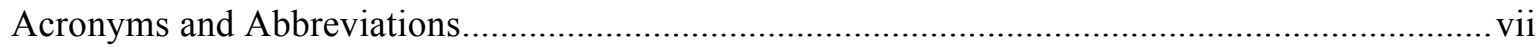

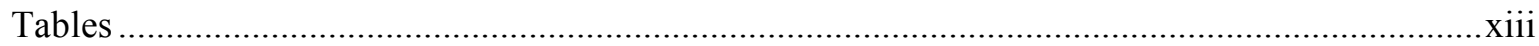

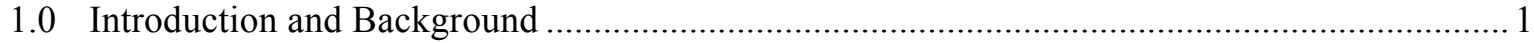

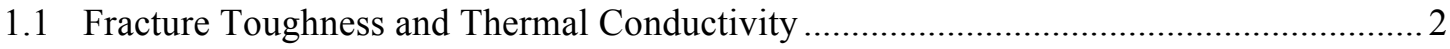

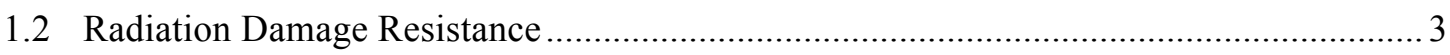

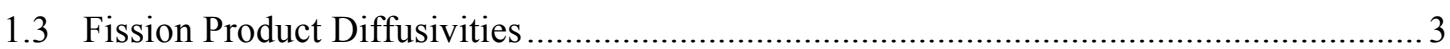

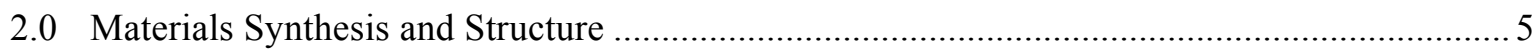

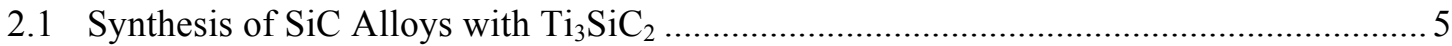

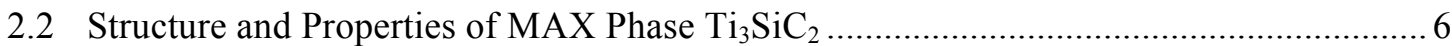

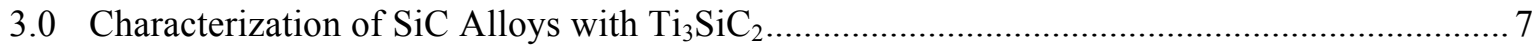

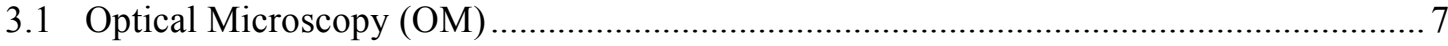

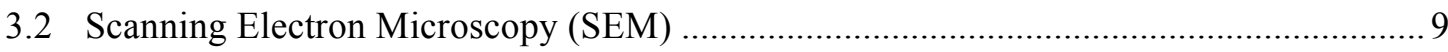

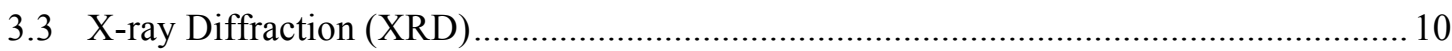

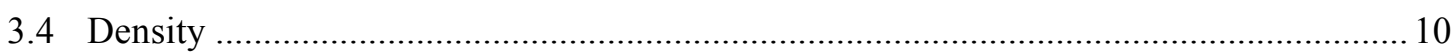

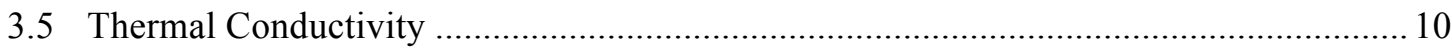

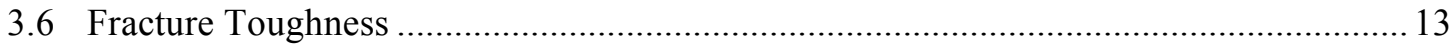

4.0 Fission Product Surrogate Diffusion …........................................................................... 14

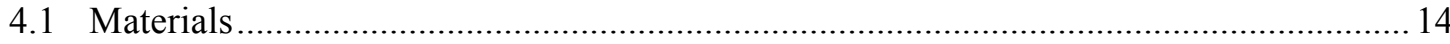

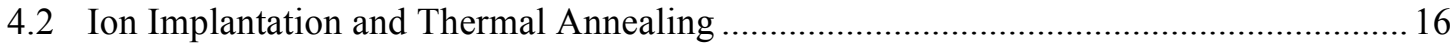

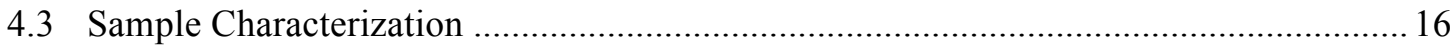

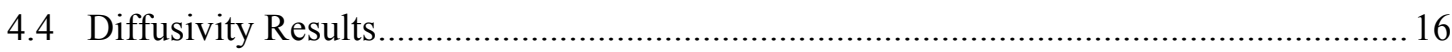

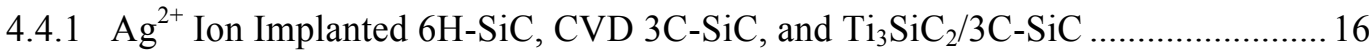

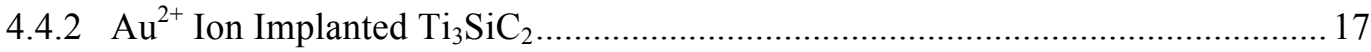

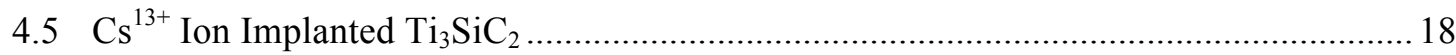

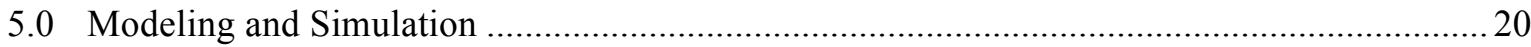

5.1 Prediction of Elastic Properties of Composites Containing CNTs ..................................2 20

5.2 A Mechanistic Damage Model for MWCNT Ceramic Composites .................................21

5.3 Fracture Toughness Prediction for MWCNT Reinforced Ceramics ................................ 22

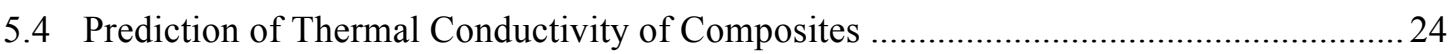

5.4.1 Prediction for a 2D-Hi-Nicalon ${ }^{\mathrm{TM}} /$ Pyrolitic Carbon/ICVI-SiC Composite .......... 25

5.4.2 Prediction for a 2D-Hi-Nicalon Type-S/PyC/ICVI-SiC Composite ......................22 
5.5 Prediction of Thermal Conductivities for Irradiated SiC .............................................2 28

5.5.1 Prediction of thermal conductivity for unirradiated $\mathrm{SiC}$ constituents ...................2. 28

5.5.2 Prediction of thermal conductivity for irradiated SiC constituents .......................29

5.5.3 Prediction of Thermal Conductivity for Irradiated SiC/SiC Composites............... 30

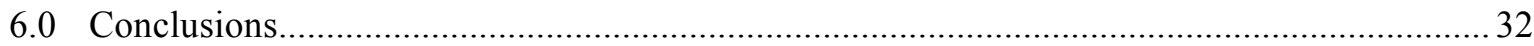

6.1 Thermal and Mechanical Properties with Microstructural Characterization ....................32

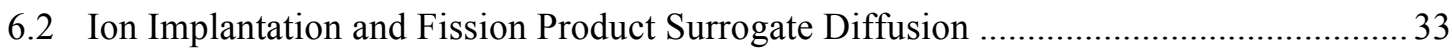

6.2.1 $\mathrm{Ag}^{2+}$ ion implanted $\mathrm{Ti}_{3} \mathrm{SiC}_{2} / 3 \mathrm{C}-\mathrm{SiC}$ dual-phase nanocomposite .......................... 34

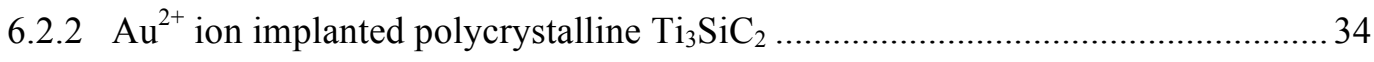

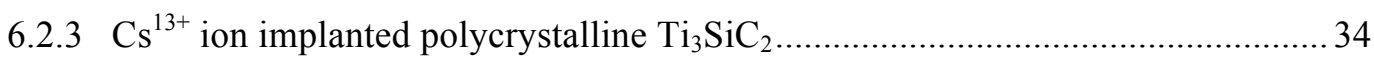

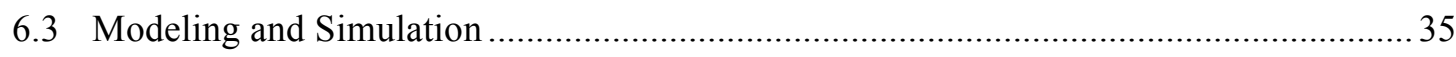

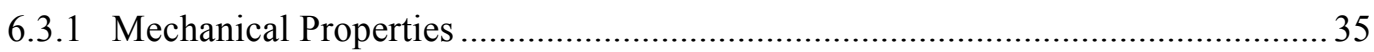

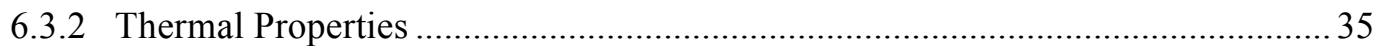

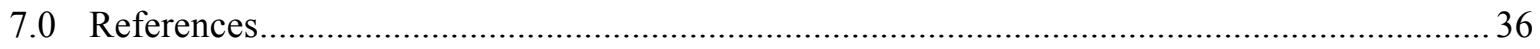




\section{Figures}

Figure 1. A gel cast mixture of polycarbosilane polymer filled with 30 -vol\% SiC-particles and then filled with $40-\mathrm{vol} \% \mathrm{Si}+\mathrm{TiC}$ powders and cured at $60^{\circ} \mathrm{C}$. This creates a smooth solid green disk that can be handled and machined. The smaller disk on the left is a 1-inch diameter $(2.54 \mathrm{~cm})$ that is used for hot pressing while the larger disk on the right is 2 inches $(5.08 \mathrm{~cm})$ in diameter for future use.

Figure 2. Unit cell of $\mathrm{Ti}_{3} \mathrm{SiC}_{2}$ : (a) polyhedra of $\mathrm{Ti}_{6} \mathrm{C}$ separated by Si layers and (b) close-packed hexagonal structure showing stacking with $\mathrm{C}$ occupying the octahedral sites within Ti-Ti layers.

Figure 3. Ternary isotherm section of Ti-Si-C system at $1250^{\circ} \mathrm{C}(1523 \mathrm{~K})$. The $3: 2$ mole ratio of $\mathrm{Si}$ TiC (connected by the dashed line) reacts to give composition marked as TSC1 on this diagram, which is on the join between $\mathrm{SiC}$ and $\mathrm{Ti}_{3} \mathrm{SiC}_{2}$. Overall, this diagram indicates that four phases $\left(\mathrm{SiC}, \mathrm{TiC}, \mathrm{Ti}_{3} \mathrm{SiC}_{2}\right.$, and $\left.\mathrm{TiSi}_{2}\right)$ are expected to occur in this $\mathrm{SiC}$-alloy system at equilibrium.

Figure 4. Optical micrograph showing $\mathrm{SiC} / \mathrm{Ti}_{3} \mathrm{SiC}_{2}$ interpenetrating phase microstructure visible in several large colonies surrounded by porous $\mathrm{SiC}$-polymer pyrolysis dark grey regions. The light grey platelets in the large white particles are the $\mathrm{SiC}$ that forms during the displacement reaction between $\mathrm{Si}$ and $\mathrm{TiC}$. This sample was hot-pressed at $1550^{\circ} \mathrm{C}(1823 \mathrm{~K})$ in argon.

Figure 5. Optical micrograph of hot-pressed SiC-alloy at $1800^{\circ} \mathrm{C}$ and $20 \mathrm{MPa}$. The SiC-platelet features in Fig. 4 are no longer present but are replaced by a more blocky $\mathrm{SiC} / \mathrm{Ti}_{3} \mathrm{SiC}_{2}$ phase structure. The light grey phase is $\mathrm{Ti}_{3} \mathrm{SiC}_{2}$ and the darker grey phase is $\mathrm{SiC}$, both from the displacement reaction and from the polymer pyrolysis plus the $\mathrm{SiC}$-filler. $\mathrm{SiC}$ alignment within the $\mathrm{Ti}_{3} \mathrm{SiC}_{2}$ matrix is still evident.

Figure 6. SEM images of a SiC-alloy hot pressed at $1800^{\circ} \mathrm{C}(2073 \mathrm{~K})$ and $20 \mathrm{MPa}$ pressure from $\mathrm{SiC}$-filled polymer plus $\mathrm{Si}+\mathrm{TiC}$ powders at $63 \%$ powder loading. The white phase is the $\mathrm{Ti}_{3} \mathrm{SiC}_{2}$ phase and the darker grey phase is $\mathrm{SiC}$. Note that the pores are contained entirely within the $\mathrm{SiC}$ phase.

Figure 7. XRD data from each of the samples listed in Table 2. Residual TiC is observed in some of the samples but the major phases are $\mathrm{SiC}$ and $\mathrm{Ti}_{3} \mathrm{SiC}_{2}$ as shown.

Figure 8. Thermal conductivity data from Ref. [64] showing the effects of adding $\mathrm{SiC}$ to $\mathrm{Ti}_{3} \mathrm{SiC}_{2}$ to increase its thermal conductivity. PNNL average thermal conductivity data for the six nominally identical specimens in Table 2 is shown in blue on this graph and corresponds quite well with this published data.

Figure 9. Measured fracture toughness from each of the samples from Table 2 as determined using the indentation fracture toughness method. Ten indents were used for each data point shown in the figure. All of the samples showed an increase in toughness as compared to Hexoloy SiC, which was also tested.

Figure 10. Picture of two polycrystalline $\mathrm{Ti}_{3} \mathrm{SiC}_{2} / 3 \mathrm{C}$-SiC nanocomposite plates $\left(3 \times 6 \times 1 \mathrm{~mm}^{3}\right)$, a polycrystalline CVD 3C-SiC disk ( $8 \mathrm{~mm}$ in diameter and $1 \mathrm{~mm}$ in thickness) and a $6 \mathrm{H}-\mathrm{SiC}$

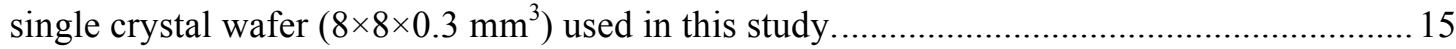


Figure 11. XRD pattern of a polycrystalline CVD 3C-SiC with an average crystallite size of 33.4 $\mathrm{nm}$.

Figure 12. XRD pattern of a dual-phase nanocomposite $\mathrm{Ti}_{3} \mathrm{SiC}_{2} / 3 \mathrm{C}$-SiC with average crystallite sizes of $34 \mathrm{~nm}$ for $\mathrm{Ti}_{3} \mathrm{SiC}_{2}$ and $23 \mathrm{~nm}$ for $3 \mathrm{C}-\mathrm{SiC}$.

Figure 13. XRD pattern of a polycrystalline $\mathrm{Ti}_{3} \mathrm{SiC}_{2}$ plate cut and polished from a hot-pressed bulk ingot (inserted optical image).

Figure 14. (a) $2.0 \mathrm{MeV} \mathrm{He}{ }^{+} \mathrm{RBS}$ spectra for (a) a polycrystalline $\mathrm{CVD} 3 \mathrm{C}-\mathrm{SiC}$ and (b) a $\mathrm{Ti}_{3} \mathrm{SiC}_{2} / 3 \mathrm{C}$-SiC nanocomposite implanted $7^{\circ}$ off normal with $400 \mathrm{keV} \mathrm{Ag}^{2+}$ at $873 \mathrm{~K}$ to $2.8 \times 10^{16} \mathrm{ions} / \mathrm{cm}^{2}$. The Ag peak shown in (b) is due to out-diffusion of Ag to the surface of the $\mathrm{Ti}_{3} \mathrm{SiC}_{2} / 3 \mathrm{C}-\mathrm{SiC}$ nanocomposite.

Figure 15. A sequence of in-situ $3.0 \mathrm{MeV} \mathrm{He}{ }^{+} \mathrm{RBS}$ spectra for a polycrystalline $\mathrm{Ti}_{3} \mathrm{SiC}_{2}$ implanted with $2.0 \mathrm{MeV} \mathrm{Au}^{2+}$ at various implantation temperatures to the same ion fluence of $1.0 \times 10^{16}$ ions $/ \mathrm{cm}^{2}$.

Figure 16. $30 \mathrm{~min}$ isochronal annealing of a polycrystalline $\mathrm{Ti}_{3} \mathrm{SiC}_{2}$ implanted with $1.0 \mathrm{MeV}$ $\mathrm{Cs}^{13+}$ at $673 \mathrm{~K}$ to an ion fluence of $5.7 \times 10^{16} \mathrm{ions} / \mathrm{cm}^{2}$.

Figure $17.1073 \mathrm{~K}$ isothermal annealing of a polycrystalline $\mathrm{Ti}_{3} \mathrm{SiC}_{2}$ implanted with $1.0 \mathrm{MeV}$ $\mathrm{Cs}^{13+}$ at $673 \mathrm{~K}$ to an ion fluence of $5.7 \times 10^{16} \mathrm{ions} / \mathrm{cm}^{2}$.

Figure 18. Schematic of the EMTA Homogenization Procedure....

Figure 19. Measured and Predicted Shear Modulus for a MWCNT/3YSZ System as a Function of MWCNT Volume Fraction. The experimental results are from Mazaheri, Mari [74].

Figure 20. Tensile Stress/Strain Response Predicted for MWCNT/3YSZ as a Function of the MWCNT Weight Fraction

Figure 21. Predicted and Experimental Mode I Fracture Toughness vs. MWCNT Volume Fraction for the MWCNT/3YSZ Composites. The experimental results were determined by Mazaheri et al. [74] via bending tests of single edge V-notched beam specimens.

Figure 22. Predicted Stress Intensity Factor vs. Crack Advance for the MWCNT/3YSZ Composites as a Function of MWCNT Content.

Figure 23. Thermal conductivities of the equivalent fibers predicted by EMTA for the fibers with thin and thick coating layers.

Figure 24. Thermal conductivities predicted by EMTA for the DuPont $2 \mathrm{D} \mathrm{SiC} / \mathrm{SiC}$ woven composite with the thin fiber coating layer: (a) In-plane thermal conductivities, $k_{11}$ and $k_{22}$, and (b) transverse thermal conductivity $k_{33}$ compared to Youngblood et al.'s experimental results [84].

Figure 25. Transverse thermal conductivities predicted by EMTA for the 2D Hi-Nicalon Type$\mathrm{S} / \mathrm{PyC} / \mathrm{ICVI}-\mathrm{SiC}$ composite as a function temperature using the assumed and adjusted matrix thermal conductivities - The symbols denote Youngblood experimental results [87].

Figure 26. Thermal conductivities predicted for unirradiated $\mathrm{SiC}$ constituents based on the experimental data for CVD-SiC [91] and by the application of Collins et al.'s relation [88] in the elevated temperature range. 
Figure 27. Thermal conductivities vs. irradiation dose predicted for $\mathrm{SiC}$ constituents at $473 \mathrm{~K}$ in (a) and $1073 \mathrm{~K}$ in (b) using the computed thermal resistance results at this temperature.........30

Figure 28. Irradiation temperature (IT) thermal conductivity vs. irradiation temperature predicted by MD/EMTA for the example Tyranno-SA/ICVI-SiC composite compared to room temperature (RT) thermal conductivity vs. irradiation temperature measured by Katoh et al. [96] for a Tyranno-SA3/ICVI-SiC composite. Crocombette et al.'s as well as Samolyuk et al.'s MD data used in the computations are from Refs. [93, 94].

Figure 29. Plot of thermal conductivity as a function of sample density. There is a slight negative correlation between density and conductivity that is unexpected. For the most part, however, this plot shows a lack of a strong correlation since the fitted line has a correlation factor less than 0.3 .

Figure 30. Plot of fracture toughness (indentation method) as a function of sample density. Compared to the lack of correlation for the thermal data this dataset does indicate a general improvement of toughness with increasing density, which would be expected as porosity is decreased.

\section{Tables}

Table 1 - Research and Use Issues for SiC-based Materials as Nuclear Reactor Materials 2

Table 2. Basic Property Data for Hot-Pressed Nanocrystalline $\mathrm{SiC}$ and $\mathrm{Ti}_{3} \mathrm{SiC}_{2}$ Dual Phase Materials 7

Table 3. Average of EDS data for $\mathrm{SiC}$ and $\mathrm{Ti}_{3} \mathrm{SiC}_{2}$ phases from $\mathrm{SEM}$ data................................. 10

Table 4. Materials, ion implantation and thermal annealing conditions........................................ 14

Table 5. R-curves Power-Law Coefficients Identified for the MWCNT/3YSZ Composites 23 


\subsection{Introduction and Background}

$\mathrm{SiC}$ and $\mathrm{SiC}$-based composites have been investigated for several years as candidate structural and insulator materials for fusion energy systems [1-10]. Early SiC-based fibers for SiC-composites were found to be unstable under irradiation [11], but more mature SiC-fibers have emerged as a successful nanocrystalline $\mathrm{SiC}$ engineered material polymerized from high-purity polymers and e-beam crystallized $[1,12]$. SiC-based composites have thus emerged as a promising structural material for fusion energy systems, including first wall and breeder-blanket materials. Joining, thermal conductivity, and gas permeation remain as engineering issues for this application. While SiC-based composites, such as the continuous, Hi-Nicalon Type S fiber, 2D woven, chemical vapor infiltration (CVI)-SiC materials [1, 2], may have a place in advanced reactors, the gas permeability and thermal conductivity issues do not allow some critical applications. A dense SiC-based material system with high thermal conductivity and small impurity diffusion coefficients is required for this and other critical reactor materials applications. However, monolithic $\mathrm{SiC}$ has low fracture toughness and cannot be considered without some reinforcement phase. The critical issues that require resolution in order for new SiC-based materials to be considered for advanced reactor uses are 1) fracture toughness, 2) radiation damage, 3) thermal conductivity, and 4) fission product mobilities. Moving away from expensive fibers and CVI synthesis provides a low-cost synthesis method that is an additional advantage.

Overall radiation damage tolerance and swelling at low temperatures is considered an issue for using SiC-based materials at $573 \mathrm{~K}$, which is the temperature range for conventional light water reactors. The vast majority of the data indicates that swelling in $\mathrm{SiC}$ is significant at these temperatures, saturating at about $2 \%$ swelling [13]. Thermal conductivity is also degraded at these irradiation temperatures, decreasing to about $10 \mathrm{~W} /(\mathrm{m} \cdot \mathrm{K})$ or less at $573 \mathrm{~K}$ irradiations $[13,14]$ due to an accumulation of point defect damage. These data suggest that it is far better for SiC-based materials to operate at higher temperatures in terms of property degradation. For example, at $1073 \mathrm{~K}$ irradiation swelling in $\mathrm{SiC}$ is less than $1 \%$ and thermal conductivity is upwards of $20 \mathrm{~W} /(\mathrm{m} \cdot \mathrm{K})$.

Increasing the operating temperature by at least $200 \mathrm{~K}$ over current operating temperatures results in improved performance for SiC-based materials, and the incorporation of carbon nanotubes (CNTs) should alleviate the thermal conductivity issues that are of concern for many nuclear applications of SiC. Moving away from expensive SiC-fibers to CNTs may also reduce manufacturing costs since CNTs are becoming more of a commodity item. Others have shown remarkable improvements in materials properties using CNTs of varying types [15].

The issues of 1) radiation damage tolerance and swelling at low temperatures, 2) thermal conductivity, and 3) capability of low-cost synthesis methods are classified as problematic to $\mathrm{SiC}$ in general and are specifically addressed in this research by advocating higher use temperatures, CNTs for improved thermal conductivity, and also for lower cost synthesis methods. The proposed material, then, is not a fiberreinforced composite material with the associated high cost of fiber and gas permeability issues [13]. However, moving away from continuous fiber reinforced material exposes the low fracture toughness of $\mathrm{SiC}$, while at the same time making a gas impermeable material possible via near-theoretical dense processing. The critical issue then becomes fracture toughness as long as the irradiation temperature exceeds about $1000 \mathrm{~K}$. Table 1 lists the various issues facing $\mathrm{SiC}$-based materials with suggested approaches to resolve them. An issue that has been overlooked for SiC-based alloys is the ability to block the diffusion of fission products. Therefore, this research is an integral part of this study. 
Table 1 - Research and Use Issues for SiC-based Materials as Nuclear Reactor Materials

\begin{tabular}{|c|c|c|}
\hline Issue & Description & Resolution \\
\hline Radiation Damage/Swelling & $\begin{array}{l}\text { Swelling is significant below } \\
1173 \mathrm{~K} \text { but saturates at low } \\
\text { doses. }\end{array}$ & $\begin{array}{l}\text { Nanocrystalline } \mathrm{SiC} / \mathrm{Ti}_{3} \mathrm{SiC}_{2} \text { with } \\
\mathrm{CNT} \text { reinforcement may have } \\
\text { superior damage resistance. } \\
\text { Operating temperatures adequate to } \\
1700 \mathrm{~K} \text { to avoid peak swelling. }\end{array}$ \\
\hline Thermal Conductivity & $\begin{array}{l}\text { Radiation damage creates large } \\
\text { phonon scattering, reduces } \mathrm{K}_{\text {th }} \\
\text { especially for } \mathrm{SiC} \text {-fiber } \\
\text { composites made by CVI. }\end{array}$ & $\begin{array}{l}\text { Avoid porous fiber composite CVI } \\
\text { architecture with all the internal } \\
\text { interfaces, add CNTs with superior } \\
\mathrm{K}_{\text {th }} \text {, operate above } 823 \mathrm{~K} \text {. }\end{array}$ \\
\hline Gas Permeable & $\begin{array}{l}\text { Porous SiC-fiber composites by } \\
\text { CVI are highly gas permeable. }\end{array}$ & $\begin{array}{l}\text { Avoid CVI architecture. Near } \\
\text { theoretical dense nanocrystalline } \\
\text { composites will be gas impermeable. }\end{array}$ \\
\hline Fracture Toughness & $\begin{array}{l}\text { Monolithic } \mathrm{SiC} \text { is } \text { brittle } \\
\text { material; continuous } \mathrm{SiC} \text {-fiber } \\
\text { materials have requisite } \\
\text { toughness, with strong R-curve. }\end{array}$ & $\begin{array}{l}\text { Design tough nanocomposite using } \\
\mathrm{Ti}_{3} \mathrm{SiC}_{2} \text {-phase reinforcement plus } \\
\mathrm{CNT} \text { mechanical reinforcement with } \\
\text { 3D texture. }\end{array}$ \\
\hline Fission Product Diffusion & $\begin{array}{l}\text { Micro-cracks and pores in CVD } \\
\text { SiC allow radionuclide }{ }^{110 \mathrm{~m}} \mathrm{Ag} \text { to } \\
\text { migrate and potentially to release } \\
\text { to the environment. }\end{array}$ & $\begin{array}{l}\mathrm{SiC}^{\mathrm{Ti}} \mathrm{Ti}_{3} \mathrm{SiC}_{2}+\mathrm{CNT} \text { may block the } \\
\text { diffusion pathway by eliminating the } \\
\text { micro-cracks interconnected with } \\
\text { pores. }\end{array}$ \\
\hline Lower Cost Synthesis & $\begin{array}{l}\text { Continuous SiC-fiber composites } \\
\text { made by CVI have high costs } \\
\text { due to high cost of fiber. }\end{array}$ & $\begin{array}{l}\mathrm{SiC} / \mathrm{Ti}_{3} \mathrm{SiC}_{2}+\mathrm{CNT} \text { composites will } \\
\text { have reduced processing costs } \\
\text { compared to } \mathrm{SiC} \text {-fiber composites. }\end{array}$ \\
\hline
\end{tabular}

\subsection{Fracture Toughness and Thermal Conductivity}

-While continuous-fiber reinforced $\mathrm{SiC}$-composites do have adequate fracture toughness via the wellunderstood debonding fiber toughening mechanics, an approach using CNTs to improve both properties requires some additional justification. One novel approach is using CNT mats that are textured in 3D using new imprinting techniques to achieve more substantial toughening compared to untextured CNT mats or to dispersed CNTs within $\mathrm{SiC} / \mathrm{Ti}_{3} \mathrm{SiC}_{2}$ nanocomposites. To the best of our knowledge, this approach has not been tried yet by other researchers and clearly represents a new approach to composite toughening using CNTs. With regard to fracture toughness and thermal conductivity, a $\mathrm{SiC} / \mathrm{Ti}_{3} \mathrm{SiC}_{2}+$ CNT nanocrystalline composite could have adequate properties if well designed. Three different mechanisms are being investigated to improve fracture toughness in these nanocrystalline composites. One is through the use of $\mathrm{SiC} / \mathrm{Ti}_{3} \mathrm{SiC}_{2}$ composite toughening that makes use of the intrinsic toughness of $\mathrm{Ti}_{3} \mathrm{SiC}_{2}$-phase materials. The second is the use of CNT toughening mechanics. Thirdly, the overall 3D architecture of the CNT mats can provide energy absorption and enhanced fracture toughness.

Prior work at PNNL has demonstrated that solid-state displacement reactions between TiC and Si lead to several tough alloys consisting of $\mathrm{Ti}_{3} \mathrm{SiC}_{2}$ and $\mathrm{SiC}[16,17]$. A displacement reaction occurs when two (or more) materials are combined and undergo a simultaneous reaction to produce two (or more) product phases. The displacement reaction between $\mathrm{Si}+\mathrm{TiC}$ produces $\mathrm{SiC}+\mathrm{Ti}_{3} \mathrm{SiC}_{2}$ in an interpenetrating phase 
morphology. The two product phases often interpenetrate since they form via short-range diffusion simultaneously and, therefore, remain proximate during the reaction. The phase morphology produced by the $\mathrm{Si}+\mathrm{TiC}$ reaction consists of $\mathrm{SiC}$-platelets aligned within blocky $\mathrm{Ti}_{3} \mathrm{SiC}_{2}$ grains, which contributes to an intrinsic toughening. PNNL-produced $\mathrm{SiC} / \mathrm{Ti}_{3} \mathrm{SiC}_{2}$ composite materials exhibit a $\mathrm{K}_{\mathrm{IC}}$ toughness of almost $10 \mathrm{MPa} \sqrt{ } \mathrm{m}$ without further optimization. The increased toughness is attributed to the intrinsic toughness of the $\mathrm{Ti}_{3} \mathrm{SiC}_{2}$ phase, one of the so-called MAX phase layered ceramic structures [17-22], which grows in an interpenetrating manner with the $\mathrm{SiC}$ phase during the displacement reaction. In addition, the growth during displacement reaction processing provides a highly aligned microstructure that enhances this toughness. The addition of CNTs, as either individual entities or as textured 3D mats, will also enhance the fracture toughness compared to monolithic $\mathrm{SiC}$ [13]. The 3D texturing effect is more difficult to quantify without additional data, however the energy absorption due to CNT straightening and interlocking, as well as crack deflection and tortuosity will achieve additional toughening compared to simple CNT dispersions in a SiC-matrix. The goal is to synthesize a material with a $\mathrm{K}_{\mathrm{IC}}$ toughness of at least 15-20 with a substantial R-curve response, and it is anticipated that the 3D texturing will help achieve this toughness increase.

CNTs have been shown to increase thermal properties for almost all materials that they can be distributed in [23-26]. The results of small additions of CNTs to polymers, for example, lead to thermal conductivity increases of up to $60 \%$ depending on the loading and on the type of CNT. Additions of CNTs to conventional C-fiber-reinforced SiC-composites also indicate improved thermal conductivity [23]. This is significant because present $\mathrm{SiC}_{\mathrm{f}} / \mathrm{SiC}$ composites are borderline for thermal conductivity for nuclear applications and this critical property only degrades under irradiation [13].

\subsection{Radiation Damage Resistance}

Although $\mathrm{SiC}$ has excellent radiation damage resistance it is not immune to radiation damage processes. Under $2 \mathrm{MeV} \mathrm{Au}^{2+}$ ion irradiation at room temperature, nanostructured high-purity 3C-SiC, composed of 4.6-nm crystallites, was fully amorphized at a dose comparable to the amorphization dose for bulk $\mathrm{SiC}$ [27]. The behavior can be attributed to high ion flux and sluggish migration of point defects within the $\mathrm{SiC}$ grain interior. Amorphization in nanocrystalline $3 \mathrm{C}-\mathrm{SiC}$ is likely to arise from local defect accumulation and interaction within the interior of grains, leading to a catastrophic disruption and collapse of the crystal structure, quite similar to the processes in ion-irradiated bulk single-crystal SiC. Recent results [28] have revealed that, under identical irradiation conditions with $\mathrm{Si}^{+}$ions, full amorphization of $3 \mathrm{C}-\mathrm{SiC}$ with grain sizes ranging from $2.0-3.8 \mathrm{~nm}$ requires a lower dose than for single crystal $3 \mathrm{C}-\mathrm{SiC}$. The average size of the $3 \mathrm{C}-\mathrm{SiC}$ crystallites, observed from the (111) plane diffraction, decreased nonlinearly from $3.8 \mathrm{~nm}$ for an unirradiated sample to $1.5 \mathrm{~nm}$ for a fluence of $12 \mathrm{Si}^{+} / \mathrm{nm}^{2}$ at room temperature, and further decreased until the material was fully amorphized at $0.24 \mathrm{dpa}$. This behavior has been attributed to interface amorphization during the ion irradiation. Recent results [29] indicate that although nanograins of $\mathrm{SiC}$ can be readily amorphized under ion irradiation below $500 \mathrm{~K}$, nanograins at $550 \mathrm{~K}$ grow to larger sizes; furthermore, the grain size tends to saturate at a high fluences [29]. The observed sharp transition from irradiation-induced interface-driven amorphization at $500 \mathrm{~K}$ to crystallization at $550 \mathrm{~K}$ is an indication of the structural stability of the nanostructured $\mathrm{SiC}$ under ion irradiation. Clearly, more research efforts are needed to study the higher-dose behavior of nanocrystalline $\mathrm{SiC}$ as well as to understand the physical processes.

\subsection{Fission Product Diffusivities}

Silicon carbide ( $\mathrm{SiC}$ ) and $\mathrm{SiC} / \mathrm{SiC}$ composites have been proposed and tested as a cladding material for nuclear fuels (such as $\mathrm{UCO}$ and $\mathrm{UO}_{2}$ ) in the tri-structural-isotropic (TRISO)-coated particle design 
[30, 31]. It consists of four layers of surface coatings, including a $\mathrm{SiC}$ layer of several to tens of microns in thickness. The SiC layer not only provides the mechanical strength for the fuel particle, but also acts as an impenetrable barrier for fission products, including metallic and gaseous species. The behavior of fission products in the TRISO-coated particles was studied up to $1573 \mathrm{~K}$ with high burn-up (up to $10 \%$ ) [32]. Tests of the post-irradiated TRISO coated fuel particles at accident temperatures of 1973 and 2073 $\mathrm{K}$ were also performed [33]. The results show that the irradiated fuel in the pre-heating test has a relatively large fractional release of the excited state ${ }^{110 \mathrm{~m}} \mathrm{Ag}$ compared to other radionuclides, such as ${ }^{137} \mathrm{Cs},{ }^{154} \mathrm{Eu}$ and ${ }^{85} \mathrm{Kr}$. The time-dependent fractional release of ${ }^{110 \mathrm{~m}} \mathrm{Ag}$ is the highest. Large cracks of the $\mathrm{SiC}$ layer was also found after annealing at the extremely high temperatures.

Our early study [34] of Ag diffusivity in both crystalline and amorphized $\mathrm{SiC}$ indicated that $\mathrm{Ag}$ is immobile in $\mathrm{SiC}$ up to $1573 \mathrm{~K}$ even in the presence of ion irradiation. The results were confirmed by a number of research groups [35, 36]. First-principles calculations [37] suggest that $\mathrm{Ag}$ is immobile in $\mathrm{SiC}$ bulk, but becomes mobile on $\mathrm{SiC}$ surfaces. The inner surfaces of the interconnected pores and microcracks in CVD SiC could provide a faster diffusion path for Ag to reach the surface of the fuel particle. $\mathrm{Ag}$ could also evaporate and release in the gas form through the pathway. It is currently believed that micro-cracks and pores in the CVD SiC layer play a key role in the $\mathrm{Ag}$ transport. $\mathrm{SiC}$ as a cladding material has a number of potential advantages, including good high-temperature corrosion properties, great high-temperature strength, low effective neutron absorption cross section, and good dimensional stability at high temperatures. However, it is brittle, which can promote in-service failure. The material is vulnerable to oxidation under certain conditions and its susceptibility to stress corrosion cracking is not yet clear. It gradually loses strength due to neutron irradiation, affecting its mechanical integrity during service.

In order to improve fuel performance and prevent fission products from release, more ductile cladding materials with very low diffusivities of fission products at reactor-relevant high temperatures need to be explored. MAX phases $\left(M_{n+1} A X_{n}\right.$ with $n=1,2$, or 3, where $M$ is an early transition metal, $A$ is mostly elements in group 13 or 14 , and $\mathrm{X}$ is $\mathrm{C}$ or $\mathrm{N}$ ) have a layered, hexagonally close-packed structure. They share outstanding properties of both metals (machinable, ductile, highly thermally conductive, highly radiation-resistant, etc.) and ceramics (elastically stiff, highly corrosion resistant, thermal shock resistant, having a high melting point, etc.). As such, MAX phase materials are considered as hybrids of ceramics and metals. The unique combination of the properties may make them good candidates for use as structural materials in nuclear reactors. Titanium silicon carbide $\left(\mathrm{Ti}_{3} \mathrm{SiC}_{2}\right)$, the most studied MAX phase to date, has fracture toughness about three times higher than $\mathrm{SiC}$ at ambient temperature [38]. The ternary compound has been proposed as a possible fuel-cladding material [39-41]. To the best of our knowledge, there have been no diffusion studies of fission products in $\mathrm{Ti}_{3} \mathrm{SiC}_{2}$ or other MAX phases to date. It is of scientific interest and technological importance to investigate and understand the diffusion behavior, especially at elevated temperatures. In this study, fission product surrogates ( $\mathrm{Ag}$ and $\mathrm{Cs}$ ) and a noble metal $(\mathrm{Au})$ were introduced into $\mathrm{MAX}$ phase $\mathrm{Ti}_{3} \mathrm{SiC}_{2}, \mathrm{SiC}$, and a dual-phase nanocomposite of $\mathrm{Ti}_{3} \mathrm{SiC}_{2} / \mathrm{SiC}$ using ion implantation. The diffusion behavior of the implanted species and structural changes were studied as a function of annealing temperature (isochronal), duration (isothermal) and irradiation status (present or absent) using Rutherford backscattering spectrometry (RBS), x-ray diffraction (XRD) and helium ion microscopy (HIM). 


\subsection{Materials Synthesis and Structure}

\subsection{Synthesis of SiC Alloys with $\mathrm{Ti}_{3} \mathrm{SiC}_{2}$}

SiC-based alloys are being synthesized using a commercial polycarbosilane polymer consisting of either pure polycarbosilane or polycarbosilane filled with SiC-particles ${ }^{1}$, with added $\mathrm{Si}$ and TiC powders. $\mathrm{Si}$ and $\mathrm{TiC}$ undergo a solid-state displacement reaction to form a dual-phase nanocomposite consisting of $\mathrm{SiC}+\mathrm{Ti}_{3} \mathrm{SiC}_{2}$. The materials are combined at maximum powder loading amounts, which is typically about $70 \%$ by volume. The Si powders are $99.995 \%$ purity and less than $10-\mu \mathrm{m}$ in diameter. The TiC powders are $99.95 \%$ purity and $2-\mu \mathrm{m}$ in diameter. The $\mathrm{Si}$ and $\mathrm{TiC}$ powders are combined using ball mixing for $16 \mathrm{~h}$ using zirconia balls as the mixing media at low mixing rates of 30 to $40 \mathrm{RPM}$. The polymers are then added to the mixed $\mathrm{Si}+\mathrm{TiC}$ powders and further ball-mixed under inert atmospheres for an additional $16 \mathrm{~h}$ followed by $20 \mathrm{~min}$ sonication step for suspending the powders in the liquid prior to gel casting. The liquid slurries are then cured at $60^{\circ} \mathrm{C}$ for several hours to several days in an inert gas oven. This forms a green solid disk that is suitable for further processing, such as hot pressing (See Figure 1). The pure polycarbosilane requires several days to cure whereas the polymer filled with SiC-particles (SL-MS30) requires only a few hours.

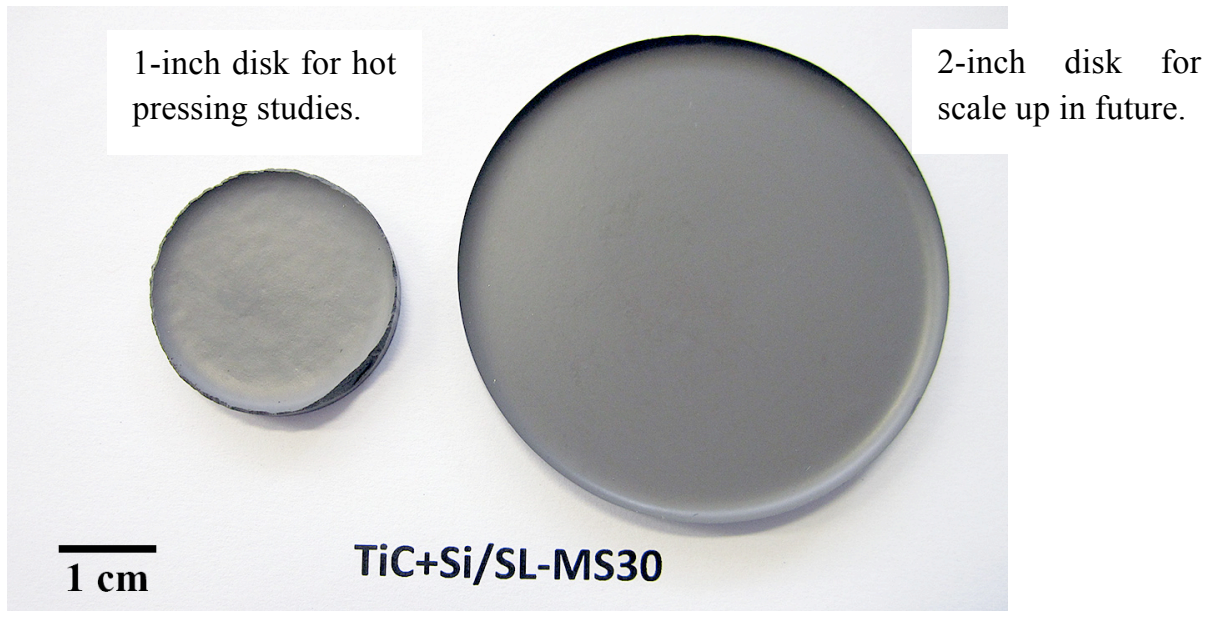

Figure 1. A gel cast mixture of polycarbosilane polymer filled with $30-\mathrm{vol} \% \mathrm{SiC}_{\text {-particles }}{ }^{2}$ and then filled with $40-\mathrm{vol} \% \mathrm{Si}+\mathrm{TiC}$ powders and cured at $60^{\circ} \mathrm{C}$. This creates a smooth solid green disk that can be handled and machined. The smaller disk on the left is a 1-inch diameter $(2.54 \mathrm{~cm})$ that is used for hot pressing while the larger disk on the right is 2 inches $(5.08 \mathrm{~cm})$ in diameter for future use.

X-ray diffraction (XRD) and differential thermal analysis (DTA) were used to study the pyrolysis of these polymers, which can be fully crystallized above $1550^{\circ} \mathrm{C}(1823 \mathrm{~K})$. Although both polymers were investigated during this initial study, it proved easier to work with the filled polymer system, the SLMS30 system together with the added $\mathrm{Si}+\mathrm{TiC}$ powders. The cured green disks were smoothed to remove the edges formed from the molding step, wrapped in graphite paper (Grafoil) and hot-pressed in a graphite die at $1800^{\circ} \mathrm{C}(2073 \mathrm{~K})$ and $20 \mathrm{MPa}$ for $2 \mathrm{~h}$. The disks were typically 3-mm in thickness and consolidated to 2 -mm thick after hot pressing.

\footnotetext{
${ }^{1}$ Starfire Systems, Inc., Schenectady, NY

${ }^{2}$ SL-MS30 is a Starfire designation referring to $30-\mathrm{vol} \% \mathrm{SiC}$-particulate filled polycarbosilane
} 


\subsection{Structure and Properties of MAX Phase $\mathrm{Ti}_{3} \mathrm{SiC}_{2}$}

Titanium silicon carbide is one of the MAX phases in the group 312, and is the only known Sicontaining bulk MAX phase. MAX phases have a hexagonal, layered structure with space group $\mathrm{P}_{3} / \mathrm{mmc}$ (194); combining $\mathrm{M}_{6} \mathrm{X}$ octahedra with a single intercalating layer A. There are over 60 MAX phases currently known in 3 groups $(211,312$ and 413) with different compositions and lattice parameters [42]. MAX phases with new compositions are still being discovered, especially in the group 413. Figure 2 shows the lattice structure of $\mathrm{Ti}_{3} \mathrm{SiC}_{2}$ unit cell $[42,43]$ with $a=0.307 \mathrm{~nm}, c=1.767 \mathrm{~nm}$ and a theoretical density of $4.52 \mathrm{~g} / \mathrm{cm}^{3}$. The close-packed Ti and Si layers are arranged in the sequence of Ti-Ti-Ti-Si-TiTi-Ti-Si, with $\mathrm{C}$ occupying the octahedral sites between the Ti layers, forming $\mathrm{Ti}_{6} \mathrm{C}$ polyhedra that are edge sharing. Si atoms are located at the center of trigonal prisms. There are two polymorphs of $\mathrm{Ti}_{3} \mathrm{CSi}_{2}$, i.e., $\alpha$ and $\beta$ polytypes, with stacking sequences of $\mathrm{A} \gamma \mathrm{BaB} \gamma \mathrm{A} \beta \mathrm{CaC} \beta \mathrm{A} \gamma \mathrm{BaB} \gamma \mathrm{A}$ and $\mathrm{A} \gamma \mathrm{BcB} \gamma \mathrm{A} \beta \mathrm{CbC} \beta \mathrm{A} \gamma \mathrm{BcB} \gamma \mathrm{A}$, respectively, where the capital letters denote Ti layers, low-case letters $\mathrm{Si}$ layers, and Greek letters $C$ positions. Since transformation from $\alpha$ - to $\beta-\mathrm{Ti}_{3} \mathrm{SiC}_{2}$ does not involve breaking the strong Ti-C bonds, the process has relatively low activation energy. The simulated diffraction patterns of the two polytypes look similar, but can be readily distinguishable by the locations of their $100 \%$ reflection peaks $\left(2 \theta=\sim 39.5^{\circ}\right.$ for $\alpha-\mathrm{Ti}_{3} \mathrm{SiC}_{2}$ and $\sim 42.5^{\circ}$ for $\left.\beta-\mathrm{Ti}_{3} \mathrm{SiC}_{2}\right)$. There is a repeat of two $\mathrm{Ti}_{6} \mathrm{C}$ octahedra with an intercalating layer of $\mathrm{Si}$ atoms in the $\mathrm{Ti}_{3} \mathrm{SiC}_{2}$ structure (group 312), while MAX phases in groups 211 and 413 have repeats of one and three $\mathrm{M}_{6} \mathrm{X}$ octahedra, respectively.
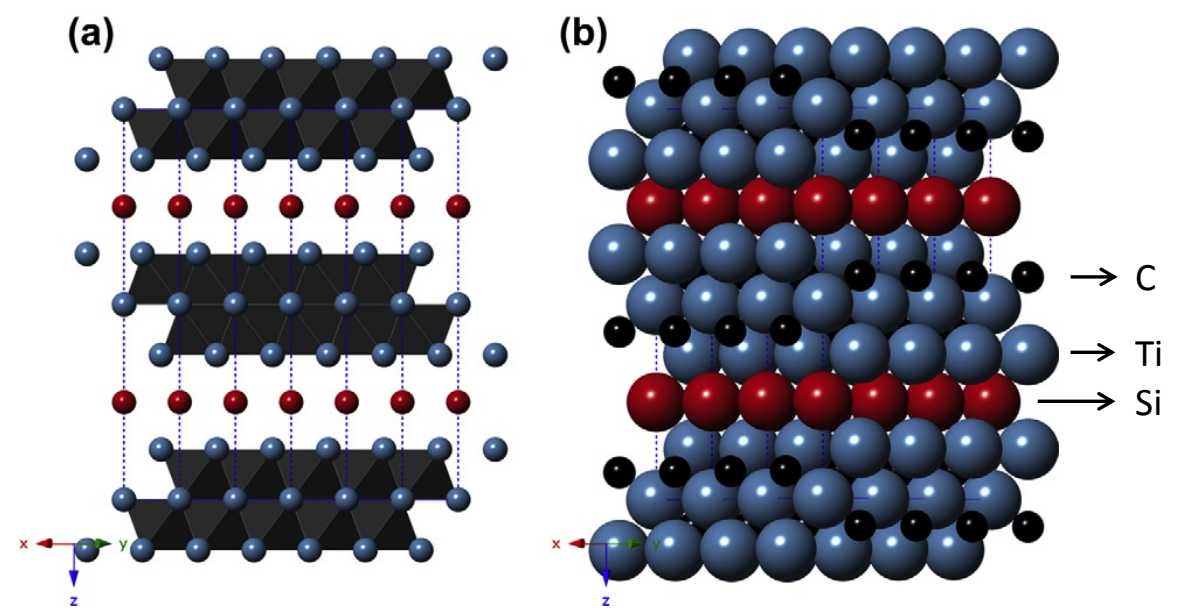

Figure 2. Unit cell of $\mathrm{Ti}_{3} \mathrm{SiC}_{2}$ : (a) polyhedra of $\mathrm{Ti}_{6} \mathrm{C}$ separated by Si layers and (b) close-packed hexagonal structure showing stacking with $\mathrm{C}$ occupying the octahedral sites within Ti-Ti layers.

In general, MAX phases, including $\mathrm{Ti}_{3} \mathrm{SiC}_{2}$, are considered as a hybrid of metals and ceramics because they have both metallic nature of the M-X bonds that are exceptionally strong and the elongated M-A bonds that are relative weak (especially in shear) in the layered structure, resulting in an unusual combination of physical and chemical properties. The ternary compounds are elastically stiff, yet relatively soft and readily machinable. They behave like a "ductile ceramic" with high fracture toughness and good thermal and electrical conductivities. The materials are the only polycrystalline solids that deform by a combination of kink and shear bands, together with the delamination of individual grains. Dislocations in MAX phases multiply and are mobile at room temperature, glide on the basal plane, and are arranged either in arrays or kink boundaries [44]. $\mathrm{Ti}_{3} \mathrm{SiC}_{2}$ combines mechanical anisotropy with thermal properties that are fairly isotropic $\left(\alpha_{\mathrm{a}}=8.6 \times 10^{-6} \mathrm{~K}^{-1}\right.$ and $\alpha_{\mathrm{c}}=9.7 \times 10^{-6} \mathrm{~K}^{-1}$ [45]). It has a thermal 
conductivity ranging from $\mathrm{k}_{\mathrm{th}}=37 \mathrm{Wm}^{-1} \mathrm{~K}^{-1}$ at $300 \mathrm{~K}$ to $32 \mathrm{Wm}^{-1} \mathrm{~K}^{-1}$ at $1300 \mathrm{~K}$, mostly from electronic contributions. Pure $\mathrm{Ti}_{3} \mathrm{SiC}_{2}$ is thermally stable up to at least $1973 \mathrm{~K}$ [46], but decomposes in vacuum between 1273 and $1473 \mathrm{~K}$ [47] due to low barriers to Si loss. Polycrystalline $\mathrm{Ti}_{3} \mathrm{SiC}_{2}$ can be oxidized in air over the temperature range between 1173 and $1673 \mathrm{~K}$ [48]. With the exception of $\mathrm{HNO}_{3}$, MAX phase $\mathrm{Ti}_{3} \mathrm{SiC}_{2}$ has a very low corrosion rate in many of the common acids and $\mathrm{NaOH}$ at room temperature [49]. It is also resistant to thermal shock $[50,51]$ and creep $[52,53]$, and is tolerant to mechanical damage and irradiation-induced amorphization [39-41, 54, 55].

\subsection{Characterization of SiC Alloys with $\mathrm{Ti}_{3} \mathrm{SiC}_{2}$}

Hot-pressed $\mathrm{SiC} / \mathrm{Ti}_{3} \mathrm{SiC}_{2}$ materials in the form of thin disks were fabricated as discussed above and were characterized using optical and scanning electron microscopy, density via Archimedes method, thermal conductivity using laser flash methods, and fracture toughness using indentation methods. The disks were also used for the density measurements but were then sectioned and polished in cross-section for the microscopy studies, XRD, and indentation fracture toughness testing. Table 2 lists the major results from the characterization work to date.

Table 2. Basic Property Data for Hot-Pressed Nanocrystalline $\mathrm{SiC}$ and $\mathrm{Ti}_{3} \mathrm{SiC}_{2}$ Dual Phase Materials

\begin{tabular}{|l|c|c|c|c|c|c|}
\hline \multicolumn{1}{|c|}{ Sample I.D. } & $\begin{array}{c}\rho \\
\left(\mathrm{g} / \mathrm{cm}^{3}\right)\end{array}$ & $\begin{array}{c}\mathrm{K}_{\text {th }}\left(25^{\circ} \mathrm{C}\right) \\
(\mathrm{W} / \mathrm{m} \cdot \mathrm{K})\end{array}$ & $\begin{array}{c}\mathrm{K}_{\text {th }}\left(300^{\circ} \mathrm{C}\right) \\
(\mathrm{W} / \mathrm{m} \cdot \mathrm{K})\end{array}$ & $\begin{array}{c}\mathrm{K}_{\text {th }}\left(500^{\circ} \mathrm{C}\right) \\
(\mathrm{W} / \mathrm{m} \cdot \mathrm{K})\end{array}$ & $\begin{array}{c}\mathrm{Ti}-\mathrm{Phase} \\
(\%)\end{array}$ & $\begin{array}{c}\mathrm{K}_{\mathrm{c}} \\
(\mathrm{MPa} \sqrt{\mathrm{m}})\end{array}$ \\
\hline \hline Hexoloy SiC & $\mathbf{3 . 1 0}$ & $\mathbf{1 1 3 . 3}$ & $\mathbf{7 8 . 6}$ & $\mathbf{6 6 . 9}$ & - & $\mathbf{4 . 6}$ \\
\hline S30-TSC57-HP-T18-052 & 3.79 & 56.1 & 42.0 & 39.0 & - & 4.7 \\
\hline S30-TSC57-HP-T18-053 & 3.66 & 26.0 & 33.6 & - & - & 4.8 \\
\hline S30-TSC60-HP-T18-060 & 3.83 & 49.2 & 63.5 & 59.6 & $39.2 \%$ & 5.0 \\
\hline S30-TSC63-HP-T18-079 & 3.83 & 18.8 & 32.6 & 35.2 & $44.4 \%$ & 7.5 \\
\hline S30-TSC63-HP-T18-080 & 3.81 & 39.6 & 37.7 & 36.0 & $36.8 \%$ & 5.4 \\
\hline S30-TSC63-HP-T18-089 & 3.80 & 29.0 & 28.1 & 28.4 & $31.5 \%$ & 5.2 \\
\hline S30DCP-TSC63-HP-T18-093 & 4.03 & 20.2 & 24.2 & 26.1 & - & 5.7 \\
\hline S30DVB-TSC63-HP-T18-094 & 4.03 & 23.6 & 27.0 & 28.1 & - & 5.8 \\
\hline
\end{tabular}

The densities of the hot-pressed materials approach the theoretical density of solid bodies that are $50 \% \mathrm{SiC}$ and $50 \% \mathrm{Ti}_{3} \mathrm{SiC}_{2}$, which is $3.87 \mathrm{~g} / \mathrm{cm} 3$. The majority of the samples produced contain significant porosity that appears to be related to the inability of the hot press to achieve higher pressures during hot pressing. Note that the fracture toughness values are all above that of Hexoloy $\mathrm{SiC}$ but that measured thermal conductivities are lower.

\subsection{Optical Microscopy (OM)}

Optical microscopy (OM) was used to image the samples from 50x to 500x with a DIC prism in order to observe the phase morphologies, determine porosity, and perform simple stereological measurements. The main findings from the OM data presented here is that the SiC-alloy has been synthesized and consists of a porous $\mathrm{SiC}$ phase and a dense $\mathrm{Ti}_{3} \mathrm{SiC}_{2}$ phase having an overall microstructure consistent with an annealed displacement reaction structure. The porosity is apparently due to the fact that the hot pressing is being performed at a pressure that is too low to allow densification of the filled polymers.

To help understand the phases that are in the OM images, Figure 3 shows the phase diagram for the ternary $\mathrm{Ti}-\mathrm{Si}-\mathrm{C}$ system that is appropriate for the $\mathrm{SiC}$-based alloys being synthesized using SiC-polymers 
and $\mathrm{Si}+\mathrm{TiC}$ powders. These react together to form $\mathrm{SiC}$ from the polycarbosilane plus $\mathrm{SiC}+\mathrm{Ti}_{3} \mathrm{SiC}_{2}$ from a displacement reaction between the $\mathrm{Si}$ and TiC. Previous work at PNNL using these reactions to form interpenetrating phase composites $[17,56]$ in a variety of systems involving metal carbides and $\mathrm{Si}$ and on joining $\mathrm{SiC}$ using $\mathrm{Si}+\mathrm{TiC}$ [57-61] has resulted in a deep understanding of the microstructure formation during these complex reactions $[62,63]$.

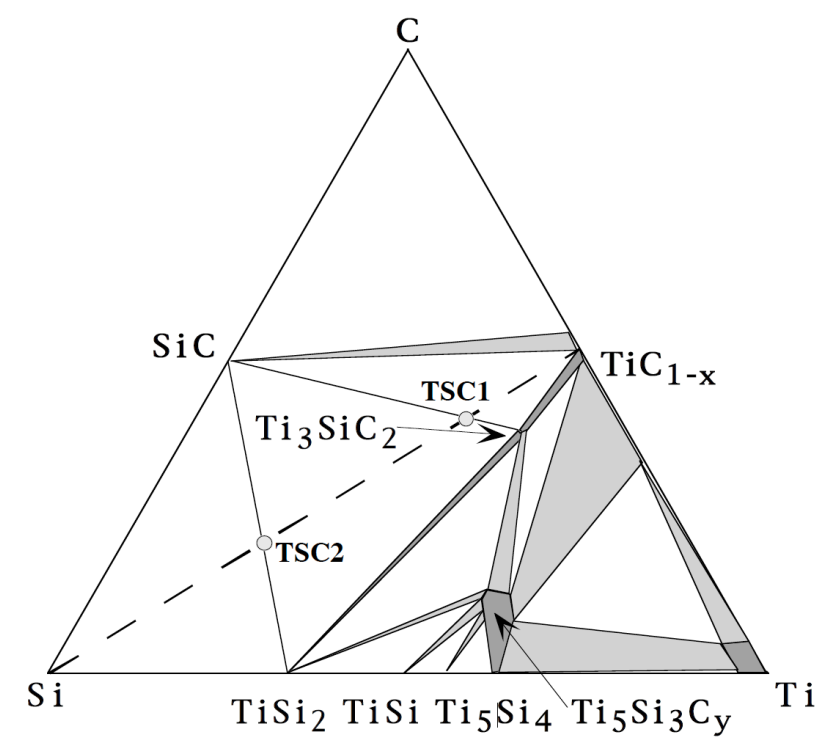

Figure 3. Ternary isotherm section of Ti-Si-C system at $1250^{\circ} \mathrm{C}(1523 \mathrm{~K})$. The $3: 2$ mole ratio of $\mathrm{Si}$ TiC (connected by the dashed line) reacts to give composition marked as TSC1 on this diagram, which is on the join between $\mathrm{SiC}$ and $\mathrm{Ti}_{3} \mathrm{SiC}_{2}$. Overall, this diagram indicates that four phases ( $\mathrm{SiC}, \mathrm{TiC}$, $\mathrm{Ti}_{3} \mathrm{SiC}_{2}$, and $\mathrm{TiSi}_{2}$ ) are expected to occur in this $\mathrm{SiC}$-alloy system at equilibrium.

Figure 4 shows one of the early results from hot-pressing the pure $\mathrm{SiC}$ polymer, polycarbosilane, filled with $\mathrm{Si}+\mathrm{TiC}$ powders at $1550^{\circ} \mathrm{C}$ in argon. The characteristic dual phase observed in the large white particles is due to the simultaneous growth of $\mathrm{SiC}$ as platelets oriented within the $\mathrm{Ti}_{3} \mathrm{SiC}_{2}$ matrix phase. The two phases form together as the $\mathrm{Si}+\mathrm{TiC}$ displacement reaction occurs due to coupled diffusion at elevated temperatures $[62,63]$. The darker grey regions are the SiC phase from the polycarbosilane pyrolysis. Some porosity is also visible in the image. XRD studies have shown that better yield of crystalline $\mathrm{SiC}$ is obtained at higher temperatures and that hot pressing at temperatures higher than $1550^{\circ} \mathrm{C}$ would also give higher overall densities. It was also decided to work with the $\mathrm{SiC}$-filled polymer, denoted as SL-MS30, since higher ceramic yields are achievable. Green curing time is also reduced and much higher densities are obtained.

Figure 5 shows a typical hot-pressed microstructure following hot pressing at $1800^{\circ} \mathrm{C}(2073 \mathrm{~K})$ and $20 \mathrm{MPa}$ pressure in graphite dies under vacuum. At $1800^{\circ} \mathrm{C}$ the displacement reaction microstructure is best described as blocky $\mathrm{SiC}$ dispersed within and around a larger grained $\mathrm{Ti}_{3} \mathrm{SiC}_{2}$ phase. 


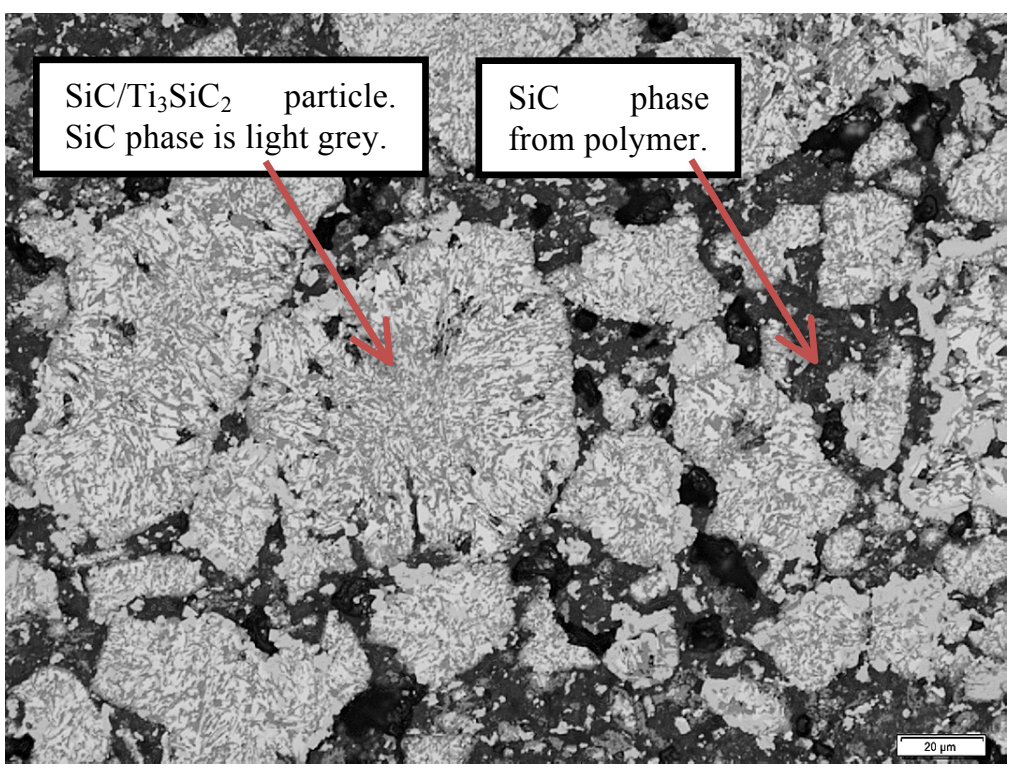

Figure 4. Optical micrograph showing $\mathrm{SiC} / \mathrm{Ti}_{3} \mathrm{SiC}_{2}$ interpenetrating phase microstructure visible in several large colonies surrounded by porous $\mathrm{SiC}$-polymer pyrolysis dark grey regions. The light grey platelets in the large white particles are the $\mathrm{SiC}$ that forms during the displacement reaction between $\mathrm{Si}$ and $\mathrm{TiC}$. This sample was hot-pressed at $1550^{\circ} \mathrm{C}(1823 \mathrm{~K})$ in argon.

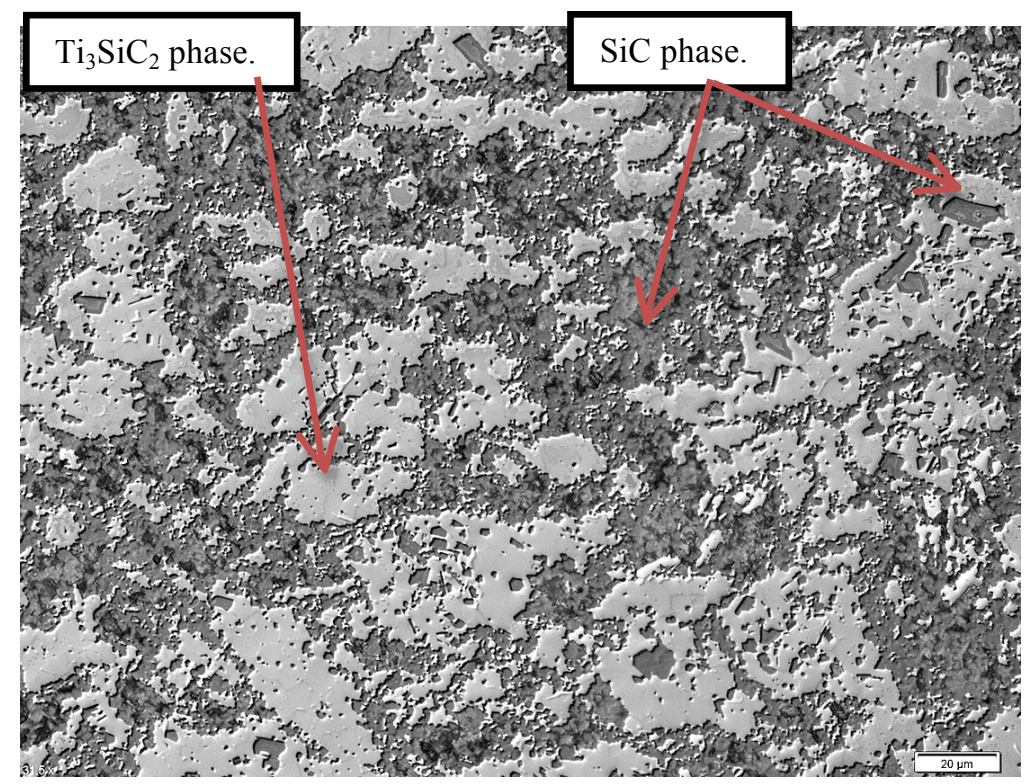

Figure 5. Optical micrograph of hot-pressed $\mathrm{SiC}$-alloy at $1800^{\circ} \mathrm{C}$ and $20 \mathrm{MPa}$. The SiC-platelet features in Fig. 4 are no longer present but are replaced by a more blocky $\mathrm{SiC} / \mathrm{Ti}_{3} \mathrm{SiC}_{2}$ phase structure. The light grey phase is $\mathrm{Ti}_{3} \mathrm{SiC}_{2}$ and the darker grey phase is $\mathrm{SiC}$, both from the displacement reaction and from the polymer pyrolysis plus the $\mathrm{SiC}$-filler. $\mathrm{SiC}$ alignment within the $\mathrm{Ti}_{3} \mathrm{SiC}_{2}$ matrix is still evident.

\subsection{Scanning Electron Microscopy (SEM)}

Scanning electron microscopy (SEM) was performed to obtain higher magnification images as well as perform energy dispersive X-ray spectroscopy (EDS) for compositional information in conjunction with $\mathrm{X}$-ray diffraction (XRD). The SEM images reveal information that is not observed in the OM images and 
also provide detailed spatial compositional information. Figure 6(a-c) show a sequence of SEM images of increasing magnification of the sample shown in Fig. 5 and reveal 1) the $\mathrm{Ti}_{3} \mathrm{SiC}_{2}$ phase is polycrystalline and dense, 2) the $\mathrm{SiC}$ phase is blocky, fine-grained, and often crystallographically-aligned with the $\mathrm{Ti}_{3} \mathrm{SiC}_{2}$ particles, and 3) the porosity is always in the $\mathrm{SiC}$ phase.

The loss of the interpenetrating phase where the $\mathrm{SiC}$-platelets are present throughout the $\mathrm{Ti}_{3} \mathrm{SiC}_{2}$ phase is a consequence of the hot-press temperature of $1800^{\circ} \mathrm{C}$. This is not a desirable outcome but the tradeoff is seen in the densities. For example, the sample shown in Fig. 4 pressed at $1550^{\circ} \mathrm{C}$ has a density of $2.6 \mathrm{~g} / \mathrm{cm}^{3}$ while the sample shown in Fig. 5 and pressed at $1800^{\circ} \mathrm{C}$ has a density of $3.8 \mathrm{~g} / \mathrm{cm}^{3}$. The sample in Fig. 5 has a density of $3.83 \mathrm{~g} / \mathrm{cm}^{3}$, which is quite good.

The EDS data for the specimens listed in Table 2 is provided as an average for the $\mathrm{SiC}$ phase and for the $\mathrm{Ti}_{3} \mathrm{SiC}_{2}$ phase for all the samples as $\mathrm{Si}: \mathrm{C}$ is 1.01:0.99 for the $\mathrm{SiC}$ phase and as $\mathrm{Ti}: \mathrm{Si}: \mathrm{C}$ is 2.7:1.0:2.57 as shown in Table 3 using atomic percentages. This is good evidence for having formed the desired phases but the XRD data is the critical data for confirming the phase mixture.

Table 3. Average of EDS data for $\mathrm{SiC}$ and $\mathrm{Ti}_{3} \mathrm{SiC}_{2}$ phases from $\mathrm{SEM}$ data

\begin{tabular}{cccc}
\hline Phase & Ti (atomic \%) & Si (atomic \%) & C (atomic \%) \\
$\mathrm{SiC}$ & 0 & 50.1 & 49.8 \\
$\mathrm{Ti}_{3} \mathrm{SiC}_{2}$ & 43.1 & 15.9 & 41.0 \\
\hline
\end{tabular}

\subsection{X-ray Diffraction (XRD)}

The data from XRD taken using $\mathrm{Cu}-\mathrm{K}$ radiation is shown in Figure 7 for each of the samples listed in Table 2. All of these samples were hot-pressed for 2 hours at $1800^{\circ} \mathrm{C}(2073 \mathrm{~K})$ at $20 \mathrm{MPa}$ under vacuum and all had densities above $3.65 \mathrm{~g} / \mathrm{cm}^{3}$. This data confirms the phase formation deduced from the SEM and OM images.

\subsection{Density}

The densities were determined using Archimedes method with a system that uses a high specific gravity fluid and high-precision balances to achieve a total measurement accuracy of 4 significant figures. Steady progress has been made in increasing the final density into the $3.8-\mathrm{g} / \mathrm{cm}^{3}$ range.

\subsection{Thermal Conductivity}

Thermal conductivities are measured from $25^{\circ} \mathrm{C}$ to $500^{\circ} \mathrm{C}(300$ to $773 \mathrm{~K})$ in vacuum using a commercial laser flash thermal diffusivity instrument. The hot-pressed disks are cleaned and polished to remove the graphite paper residue and provide a consistent surface finish for these measurements. The data for all the samples is shown with values at $25^{\circ} \mathrm{C}, 300^{\circ} \mathrm{C}$, and $500^{\circ} \mathrm{C}$ included in Table 2 along with calibration data for Hexoloy $\mathrm{SiC}$ that agrees very well with published data for that material. Consistent with phonon-dominated heat flow in SiC-based materials, the measured thermal conductivity for Hexoloy decreases with increasing temperature. Hexoloy $\mathrm{SiC}$ is used as a standard and is tested with each sample to ensure that the instrument is maintaining its accuracy over time.

Literature data for thermal conductivity of $\mathrm{Ti}_{3} \mathrm{SiC}_{2}$ indicates that it exhibits weak temperature dependence with decreasing conductivity with increasing temperature and it ranges from about $37 \mathrm{~W} / \mathrm{m} \cdot \mathrm{K}$ at room temperature $(300 \mathrm{~K})$ to $35 \mathrm{~W} / \mathrm{m} \cdot \mathrm{K}$ at $500^{\circ} \mathrm{C}(773 \mathrm{~K})$ [45, 64]. Since the conductivity of $\mathrm{SiC}$ is higher than that for $\mathrm{Ti}_{3} \mathrm{SiC}_{2}$ it is observes, as by others, that compositing with $\mathrm{SiC}$ increases the conductivity. Since the conductivity of $\mathrm{SiC}$ is also a function of grain size and an average grain size has 


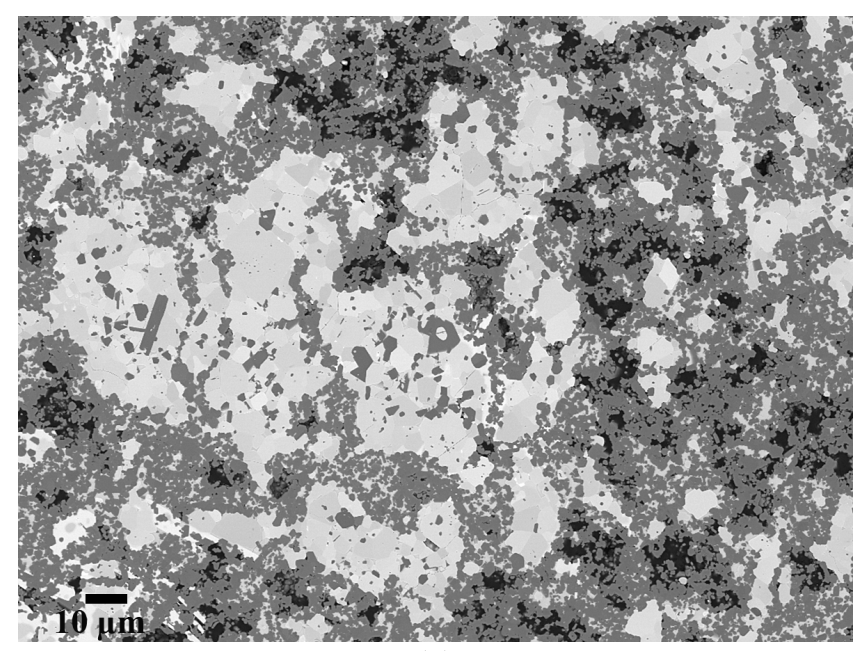

(a)

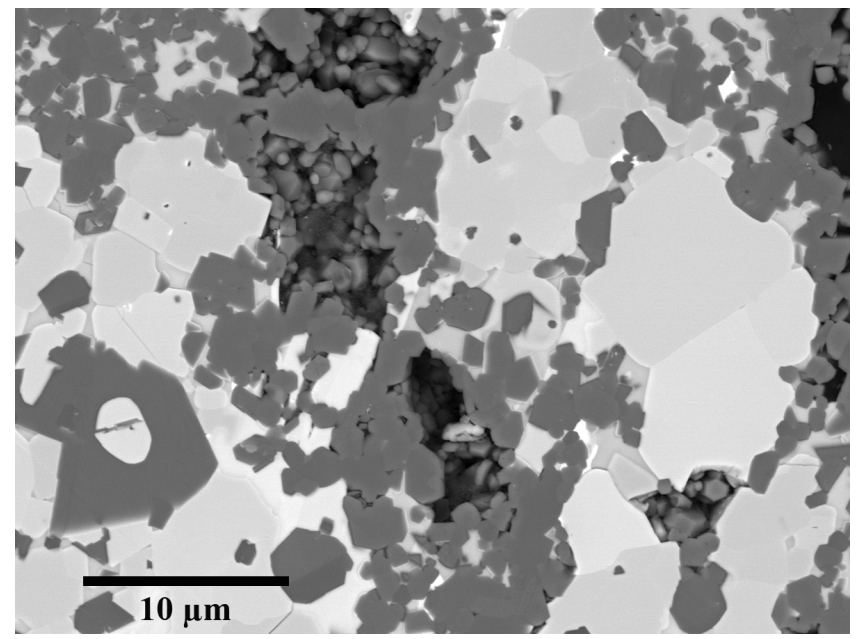

(b)

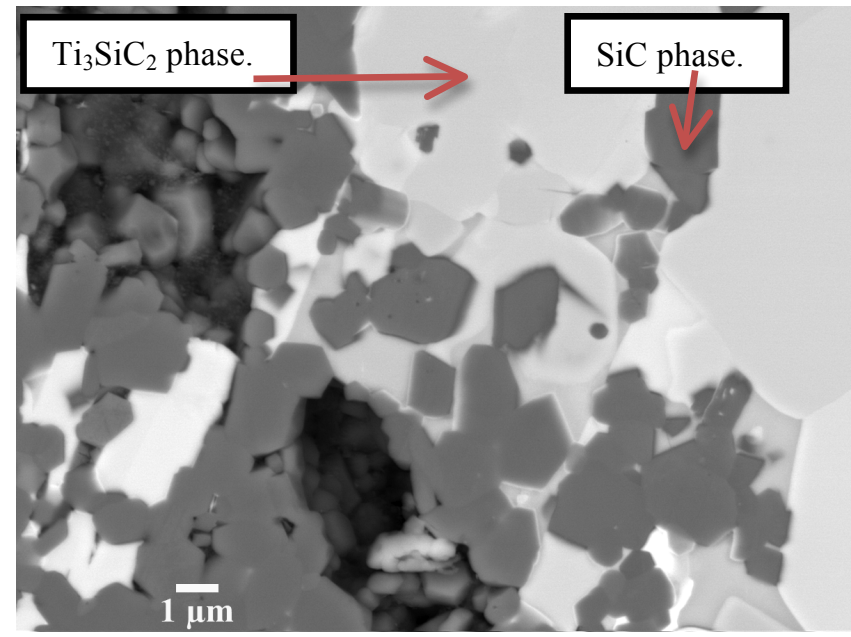

(c)

Figure 6. SEM images of a SiC-alloy hot pressed at $1800^{\circ} \mathrm{C}(2073 \mathrm{~K})$ and $20 \mathrm{MPa}$ pressure from SiCfilled polymer plus $\mathrm{Si}+\mathrm{TiC}$ powders at $63 \%$ powder loading. The white phase is the $\mathrm{Ti}_{3} \mathrm{SiC}_{2}$ phase and the darker grey phase is $\mathrm{SiC}$. Note that the pores are contained entirely within the $\mathrm{SiC}$ phase. 


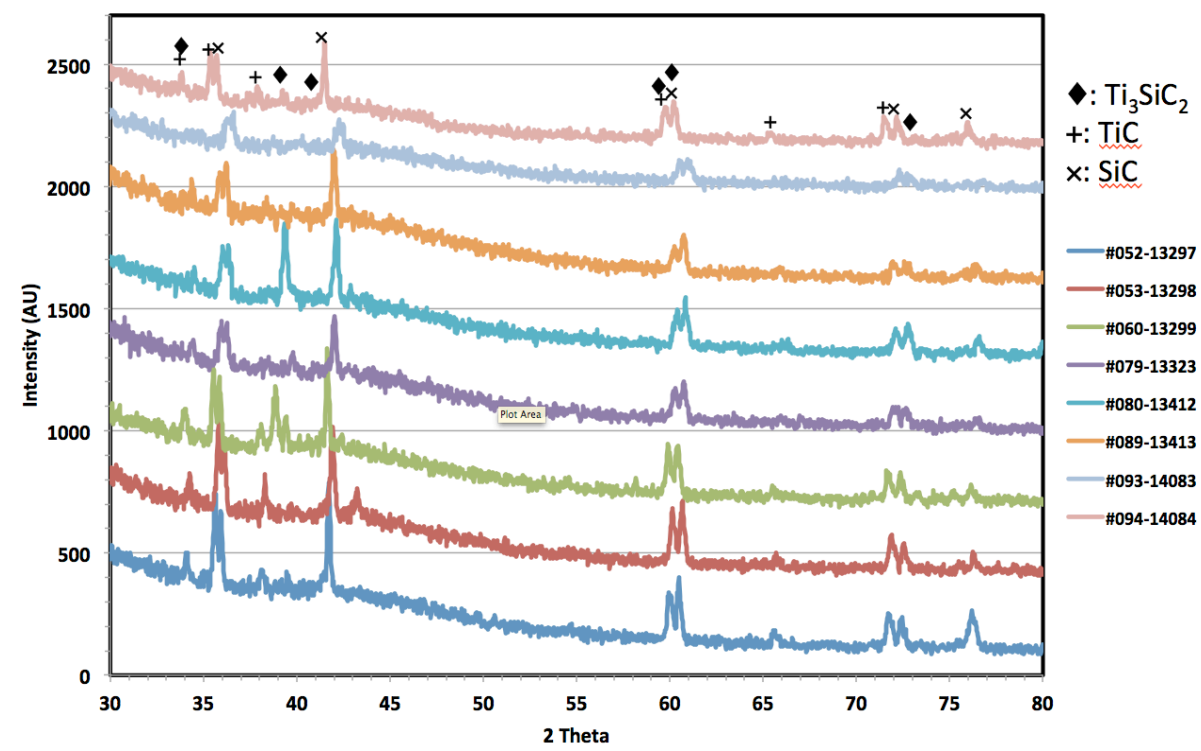

Figure 7. XRD data from each of the samples listed in Table 2. Residual TiC is observed in some of the samples but the major phases are $\mathrm{SiC}$ and $\mathrm{Ti}_{3} \mathrm{SiC}_{2}$ as shown.

not yet determined for these materials it is not yet possible to accurately estimate the contribution that $\mathrm{SiC}$ makes to the thermal conductivity but the data does show that some of the samples exhibit an increased conductivity compared to polycrystalline $\mathrm{Ti}_{3} \mathrm{SiC}_{2}$. In fact, the data, with the exception of the room temperature data, is quite consistent with the data of others in the literature for $\mathrm{SiC} / \mathrm{Ti}_{3} \mathrm{SiC}_{2}$ as shown in Figure 8. It is observed that the thermal conductivity values for the materials synthesized here fall into the range expected for a composite of $\mathrm{Ti}_{3} \mathrm{SiC}_{2}$ and $\mathrm{SiC}[45,64]$ but the data show a slight increase in thermal conductivity with increasing temperature in contrast to what is expected. At the present time the cause of this discrepancy is not understood but it must be noted that it is a real and consistent trend in the data. Values range from $36 \mathrm{~W} / \mathrm{m} \cdot \mathrm{K}$ at $25^{\circ} \mathrm{C}$ to $40 \mathrm{~W} / \mathrm{m} \cdot \mathrm{K}$ at $500^{\circ} \mathrm{C}$. The highest values produced are for Sample 060 with $49 \mathrm{~W} / \mathrm{m} \cdot \mathrm{K}$ at $25^{\circ} \mathrm{C}, 63 \mathrm{~W} / \mathrm{m} \cdot \mathrm{K}$ at $300^{\circ} \mathrm{C}$, and $60 \mathrm{~W} / \mathrm{m} \cdot \mathrm{K}$ at $500^{\circ} \mathrm{C}$, which is quite respectable conductivity for a composite material consisting of $\mathrm{SiC} / \mathrm{Ti}_{3} \mathrm{SiC}_{2}[45,64]$. 


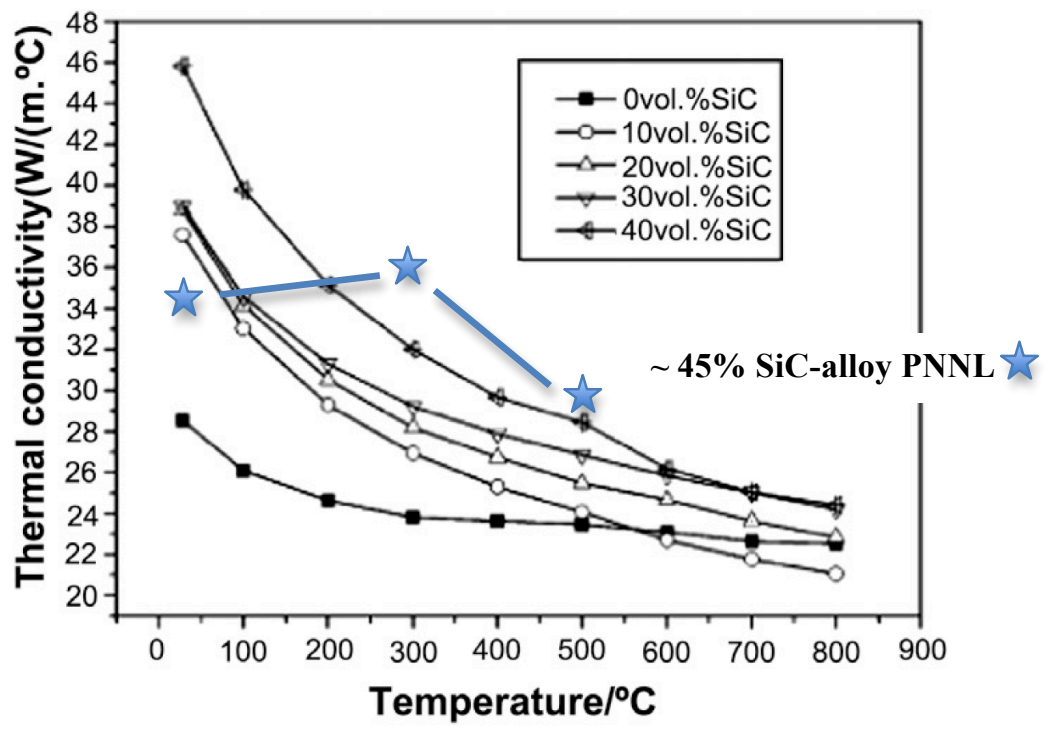

Figure 8. Thermal conductivity data from Ref. [64] showing the effects of adding $\mathrm{SiC}_{\text {to }} \mathrm{Ti}_{3} \mathrm{SiC}_{2}$ to increase its thermal conductivity. PNNL average thermal conductivity data for the six nominally identical specimens in Table 2 is shown in blue on this graph and corresponds quite well with this published data.

\subsection{Fracture Toughness}

The measured fracture toughness data is shown in Figure 9 as determined using the indentation fracture toughness method following the generally accepted methodology as outlined in Ref. [65]. As is evident, additions of $\mathrm{Ti}_{3} \mathrm{SiC}_{2}$ to $\mathrm{SiC}$ generally increase the fracture toughness but only nominally as has been noted before. Similar to the thermal conductivity data, these toughness results are consistent with literature data for fracture toughness of $\mathrm{SiC} / \mathrm{Ti}_{3} \mathrm{SiC}_{2}$ composites prepared by other methods [64].

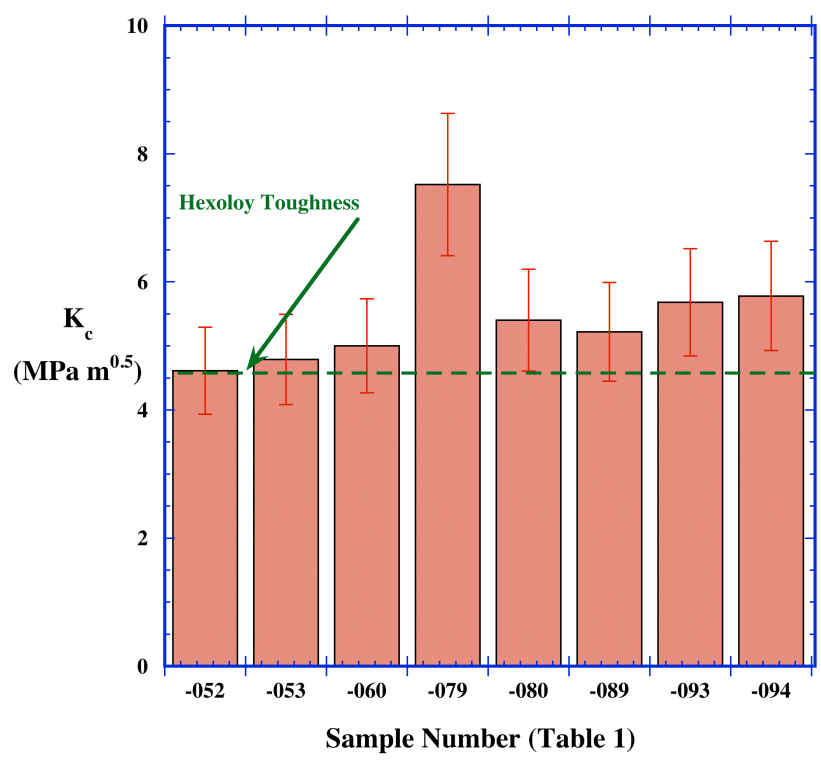

Figure 9. Measured fracture toughness from each of the samples from Table 2 as determined using the indentation fracture toughness method. Ten indents were used for each data point shown in the figure. All of the samples showed an increase in toughness as compared to Hexoloy SiC, which was also tested. 


\subsection{Fission Product Surrogate Diffusion}

\subsection{Materials}

Samples used in this study include polycrystalline $\mathrm{Ti}_{3} \mathrm{SiC}_{2} \quad\left(10 \times 10 \times 1 \quad \mathrm{~mm}^{3}\right)$, dual-phase nanocomposite of $\mathrm{Ti}_{3} \mathrm{SiC}_{2} / 3 \mathrm{C}$-SiC $\left(3 \times 6 \times 1 \mathrm{~mm}^{3}\right)$ synthesized at PNNL, CVD $3 \mathrm{C}-\mathrm{SiC}(8 \mathrm{~mm}$ in diameter and $1 \mathrm{~mm}$ in thickness), and single crystal $<0001>$-oriented $6 \mathrm{H}-\mathrm{SiC}\left(8 \times 8 \times 0.3 \mathrm{~mm}^{3}\right)$, as listed in Table 4 and shown in Figure 10. The XRD pattern from a symmetric scan based on $\mathrm{Cu} \mathrm{K}_{a}$ radiation $(\lambda=0.154$ $\mathrm{nm}$ ) for polycrystalline CVD 3C-SiC is shown in Figure 11. The data suggests that the major phase of the CVD sample is the cubic $\mathrm{SiC}(3 \mathrm{C}-\mathrm{SiC})$ with a very small fraction of the secondary phase, likely $2 \mathrm{H}-\mathrm{SiC}$, present in the sample. The average crystallite size of the $3 \mathrm{C}-\mathrm{SiC}$ is determined to be $33.4 \mathrm{~nm}$. Figure 12 shows the XRD pattern for the nanocomposite $\mathrm{Ti}_{3} \mathrm{SiC}_{2} / 3 \mathrm{C}-\mathrm{SiC}$. Two major phases in the sample are identified as being cubic phase of $\mathrm{SiC}$ and MAX phase $\alpha-\mathrm{Ti}_{3} \mathrm{SiC}_{2}$ with the average crystallite sizes of 23 and $34 \mathrm{~nm}$, respectively. No significant fraction of secondary phases is observed in the nanocomposite.

Table 4. Materials, ion implantation and thermal annealing conditions.

\begin{tabular}{|c|c|c|c|c|c|c|}
\hline Material & Ion & $\begin{array}{l}\text { Energy } \\
(\mathrm{MeV})\end{array}$ & $\begin{array}{c}\text { Fluence } \\
\left(10^{16} \text { ions } / \mathrm{cm}^{2}\right)\end{array}$ & $\begin{array}{c}\text { Sample } \\
\text { Tilt } \\
\text { (Deg.) }\end{array}$ & $\begin{array}{l}\text { Irr. Temp. } \\
\text { (K) }\end{array}$ & Ann. Temp./Time/Environment \\
\hline $\begin{array}{c}\mathrm{Ti}_{3} \mathrm{SiC}_{2} / 3 \mathrm{C}-\mathrm{SiC} \\
\mathrm{CVD} 3 \mathrm{C}-\mathrm{SiC} \\
6 \mathrm{H}-\mathrm{SiC} \\
\end{array}$ & $\mathrm{Ag}^{2+}$ & 0.4 & 2.8 & $7^{\circ}$ & 873 & $\begin{array}{c}1073,1273 \mathrm{~K} \\
120 \mathrm{~min}, \mathrm{Ar}\end{array}$ \\
\hline $\mathrm{Ti}_{3} \mathrm{SiC}_{2}$ & $\mathrm{Au}^{2+}$ & 2.0 & 1.0 & $0^{\circ}$ & $\begin{array}{r}230,300,373,473, \\
573,673,773,873\end{array}$ & None \\
\hline $\mathrm{Ti}_{3} \mathrm{SiC}_{2}$ & $\mathrm{Cs}^{13+}$ & 1.0 & 5.7 & $7^{\circ}$ & 673 & $\begin{array}{c}1073 \mathrm{~K}: 5,15,30,60,120 \mathrm{~min}, 10^{-6} \text { Torr; } \\
30 \mathrm{~min}: 723,773,823,873, \\
923,973,1023,1073 \mathrm{~K}, 10^{-6} \text { Torr; } \\
1173 \mathrm{~K}, 30 \mathrm{~min}, \mathrm{Ar}\end{array}$ \\
\hline
\end{tabular}




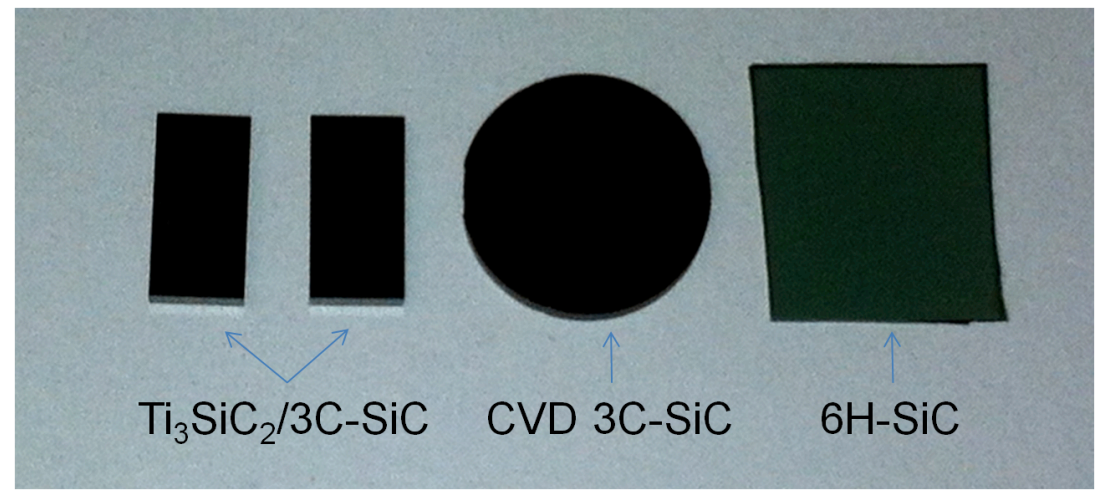

Figure 10. Picture of two polycrystalline $\mathrm{Ti}_{3} \mathrm{SiC}_{2} / 3 \mathrm{C}$-SiC nanocomposite plates $(3 \times 6 \times 1$ $\left.\mathrm{mm}^{3}\right)$, a polycrystalline CVD $3 \mathrm{C}-\mathrm{SiC}$ disk $(8 \mathrm{~mm}$ in diameter and $1 \mathrm{~mm}$ in thickness $)$ and a $6 \mathrm{H}-\mathrm{SiC}$ single crystal wafer $\left(8 \times 8 \times 0.3 \mathrm{~mm}^{3}\right)$ used in this study.

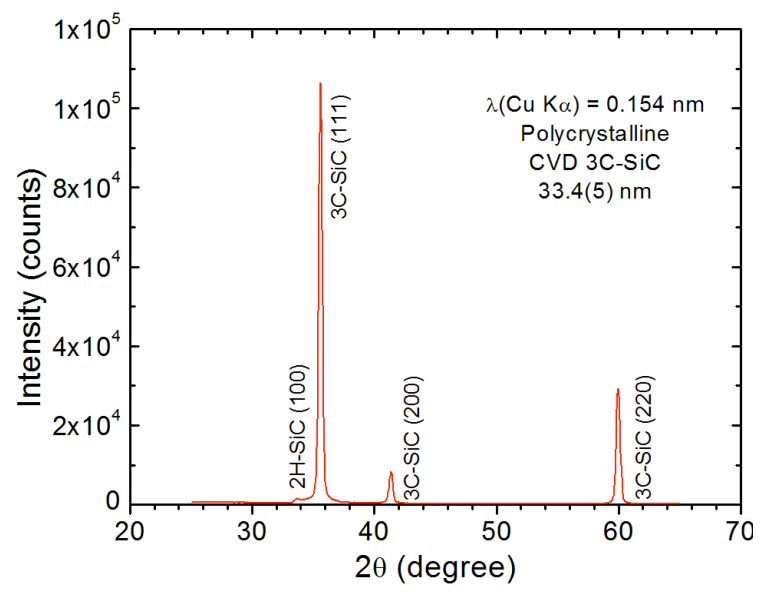

Figure 11. XRD pattern of a polycrystalline CVD 3C-SiC with an average crystallite size of $33.4 \mathrm{~nm}$.

The 6H-SiC wafer from Cree Inc. had high monocrystalline quality. A hot-pressed bulk ingot of $\mathrm{Ti}_{3} \mathrm{SiC}_{2}$ was purchased from Reade Advanced Materials and was cut into smaller samples, as shown in the inset of Fig. 13. The sample surface was ground on diamond laps and silicon carbide sand papers before it was ultrasonically cleaned, rinsed and blow dried. The final polishing was performed with a mix of solutions of Struers OPS Colloidal Silica polish and Hydrogen Peroxide. Figure 13 shows the XRD pattern of the $\mathrm{Ti}_{3} \mathrm{SiC}_{2}$ sample. The data indicates that the major phase of the sample is MAX phase $\alpha-\mathrm{Ti}_{3} \mathrm{SiC}_{2}$. The minor secondary phases include $\mathrm{TiC}$ and $\mathrm{TiSi}_{2}$.

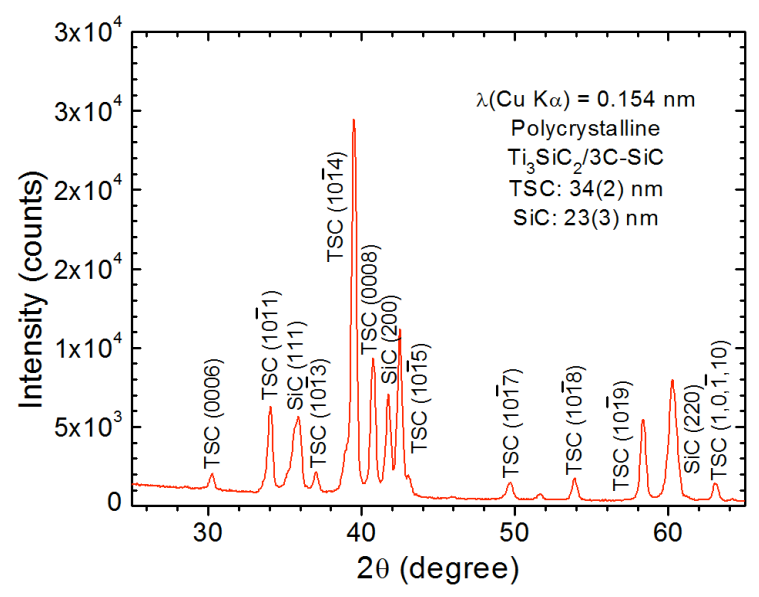

Figure 12. XRD pattern of a dual-phase nanocomposite $\mathrm{Ti}_{3} \mathrm{SiC}_{2} / 3 \mathrm{C}$-SiC with average crystallite sizes of $34 \mathrm{~nm}$ for $\mathrm{Ti}_{3} \mathrm{SiC}_{2}$ and $23 \mathrm{~nm}$ for 3C-SiC.

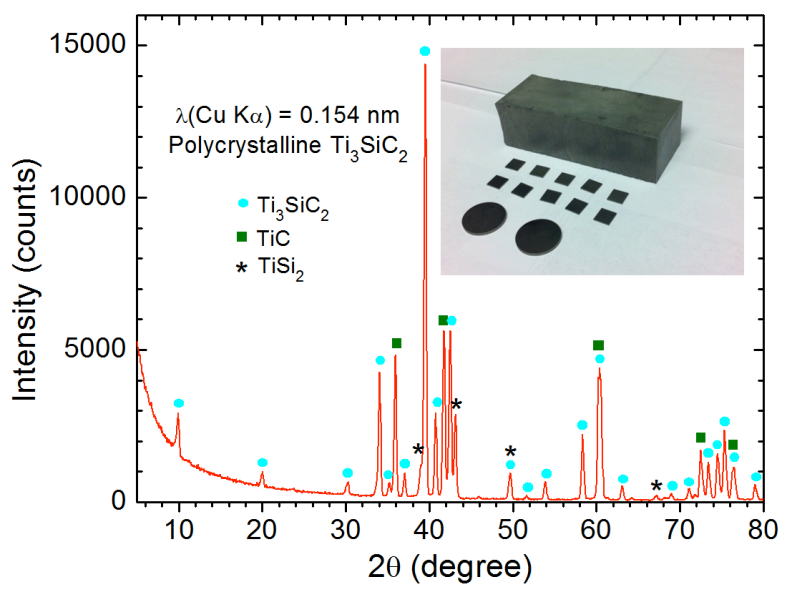

Figure 13. XRD pattern of a polycrystalline $\mathrm{Ti}_{3} \mathrm{SiC}_{2}$ plate cut and polished from a hot-pressed bulk ingot (inserted optical image). 


\subsection{Ion Implantation and Thermal Annealing}

Implantation of $400 \mathrm{keV}{ }^{107} \mathrm{Ag}^{2+}$ in $\mathrm{Ti}_{3} \mathrm{SiC}_{2} / 3 \mathrm{C}-\mathrm{SiC}, \mathrm{CVD} 3 \mathrm{C}-\mathrm{SiC}$ and $6 \mathrm{H}-\mathrm{SiC}$ was conducted $7^{\circ}$ off normal to ion fluence of $2.8 \times 10^{16} \mathrm{Ag}^{2+} / \mathrm{cm}^{2}$ at $873 \mathrm{~K}$ at INNOViON, California. The results from fulldamage cascade SRIM03 simulations [66] for $\mathrm{SiC}$ and $\mathrm{Ti}_{3} \mathrm{SiC}_{2}$ give the atomic percentages of the implanted $\mathrm{Ag}$ at the profile peak maxima are 3.5 at.\% and 3.7 at.\% with FWHM of 81 and $74 \mathrm{~nm}$ in $\mathrm{Ti}_{3} \mathrm{SiC}_{2}$ and $\mathrm{SiC}$, respectively. The simulations also suggest a dose of $110 \mathrm{dpa}$ at the damage peak (70 nm deep) in $\mathrm{Ti}_{3} \mathrm{SiC}_{2}$ and $84 \mathrm{dpa}$ at the damage peak ( $87.5 \mathrm{~nm}$ deep) in $\mathrm{SiC}$. For the dual-phase nanocomposite of $\mathrm{Ti}_{3} \mathrm{SiC}_{2} / 3 \mathrm{C}-\mathrm{SiC}$, the values are between the two respective limits. Elevated temperatures were used for the ion implantations to minimize lattice damage in $\mathrm{Ti}_{3} \mathrm{SiC}_{2}$ and $\mathrm{SiC}$. Beam rastering systems were employed to achieve uniform implantation.

2.0 $\mathrm{MeV}^{197} \mathrm{Au}^{2+}$ ion implantation in $\mathrm{Ti}_{3} \mathrm{SiC}_{2}$ was performed using an NEC 9SDH-2 pelletron 3.0 MV electrostatic tandem accelerator within the Environmental Molecular Sciences Laboratory (EMSL) at PNNL. The $\mathrm{Au}^{2+}$ ions were implanted at normal incidence to $1.0 \times 10^{16} \mathrm{Au}^{2+} / \mathrm{cm}^{2}$ at temperatures ranging from 230 to $873 \mathrm{~K}$, corresponding to $60 \mathrm{dpa}$ at the peak maximum (198 nm deep).

$1.0 \mathrm{MeV}{ }^{133} \mathrm{Cs}^{13+}$ ions were also implanted $7^{\circ}$ off normal to $5.7 \times 10^{16} \mathrm{Cs}^{13+} / \mathrm{cm}^{2}$ (239 dpa at peak) at $673 \mathrm{~K}$ using a $320 \mathrm{kV}$ high-voltage platform with an ECR-ion-source for highly charged ions at the Institute of Modern Physics (IMP), Chinese Academy of Sciences. According to the SRIM03 simulation results, the atomic percentages of 0.81 at. $\% \mathrm{Au}$ and 4.0 at.\% $\mathrm{Cs}$ at the profile peak maxima were estimated at their respective ion fluences. The corresponding FWHM is $133 \mathrm{~nm}$ for the Au peak and 162 $\mathrm{nm}$ for the Cs peak.

The $\mathrm{Ag}^{2+}$ ion implanted samples at $873 \mathrm{~K}$ were furnace annealed at 1073 and $1273 \mathrm{~K}$ for $120 \mathrm{~min}$ at each temperature under flowing $\mathrm{Ar}$ gas conditions. In-situ isothermal annealing in vacuum (10 $\left.10^{-6} \mathrm{Torr}\right)$ at $1073 \mathrm{~K}$ was performed for the $\mathrm{Cs}^{13+}$ implanted $\mathrm{Ti}_{3} \mathrm{SiC}_{2}$ for durations from 5 to $120 \mathrm{~min}$; in-situ isochronal annealing in vacuum for $30 \mathrm{~min}$ at each temperature was also conducted over the temperature range from 723 to $1073 \mathrm{~K}$. Additional furnace annealing at $1173 \mathrm{~K}$ for $30 \mathrm{~min}$ was carried out under flowing Ar gas conditions. The ion implantation and thermal annealing conditions are given in Table 4.

\subsection{Sample Characterization}

Rutherford backscattering spectrometry or non-RBS (resonant RBS) of 2.0 or $3.0 \mathrm{MeV} \mathrm{He}{ }^{+}$ions at a scattering angle of $150^{\circ}$ was performed near room temperature to measure the depth profiles of the implanted species in the materials. RBS along the $<0001>$ axial channeling direction (RBS/C) in the $\mathrm{Ag}^{2+}$ implanted $6 \mathrm{H}-\mathrm{SiC}$ single crystal was used to determine the level of lattice disorder and the substitutional fraction of the implants in the crystal lattice. The RBS/C and micro-XRD measurements were repeated under the same conditions for the annealed samples and the as-implanted samples at different implantation temperatures to study the behavior of implants and structural changes. In addition, the surface morphology of the $\mathrm{Au}^{2+}$ ion implanted $\mathrm{Ti}_{3} \mathrm{SiC}_{2}$ was examined using $\mathrm{HIM}$ under the secondary electron mode at the $\mathrm{He}^{+}$ion energy of $30 \mathrm{keV}$.

\subsection{Diffusivity Results}

\subsection{1 $\mathrm{Ag}^{2+}$ Ion Implanted 6H-SiC, CVD 3C-SiC, and $\mathrm{Ti}_{3} \mathrm{SiC}_{2} / 3 \mathrm{C}-\mathrm{SiC}$}

2.0 $\mathrm{MeV} \mathrm{He}^{+} \mathrm{RBS} / \mathrm{C}$ measurements for $6 \mathrm{H}-\mathrm{SiC}$ before and after $\mathrm{Ag}^{2+}$ ion implantation were performed at room temperature along the $<0001>$ axis. ${ }^{107} \mathrm{Ag}$ was used as surrogate for fission product ${ }^{110 \mathrm{~m}} \mathrm{Ag}$ in this study. The Ag peak shows a Gaussian distribution and is well resolved from the $\mathrm{SiC}$ spectrum. The results suggest that noticeable Ag diffusion did not occur during implantation in $6 \mathrm{H}-\mathrm{SiC}$ at 
$873 \mathrm{~K}$. This is an expected result and is consistent with our previous observations of immobile $\mathrm{Ag}$ in $\mathrm{SiC}$ below $1573 \mathrm{~K}$ [34].

Figures $14 \mathrm{a}$ and $14 \mathrm{~b}$ show the RBS spectra for the $\mathrm{Ag}^{2+}$ ion as-implanted CVD 3C-SiC and $\mathrm{Ti}_{3} \mathrm{SiC}_{2} / 3 \mathrm{C}$-SiC nanocomposite, respectively. From Figure $14 \mathrm{a}, \mathrm{Ag}$ diffusion did not occur during implantation in the polycrystalline CVD $3 \mathrm{C}-\mathrm{SiC}$ at $873 \mathrm{~K}$, indicating that the grain boundaries in the sample did not provide a faster path for Ag diffusion at the elevated temperature. The result agrees well with our previous observation [34] that suggests that Ag is immobile in both crystalline and amorphous $\mathrm{SiC}$ below $1573 \mathrm{~K}$. The $\mathrm{Si}$ and $\mathrm{Ag}$ depth scales in Figure $14 \mathrm{~b}$ are assumed to be about the same as in pure $\mathrm{SiC}$. In the $\mathrm{Ag}^{2+}$ implanted nanocomposite $\mathrm{Ti}_{3} \mathrm{SiC}_{2} / 3 \mathrm{C}-\mathrm{SiC}, \mathrm{Ag}$ profile consists of two convoluted peaks: a broad peak and a sharper peak. The broad peak corresponds to immobile Ag in $3 \mathrm{C}$-SiC, while the sharper peak is due to the Ag accumulation on the sample surface as a result of Ag outward diffusion in $\mathrm{Ti}_{3} \mathrm{SiC}_{2}$ within the nanocomposite during ion implantation at $873 \mathrm{~K}$. Similar results for the $\mathrm{Ag}$ diffusion in $\mathrm{Ti}_{3} \mathrm{SiC}_{2}$ at $873 \mathrm{~K}$ have never been reported in the literature to the best of our knowledge. It remains to be further investigated to develop the diffusion mechanisms in MAX phases and understand the roles of grain boundaries as well.
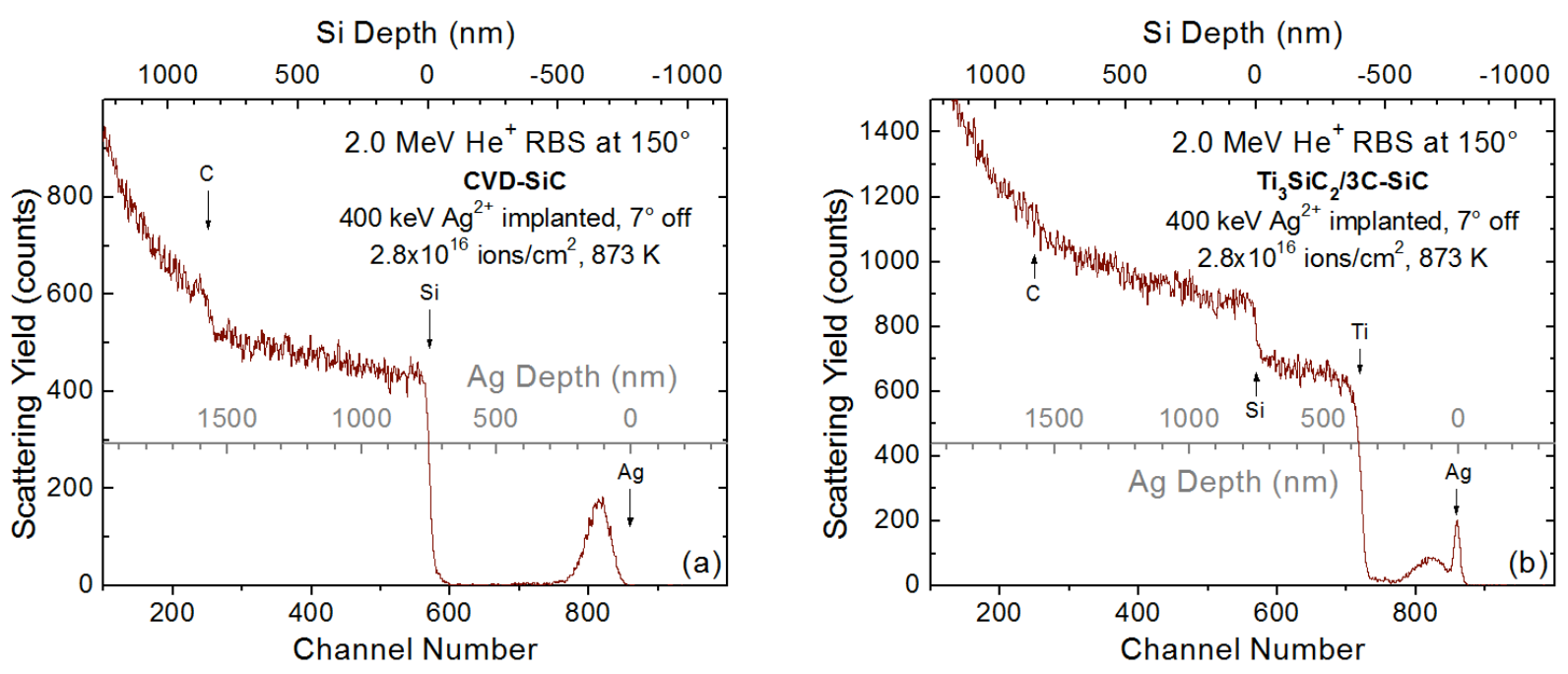

Figure 14. (a) $2.0 \mathrm{MeV} \mathrm{He}{ }^{+} \mathrm{RBS}$ spectra for (a) a polycrystalline CVD $3 \mathrm{C}-\mathrm{SiC}$ and (b) a $\mathrm{Ti}_{3} \mathrm{SiC}_{2} / 3 \mathrm{C}$ $\mathrm{SiC}$ nanocomposite implanted $7^{\circ}$ off normal with $400 \mathrm{keV} \mathrm{Ag}^{2+}$ at $873 \mathrm{~K}$ to $2.8 \times 10^{16}$ ions $/ \mathrm{cm}^{2}$. The $\mathrm{Ag}$ peak shown in (b) is due to out-diffusion of $\mathrm{Ag}$ to the surface of the $\mathrm{Ti}_{3} \mathrm{SiC}_{2} / 3 \mathrm{C}$-SiC nanocomposite.

During the thermal annealing, further Ag diffusion and accumulation at the newly formed interface were observed. Subsequent annealing at $1273 \mathrm{~K}$ for $120 \mathrm{~min}$ led to more extensive Ag out-diffusion and release. In addition, the thickness of the surface layer was slightly reduced with some $\mathrm{C}$ concentration. In contrast, $\mathrm{Ag}$ was observed to be immobile in $\mathrm{SiC}$ under the thermal annealing conditions up to the highest temperature applied (1273 K).

\subsection{2 $\mathrm{Au}^{2+}$ Ion Implanted $\mathrm{Ti}_{3} \mathrm{SiC}_{2}$}

While $\mathrm{Ag}^{2+}$ ion implantation was not performed in $\mathrm{Ti}_{3} \mathrm{SiC}_{2}$ due to a lack of samples at the time, the experiments on the dual-phase nanocomposite $\mathrm{Ti}_{3} \mathrm{SiC}_{2} / 3 \mathrm{C}$-SiC suggested Ag outward diffusion in $\mathrm{Ti}_{3} \mathrm{SiC}_{2}$ during ion implantation at $873 \mathrm{~K}$, as discussed above. Similar to noble metal Ag that does not form chemical bonds with the atoms in the host, an in-situ study of $\mathrm{Au}$ diffusion in polycrystalline $\mathrm{Ti}_{3} \mathrm{SiC}_{2}$ was conducted as a function of implantation temperature. The implanted samples were subsequently analyzed in situ near room temperature using 3.0 $\mathrm{MeV} \mathrm{He}^{+} \mathrm{RBS}$. The RBS data are shown in Figure 15, with 
elements $\mathrm{Au}, \mathrm{Ti}$ and $\mathrm{Si}$ on the sample surface indicated by arrows. The two vertical dashed lines show the depth region of the implanted $\mathrm{Au}$ and the horizontal dotted lines represent the shifted axes for the RBS spectra. From Fig. 15, the $\mathrm{Au}$ peak position, width and shape do not change up to $673 \mathrm{~K}$, suggesting that observable $\mathrm{Au}$ diffusion in $\mathrm{Ti}_{3} \mathrm{SiC}_{2}$ does not occur up to this temperature. The $\mathrm{Au}$ atoms appear to start diffusing in $\mathrm{Ti}_{3} \mathrm{SiC}_{2}$ during implantation at $773 \mathrm{~K}$, where the peak becomes slightly broader, but its position remains unchanged. There is an extensive $\mathrm{Au}$ out-diffusion in $\mathrm{Ti}_{3} \mathrm{SiC}_{2}$ during implantation at $873 \mathrm{~K}$. Au accumulation on the surface is clearly visible. The result is similar to the $\mathrm{Ag}$ outward diffusion observed in the dual-phase nanocomposite of $\mathrm{Ti}_{3} \mathrm{SiC}_{2} / 3 \mathrm{C}-\mathrm{SiC}$ during implantation at $873 \mathrm{~K}$ (Figure 14b).

\section{5 $\mathrm{Cs}^{13+}$ Ion Implanted $\mathrm{Ti}_{3} \mathrm{SiC}_{2}$}

The stable isotope ${ }^{133} \mathrm{Cs}$ was implanted as a fission surrogate for ${ }^{137} \mathrm{Cs}$ to study its diffusion behavior in MAX phase $\mathrm{Ti}_{3} \mathrm{SiC}_{2}$. The ion implantation was performed $7^{\circ}$ off normal with $1.0 \mathrm{MeV} \mathrm{Cs}{ }^{13+}$ at $673 \mathrm{~K}$ to an ion fluence of $5.7 \times 10^{16}$ ions $/ \mathrm{cm}^{2} .3 .0 \mathrm{MeV} \mathrm{He}{ }^{+}$ion RBS was used to measure the Cs depth profile in the as-implanted sample. Both isochronal and isothermal annealing experiments were followed to study Cs diffusion as a function of annealing temperature and duration using in-situ RBS method. The data for the 30-min isochronal annealing at temperatures from 723 to $1073 \mathrm{~K}$ are shown in Figure 16, which includes the Cs, Ti and Si spectra to study their evolutions. Also included in the figure is the data for the as-implanted sample at $673 \mathrm{~K}$. The Cs peaks are zoomed in by a factor of 3 for clarity. Apparently, the RBS spectra of $\mathrm{Ti}_{3} \mathrm{SiC}_{2}$ did not change under the implantation conditions, suggesting that the material composition remained the same. In all cases, the Cs peaks in the spectra are well resolved and located in a low-background region. Compared to SRIM03 prediction, the measured depth profile of Cs in as-implanted $\mathrm{Ti}_{3} \mathrm{SiC}_{2}$ shows similar peak position and FWHM, indicating that $\mathrm{Cs}$ is not very mobile in $\mathrm{Ti}_{3} \mathrm{SiC}_{2}$ during implantation at $673 \mathrm{~K}$. The peak position, FWHM and shape of the implanted Cs hardly changed after thermal annealing up to $923 \mathrm{~K}$. However, further annealing at $973 \mathrm{~K}$ leads to an abrupt change in the peak shape and reduction in intensity. The original Gaussian peak becomes two convoluted peaks with the stronger one closer

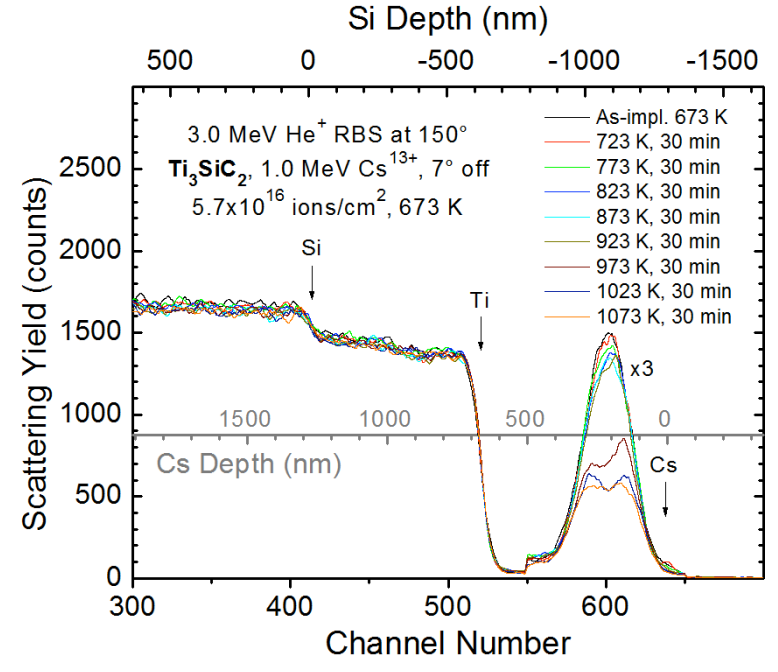

Figure 16. $30 \mathrm{~min}$ isochronal annealing of a polycrystalline $\mathrm{Ti}_{3} \mathrm{SiC}_{2}$ implanted with $1.0 \mathrm{MeV}$ $\mathrm{Cs}^{13+}$ at $673 \mathrm{~K}$ to an ion fluence of $5.7 \times 10^{16}$ 
to the surface, indicating that Cs in MAX phase $\mathrm{Ti}_{3} \mathrm{SiC}_{2}$ diffuses towards the surface at $973 \mathrm{~K}$. Cs did not accumulate on the surface at $973 \mathrm{~K}$, but likely evaporated to vacuum $\left(10^{-6}\right.$ Torr $)$ during thermal annealing. About $36 \%$ of $\mathrm{Cs}$ in $\mathrm{Ti}_{3} \mathrm{SiC}_{2}$ was released based on the reduction in the peak intensity. In contrast, $\mathrm{Cs}$ in $\mathrm{SiC}$ starts diffusing at a much higher temperature $(\sim 1473 \mathrm{~K})$ also without surface accumulation $[67,68]$. Unlike $\mathrm{Ag}$ and $\mathrm{Au}$ in $\mathrm{Ti}_{3} \mathrm{SiC}_{2}$ during ion implantation at $873 \mathrm{~K}$, the temperature for significant Cs diffusion is $\sim 100 \mathrm{~K}$ higher without evidence of Cs surface accumulation. While surface accumulation depends on chemical bonding and temperature, the increase in temperature is not a big surprise because thermal processes usually take place at lower temperatures when ion irradiation is present. Further annealing of the sample at 1023 and 1073 $\mathrm{K}$ resulted in diminishing diffusion and loss of $\mathrm{Cs}$, as shown in Fig. 16. At the end of the thermal annealing at $1073 \mathrm{~K}$ for $30 \mathrm{~min}$, about $50 \%$ Cs was released from the implanted $\mathrm{Ti}_{3} \mathrm{SiC}_{2}$.

Isothermal annealing at $1073 \mathrm{~K}$ was performed in vacuum $\left(10^{-6}\right.$ Torr $)$ for durations ranging from 5 to $120 \mathrm{~min}$. The in-situ RBS data are shown in Figure 17. The as-implanted sample shows a small peak that is barely seen, which could originate from some surface Cs. There is a small change in the Cs depth profile after $5 \mathrm{~min}$ annealing. It appears that the Cs tends to diffuse towards the surface, but accumulation of Cs on the surface is not evident, which is consistent with the data in Fig. 17. The overall reduction in the peak intensity or Cs loss is $\sim 10 \%$ at $5 \mathrm{~min}$. A more significant Cs loss of $\sim 30 \%$ relative to the total implanted Cs occurred at $15 \mathrm{~min}$, followed by a total Cs loss of $\sim 40 \%$ at $30 \mathrm{~min}$, which is statistically not very different from the percentage $(\sim 50 \%)$ of Cs released after $30 \mathrm{~min}$ isochronal annealing at $1073 \mathrm{~K}$ (Fig. 16). Further annealing for longer durations up to $120 \mathrm{~min}$ does not lead to a significant change in the Cs depth profile.

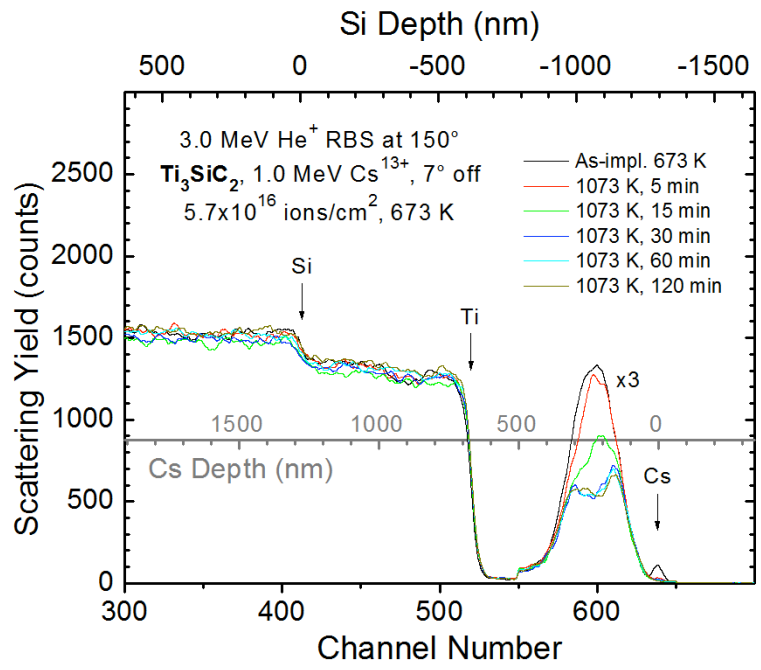

Figure 17. 1073 K isothermal annealing of a polycrystalline $\mathrm{Ti}_{3} \mathrm{SiC}_{2}$ implanted with $1.0 \mathrm{MeV}$ $\mathrm{Cs}^{13+}$ at $673 \mathrm{~K}$ to an ion fluence of $5.7 \times 10^{16}$ 


\subsection{Modeling and Simulation}

Absent a material to measure, computational models can be used to study effects of microstructure and phase content on mechanical and thermal properties, which are two properties of great interest for this NEET project. PNNL had already developed a powerful modeling methodology, an Eshelby-MoriTanaka Approach (EMTA) that could be used to model both the mechanical and thermal properties of composites. Therefore, efforts were made to model the mechanical properties of SiC-based alloys containing CNTs in order to understand the limitations of CNTs as reinforcements and to create a framework that could encompass the use of CNT mats as they are developed. In addition, the thermal properties of materials containing second phases and porosity were modeled using a similar approach [69$71]$.

\subsection{Prediction of Elastic Properties of Composites Containing CNTs}

Reinforcing a ceramic matrix with dispersed nanoparticles or carbon nanotubes (CNTs) at moderate volume fractions can achieve significant increases in elastic moduli for the resulting composite. These increases are higher than those obtained with the use of conventional fibers. The so-called nano-effect from the existence of an interphase between the nano-reinforcement phase and matrix material is responsible for the significant enhancement of the composite elastic moduli. In this work, a PNNL computer tool named EMTA for the computation of the composite thermoelastic properties [72] was modified to account for the nano-effect in multiwall carbon nanotube (MWCNT) composite. Figure 18 gives a schematic description of the EMTA computation procedure for MWCNT composites. The computation considers the unidirectional (UD) composite containing aligned single- or multiwall CNTs (Figure 18a) from which the first EMTA homogenization is performed to obtain the homogenized elastic stiffness of the CNT/interphase system (Figure 18b). Next, the second EMTA homogenization is carried out to determine the elastic stiffness of the UD composite containing aligned equivalent fibers and embedded in a matrix material (Figure 18c). Finally, the fiber orientation averaging technique [73] is applied to compute the elastic stiffness of the as-formed composite having a fiber orientation distribution (Figure 18d).

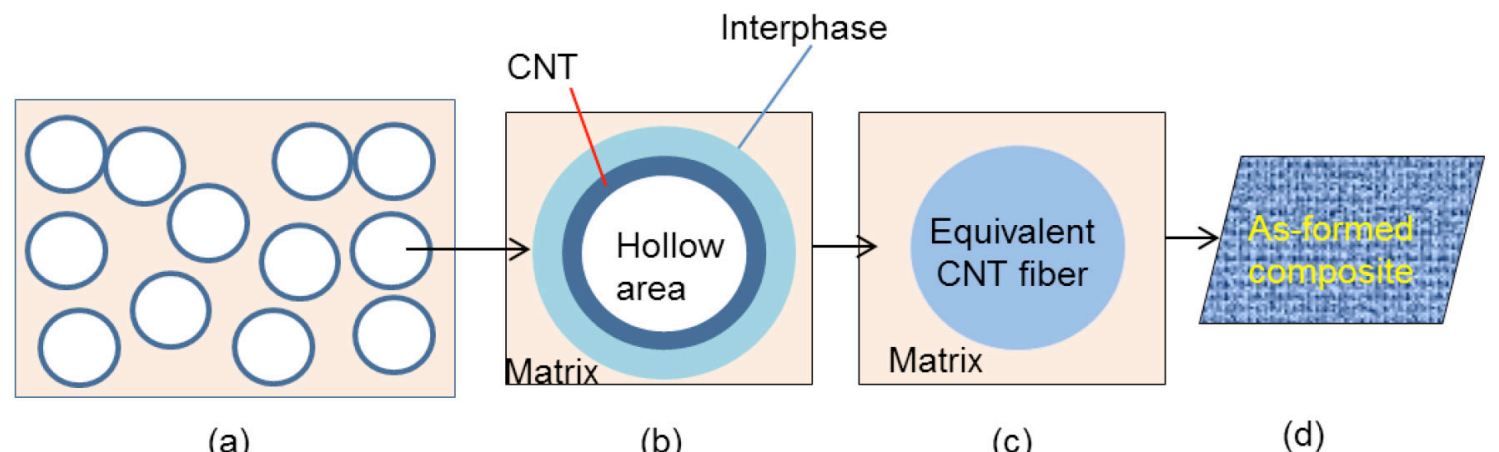

Figure 18. Schematic of the EMTA Homogenization Procedure

Figure 19 presents EMTA predictions compared to measured data [74] for the shear modulus of a MWCNT/3YSZ ( $3 \mathrm{~mol} \%$ yttria stabilized zirconia) system as a function of the MWCNT volume fraction. This composite system was processed by spark plasma sintering [74]. The results show that dispersing small MWCNT contents in 3YSZ has significantly increased the shear modulus of the as-formed composite, and a good agreement between the predicted and measured moduli is obtained using the 
EMTA model with interphase. It is noted that the difficulty to homogeneously distribute higher MWCNT contents in the matrix has limited the increase in modulus, and that explains the deviation between the predicted and experimental results for higher MWCNT volume fractions.

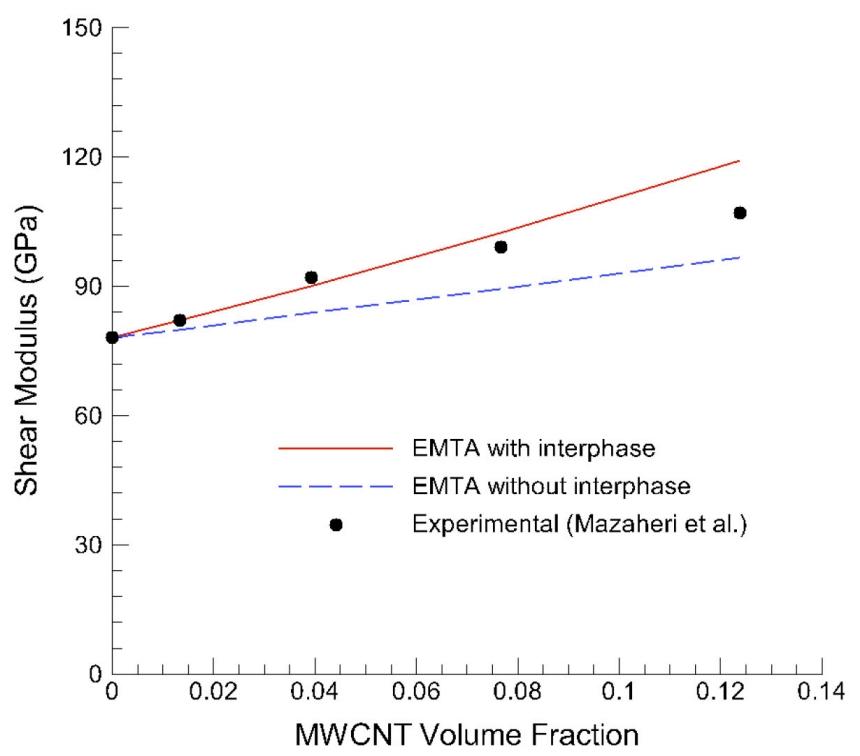

Figure 19. Measured and Predicted Shear Modulus for a MWCNT/3YSZ System as a Function of MWCNT Volume Fraction. The experimental results are from Mazaheri, Mari [74].

\subsection{A Mechanistic Damage Model for MWCNT Ceramic Composites}

We have developed a mechanistic damage model to describe matrix cracking in MWCNT ceramic composites. The model derived from a model for glass-ceramics developed by Nguyen, Koeppel [75] is termed "mechanistic" as its formulation uses both micromechanics and continuum damage mechanics. It assumes elastic MWCNTs completely randomly dispersed in a ceramic matrix whose cracking behavior is described by a continuum damage description. The damage model has been implemented in EMTANLA, a PNNL's capability used with the ABAQUS finite element (FE) package for nonlinear structural analyses [76]. The details of this damage model and its implementation are reported in our article in preparation. ${ }^{1}$

Figure 20 presents the stress/strain responses as a function of the MWCNT weight fraction predicted by the damage model for this composite system subjected to tensile loading to failure. The experimental stress/strain curves are not known. The predicted increase in tensile strength is substantial for the composite with 5-wt\% MWCNT (12.4\% volume fraction). As observed for the elastic moduli it is expected that the actual strength (if available) would be lower than the predicted strength for this value of MWCNT content because of the difficulty to homogeneously distribute MWCNTs in the matrix.

(1) Nguyen BN, et al. 2013. "Fracture Toughness Prediction for MWCNT Reinforced Ceramics Using a Modified Boundary Layer Modeling Approach. In preparation. 


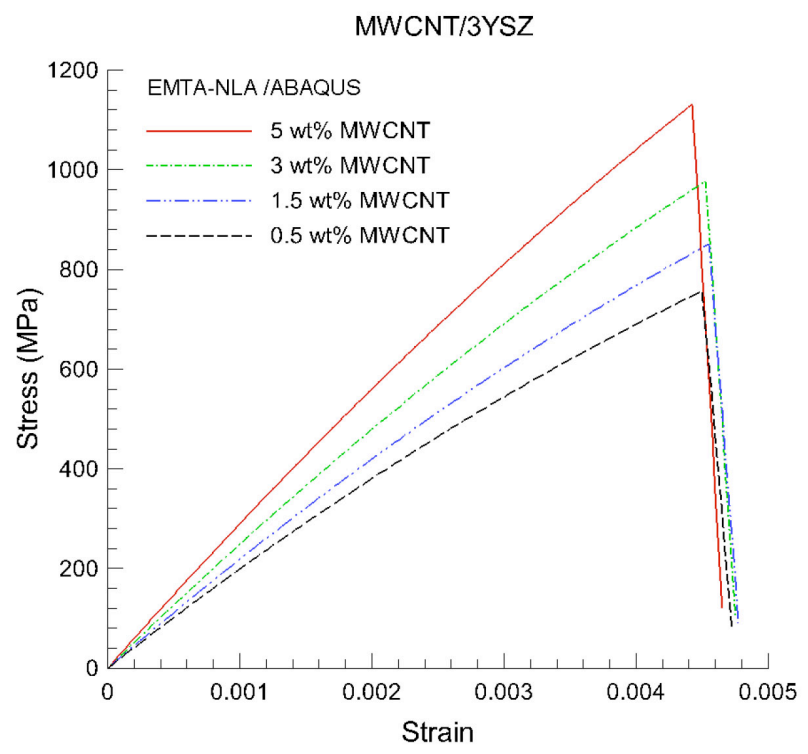

Figure 20. Tensile Stress/Strain Response Predicted for MWCNT/3YSZ as a Function of the MWCNT Weight Fraction

\subsection{Fracture Toughness Prediction for MWCNT Reinforced Ceramics}

The damage model developed for MWCNT reinforced ceramics was used in a modified boundary layer (MBL) modeling approach to predict the composite fracture toughness under Mode I loading. The MBL analysis can be efficiently used to characterize the material fracture toughness and crack resistance behavior without modeling the whole structure with the associated boundary conditions. These, however, are represented in an MBL model through the asymptotic crack-tip fields. For the MWCNT ceramic composites studied in this report, the MWCNTs are assumed to be completely randomly distributed in the ceramic matrix; thus, the homogenized behavior is isotropic, and the crack-tip fields for a crack in an elastic isotropic solid are then used as the remote boundary conditions for the MBL analysis. The composite behavior away from the process zone remains linear elastic. Under increasing loading applied via boundary conditions, damage evolves at the crack tip until attaining a critical stage characterized by the critical value of the damage variable. The critical damage stage represents the onset of crack propagation in the damage process window, and the corresponding value of $K_{\mathrm{I}}$ at this stage defines the material Mode I fracture toughness, $K_{\mathrm{I}}^{\mathrm{c}}$. The critical value of the damage variable at failure has been identified to be 0.2 for all the MWCNT/3YSZ composites studied in this report. ${ }^{1}$

Similar EMTA-NLA/ABAQUS MBL analyses using the damage model were performed for all the MWCNT/3YSZ composites with weight fractions from $0.04 \%$ to $1 \%$ (volume fractions from $0.1 \%$ to $23 \%$ ) to predict the fracture toughness of this composite system as a function of the MWCNT content. Predicted fracture toughness results are reported in Figure 21 that shows significant increases in fracture toughness with the increasing MWCNT volume fraction up to about $15 \%$. The predicted evolution appears to saturate for volume fractions higher than $15 \%$. The predicted fracture toughness for MWCNT volume fractions agrees well with experimental results also given in Fig. 21.

(1) Nguyen BN, et al. 2013. "Fracture Toughness Prediction for MWCNT Reinforced Ceramics Using a Modified Boundary Layer Modeling Approach. In preparation. 


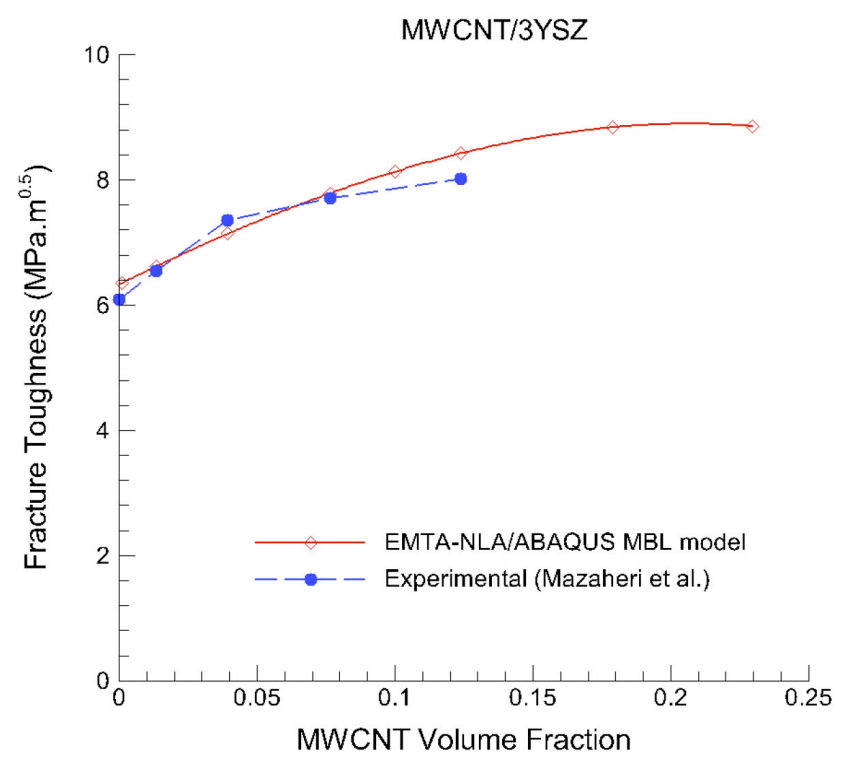

Figure 21. Predicted and Experimental Mode I Fracture Toughness vs. MWCNT Volume Fraction for the MWCNT/3YSZ Composites. The experimental results were determined by Mazaheri et al. [74] via bending tests of single edge $\mathrm{V}$-notched beam specimens.

Cracks can propagate further in the process window after initiation if the loading is increased. The present MBL analysis was also used to predict the stress intensity factor vs. crack advance (R-curve) as a function of the MWCNT content. The R-curves were also predicted by the MBL analysis for the other MWCNT/3YSZ composites with weight fractions from 0.04 to $5 \%$ and the results are reported in Figure 22. For the extent of the crack advance predicted, all the predicted R-curves can be fitted quite well by a power-law of the form:

$$
K_{\mathrm{I}}^{\mathrm{R}}=k c^{\alpha}
$$

where $K_{\mathrm{I}}^{\mathrm{R}}$ is stress intensity factor after the onset of crack propagation and $c$ is the crack advance. $k$ and $\alpha$ are the fitting coefficients. Although the experimental R-curves for the MWCNT/3YSZ composites studied in this report are not known, the predicted power-law trend was experimentally observed in other ceramic composite systems [77-79]. Table 5 gives the values of $k$ and $\alpha$ obtained from the fitting of the MBL analysis results by the power-law.

Table 5. R-curves Power-Law Coefficients Identified for the MWCNT/3YSZ Composites

\begin{tabular}{ccccc}
\hline MWCNT Content & $\mathbf{0 . 0 5}-\mathbf{w t} \%$ & $\mathbf{1 . 5}-\mathbf{w t} \%$ & $\mathbf{3 - w t \%}$ & $\mathbf{5 - w t \%}$ \\
\hline$c_{0}(\mathrm{~m})$ & $1.5 \mathrm{E}-5$ & $1.5 \mathrm{E}-5$ & $1.5 \mathrm{E}-5$ & $1.5 \mathrm{E}-5$ \\
$k\left(\mathrm{MPa} \cdot \mathrm{m}^{1 / 2} \cdot \mathrm{m}^{-\alpha}\right)$ & 13.93 & 14.82 & 18.1 & 19.22 \\
$\alpha$ & $6.73 \mathrm{E}-2$ & $6.59 \mathrm{E}-2$ & $7.74 \mathrm{E}-2$ & $7.34 \mathrm{E}-2$ \\
\hline
\end{tabular}




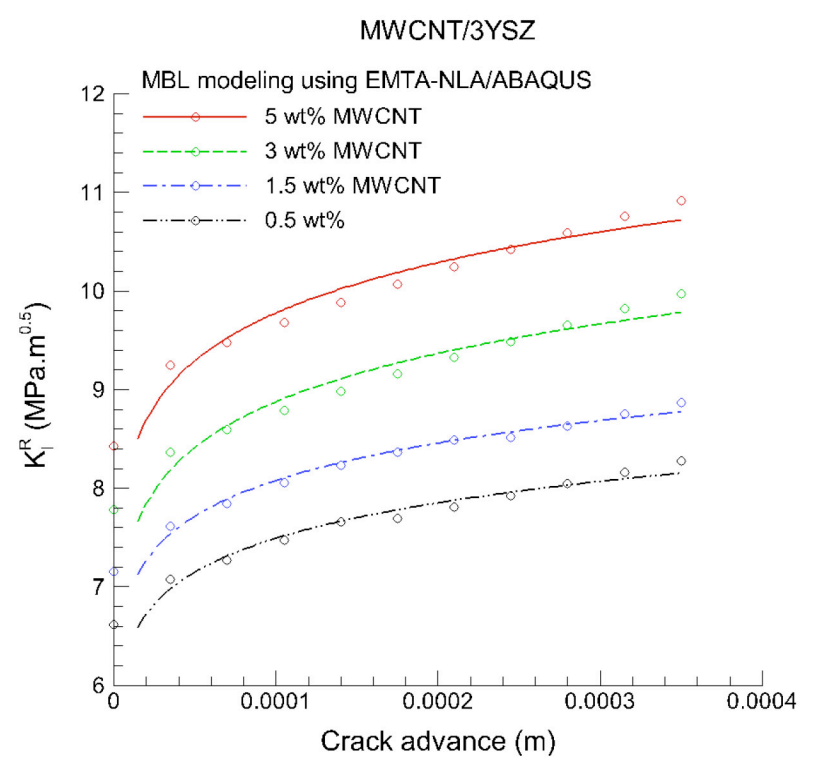

Figure 22. Predicted Stress Intensity Factor vs. Crack Advance for the MWCNT/3YSZ Composites as a Function of MWCNT Content.

\subsection{Prediction of Thermal Conductivity of Composites}

The PNNL EMTA approach makes use of the complete analogy between the variables used in elasticity and those in steady-state heat conduction established by Hatta and Taya [80], which allows the use of the formulation established for the elastic stiffness of a unidirectional (UD) composite using the Eshelby equivalent inclusion method to obtain the expression for the composite thermal conductivity by switching the variables as follows:

$$
\begin{gathered}
\text { Stress, } \sigma_{i j} \leftarrow \rightarrow \text { Heat flux, } q_{i} \\
\text { Strain, } \varepsilon_{i j} \leftarrow \rightarrow \text { Temperature gradient, } \nabla T \\
\text { Stiffness, } C_{i j k l} \leftarrow \rightarrow \text { Thermal conductivity, } k_{i j}
\end{gathered}
$$

A large body of literature on micromechanical models exists addressing the prediction of elastic properties of non-dilute aligned fiber composites. In particular, there is a family of models that has evolved from a proposal initially made by Mori and Tanaka [81]. To date, Eshelby's equivalent inclusion method [82] combined with a Mori-Tanaka type model presents one of the most efficient and accurate approaches for the prediction of composite properties [83].

The thermal conductivity tensor of a UD composite with a fiber length distribution is computed as:

$$
\mathbf{k}=\frac{\int_{0}^{\infty} \mathbf{k}^{*}(l / d) p(l) d l}{\int_{0}^{\infty} p(l) d l}
$$

where $\mathbf{k}^{*}(l / d)$ is the thermal conductivity tensor of the UD fiber composite having the fiber aspect ratio $l / d$, and $p(l) d l$ is the probability density function that can be expressed for number or weight of fibers versus fiber length, $l$. 
If the composite possesses a fiber orientation state achieved during processing, its thermal conductivity tensor also depends on its fiber orientation distribution. To account for fiber orientation effects, the fiber orientation averaging technique developed by Advani and Tucker is used [73]. The thermal conductivity tensor of the composite with distributed fiber orientation is obtained as:

$$
\bar{k}_{i j}=k_{1} a_{i j}+k_{2} \delta_{i j}
$$

where $k_{1}=k_{11}-k_{22}$ and $k_{2}=k_{22}$ are the invariants of the thermal conductivity tensor for the UD composite given by Eq. 6 for a composite with a fiber length distribution. $a_{i j}$ is the second-order orientation tensor as defined in Ref. [73] with $a_{i i}=1$.

\subsubsection{Prediction for a 2D-Hi-Nicalon ${ }^{\mathrm{TM}} /$ Pyrolitic Carbon/ICVI-SiC Composite}

The first application example in this section examines the commercial two-dimensional (2D) $\mathrm{SiC} / \mathrm{SiC}$ composite studied by Youngblood et al. [84, 85]. DuPont processed this material from plain weave HiNicalon fabric using an isothermal chemical vapor infiltration (IVCI) processed matrix. Two versions of this composite were examined in [84] including one with a 0.11 -micron-thick and one with a 1-micronthick pyrolytic carbon (PyC) fiber coating layer, termed thin and thick, respectively. Figures 23a and 23b show EMTA predictions for the thermal conductivities of the equivalent fibers that have thin or thick coating layers. As the thermal conductivity of the PyC coating layer in the $10-30 \mathrm{~W} / \mathrm{m} \cdot \mathrm{K}$ range is higher than the thermal conductivity of the $\mathrm{SiC}$ fiber, increasing the thickness of the fiber coating layer significantly increases the thermal conductivities of the equivalent fiber (homogenized fiber/coating material). When the fiber-coating layer is thin, its increased thermal conductivity has little effect on the thermal conductivities of the equivalent fibers.

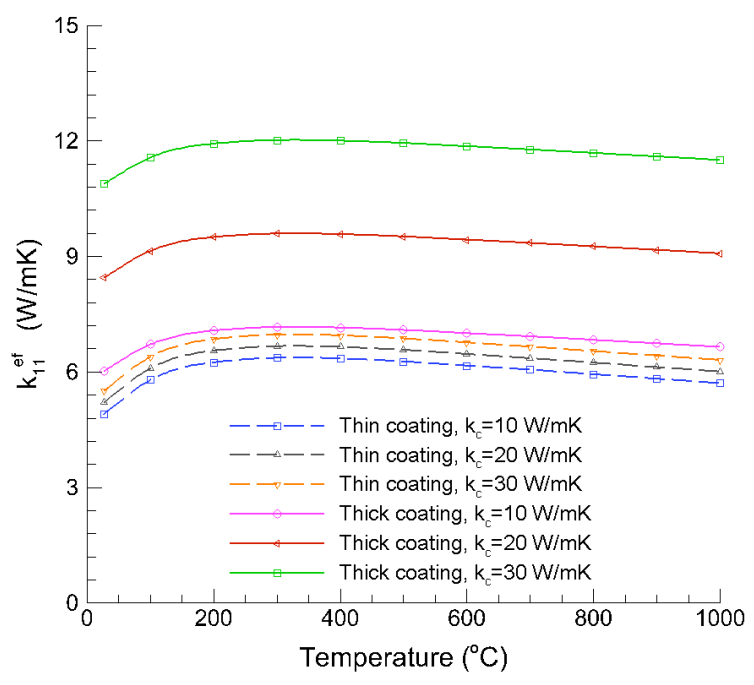

(a) 


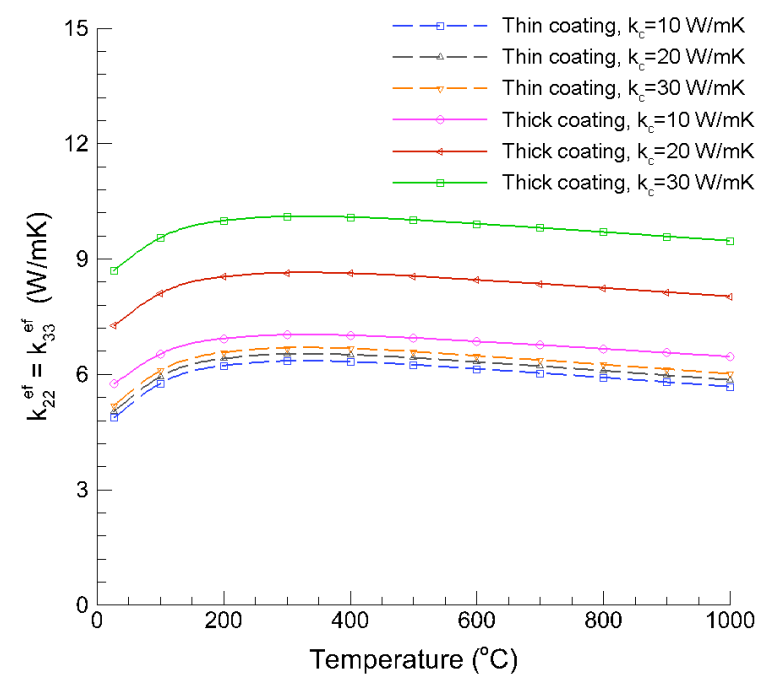

(b)

Figure 23. Thermal conductivities of the equivalent fibers predicted by EMTA for the fibers with thin and thick coating layers.

The thermal conductivities of the equivalent fibers based on thin and thick coating layers were then used in the EMTA homogenization to compute the thermal conductivities of the $2 \mathrm{D}$ woven $\mathrm{SiC} / \mathrm{SiC}$ composites [84]. Figure 24 reports the thermal conductivities predicted by EMTA for the 2D SiC/SiC woven composite with the thin fiber coating $(0.1$ micron). The evolution of the transverse thermal conductivity with temperature given in Fig. 24b is in very good agreement with Youngblood et al.'s experimental and predicted results for this composite $[84,85]$.

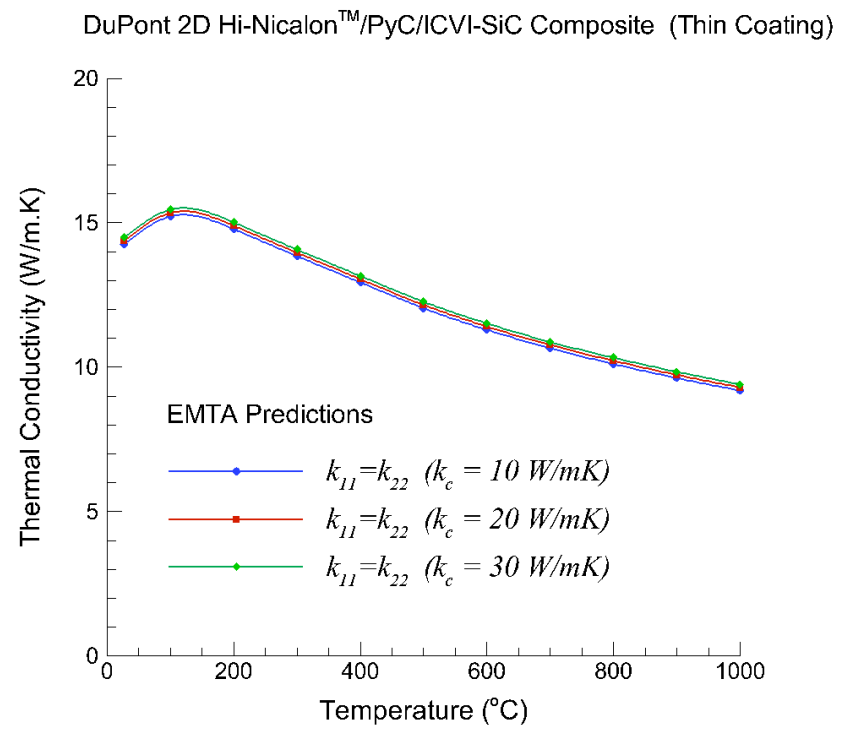

(a) 


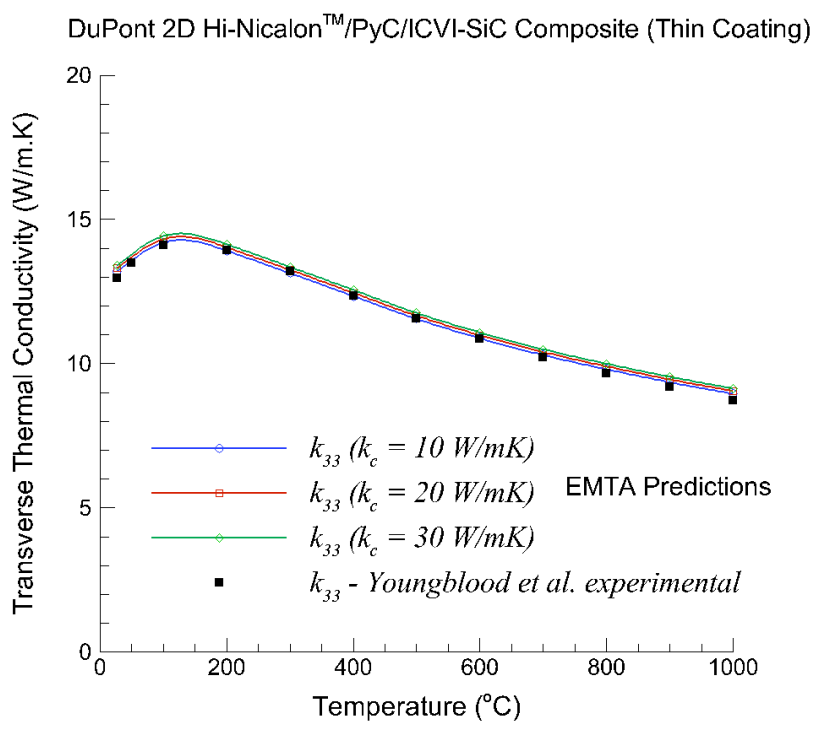

(b)

Figure 24. Thermal conductivities predicted by EMTA for the DuPont 2D SiC/SiC woven composite with the thin fiber coating layer: (a) In-plane thermal conductivities, $k_{11}$ and $k_{22}$, and (b) transverse thermal conductivity $k_{33}$ compared to Youngblood et al.'s experimental results [84].

\subsubsection{Prediction for a 2D-Hi-Nicalon Type-S/PyC/ICVI-SiC Composite}

This composite was made using the ICVI process with Hi-Nicalon Type-S fabric and a thin PyC fiber coating [86]. The mean fiber diameter and thickness of the fiber coating are 12 microns and 0.2 micron, respectively. The EMTA analysis for the 2D Hi-Nicalon Type S/ICVI-SiC composite was conducted as follows. The same value of $k_{\mathrm{c}}=10 \mathrm{~W} / \mathrm{mK}$ estimated for the thermal conductivity of the PyC fiber coating for ICVI processed composites was used in the computation. Because the experimental thermal conductivity data as a function of temperature for the $\mathrm{SiC}$ matrix of the 2D Hi-Nicalon Type S/ICVI-SiC composite are not available, the EMTA calculation for this composite was first conducted using the values for the $\mathrm{SiC}$ matrix in the DuPont $2 \mathrm{D}-\mathrm{Hi}-\mathrm{Nicalon}{ }^{\mathrm{TM}} / \mathrm{ICVI}-\mathrm{SiC}$ composite having thin fiber coating. The Hi-Nicalon Type-S fiber thermal conductivity as a function of temperature was provided in [86]. Next, a further assessment of the matrix thermal conductivity as a function of temperature can be achieved by applying the EMTA reverse engineering procedure to determine the matrix thermal conductivity for the Hi-Nicalon Type S fiber composite. Figure 25 presents the results obtained by EMTA reverse engineering compared to the predictions for the same 2D Hi-Nicalon Type-S/ICVI-SiC composite using the (assumed) initial guess values for the matrix thermal conductivity. 


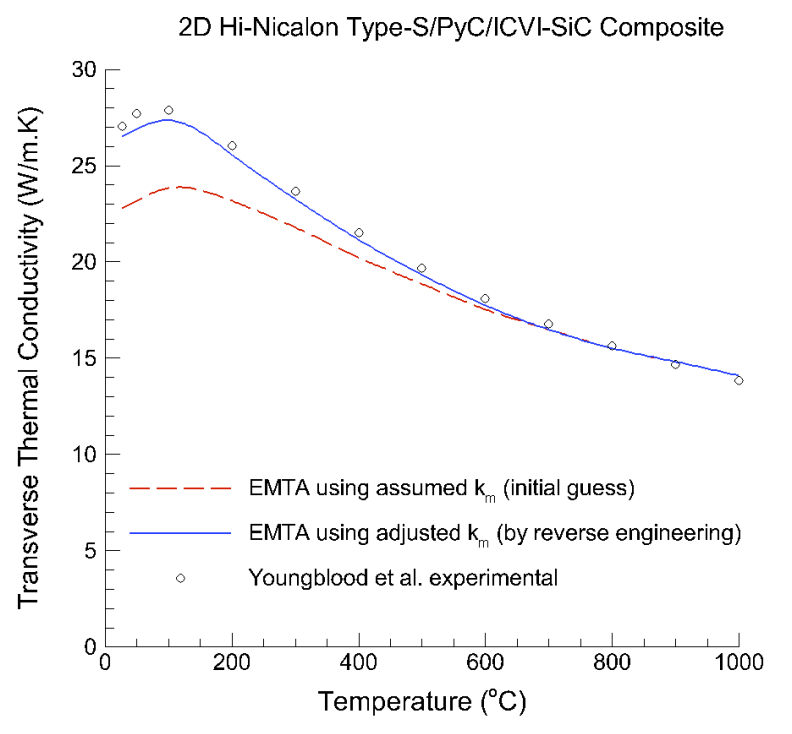

Figure 25. Transverse thermal conductivities predicted by EMTA for the 2D Hi-Nicalon Type$\mathrm{S} / \mathrm{PyC} / \mathrm{ICVI}-\mathrm{SiC}$ composite as a function temperature using the assumed and adjusted matrix thermal conductivities - The symbols denote Youngblood experimental results [87].

\subsection{Prediction of Thermal Conductivities for Irradiated SiC}

The EMTA computation is extended using MD data to include irradiated $\mathrm{SiC}$ materials and $\mathrm{SiC} / \mathrm{SiC}$ composites by treating the individual composite constituents. $\mathrm{SiC}$ constituents considered are CVD-SiC, nearly stoichiometric $\mathrm{SiC}$ fibers, and an ICVI-SiC matrix. The thermal conductivity of CVD-SiC is not used in the EMTA computations but this material is used as a reference material to estimate the thermal conductivities for other $\mathrm{SiC}$ constituents. This section describes the computational methods to predict the thermal conductivities of unirradiated and irradiated $\mathrm{SiC}$ constituents.

\subsubsection{Prediction of thermal conductivity for unirradiated SiC constituents}

Thermal conductivity data for polycrystalline CVD-SiC in the $80 \mathrm{~K}$-to-300K-temperature range were experimentally determined Collins et al. [88]. Below $200 \mathrm{~K}$, these authors observed a linear dependence of thermal conductivity with the product, $d \cdot T^{3}$ (with $d$ being the grain size, and $T$ temperature), and this was explained in terms of phonon scattering by grain boundaries. In this paper, we extend the linear dependence of the thermal conductivity of polycrystalline $\mathrm{SiC}$ with $d \cdot T^{3}$ to the elevated temperature range of interest (from $300 \mathrm{~K}$ to $1200 \mathrm{~K}$ ). As the thermal conductivity of $\mathrm{SiC}$ in this temperature range is governed by both grain boundary and phonon-phonon interaction umklapp scattering mechanisms, such an extension suggests that there is an equivalent grain size, $d_{\mathrm{eq}}$ with grain boundary scattering producing an equivalent thermal resistance equal to the total contributions from the actual grain boundary scattering and umklapp scattering.

In addition, the experimental thermal conductivity data for CVD-SiC as a function of temperature is used to determine grain size reduction factors. Next, Collins et al.'s relation is used to estimate the equivalent grain sizes of other $\mathrm{SiC}$ constituents at $300 \mathrm{~K}$, and this relation together with the as-determined grain size reduction factors are applied to compute the thermal conductivities of all the SiC constituents. For the ICVI-SiC matrix material, we also assume that it has the same grain size as the Hi-Nicalon Type$\mathrm{S}$ fiber and contains $12 \%$ void volume fraction. The experimental data for the Tyranno-SA and Hi- 
Nicalon Type-S fibers were taken from Refs. [89] and [87], respectively, while the data for the ICVI-SiC matrix were taken from [84].

\subsubsection{Prediction of thermal conductivity for irradiated SiC constituents}

Subject to neutron irradiation in the temperature range considered, thermal conductivities of $\mathrm{SiC}$ constituents degrade more or less rapidly due to accumulations of point defects that depend on the microstructural features of the polycrystalline SiC. Grain size is one of the key controlling factors of thermal conductivity degradation. In order to capture the physics of conductivity degradation in $\mathrm{SiC}$, this paper exploits the available MD results obtained for perfect crystalline $\beta$-SiC in terms of defect concentration as a function of dose, and volume swelling as a function of dose and links MD data to the experimental data for volume swelling as a function of dose obtained for CVD-SiC. As a result, defect thermal resistance as a function of defect concentration or dose can be determined to compute the thermal conductivity of $\mathrm{SiC}$ constituents using Snead's expression [90]: $1 / K_{\mathrm{rd}}=1 / K_{\text {irr }}-1 / K_{\text {unirr }}$ where $K_{\text {irr }}$ and $K_{\text {unirr }}$ denote the thermal conductivities of the irradiated and unirradiated $\mathrm{SiC}$ constituents. $K_{\text {unirr }}$ for different SiC constituents are provided in Figure 26.

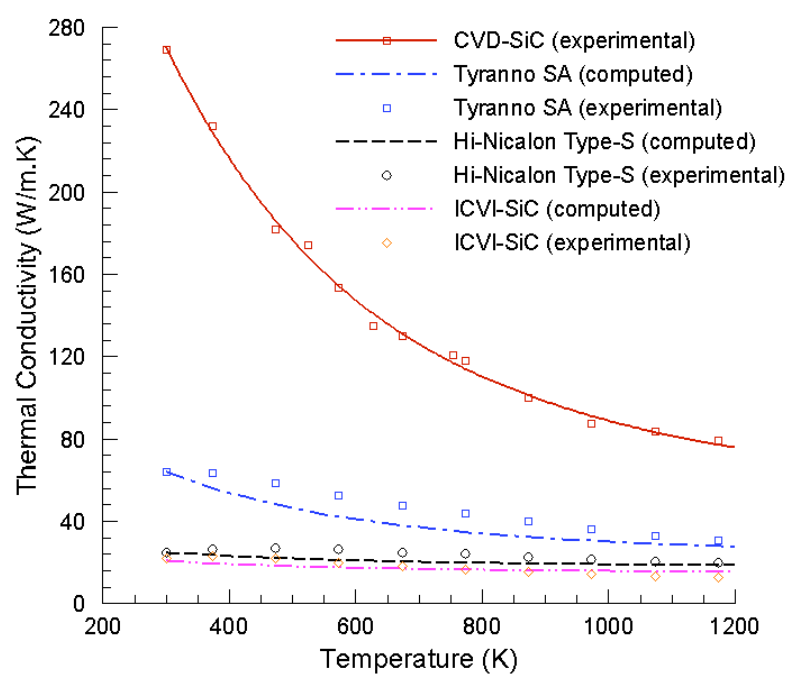

Figure 26. Thermal conductivities predicted for unirradiated $\mathrm{SiC}$ constituents based on the experimental data for CVD-SiC [91] and by the application of Collins et al.'s relation [88] in the elevated temperature range.

First, from MD swelling data, a single-point scaling is applied to the experimental data for CVD-SiC to estimate the swelling vs. dose behavior for CVD-SiC at $473 \mathrm{~K}$ and $1073 \mathrm{~K}$. Next, Crocombette et al.'s data [92, 93] as well as Samolyuk et al.'s MD results [94] were converted from defect density data as a function of thermal conductivity to defect thermal resistance as a function of defect density (expressed in atom fraction, $C_{\mathrm{v}}$ ). In addition, the Gao et al. MD swelling results [95] scaled to the experimental data for CVD-SiC are also used together with MD results for the number of point defects to determine the defect thermal resistance as a function of defect density.

Figure 27 shows the thermal conductivities of irradiated $\mathrm{SiC}$ constituents as a function of irradiation dose at $473 \mathrm{~K}$ and $1073 \mathrm{~K}$. All the thermal conductivities decrease with increasing does and stabilize corresponding to defect saturation, however the reduction is more important at $473 \mathrm{~K}$ than at $1073 \mathrm{~K}$. These findings are consistent with the experimental observations as point defects can accumulate at 
higher concentrations at lower temperature than at higher temperatures due to either small cluster formation or close-pair recombination at elevated temperatures.

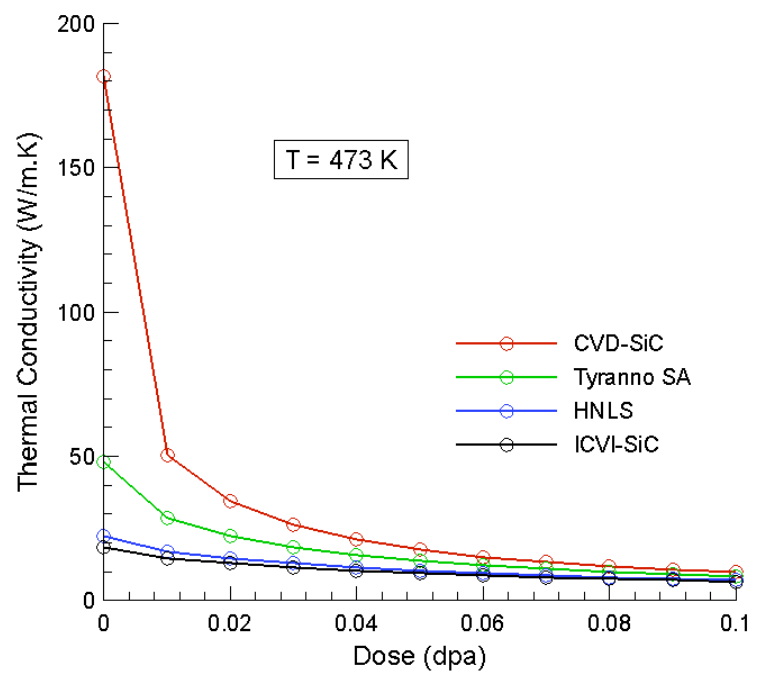

(a)

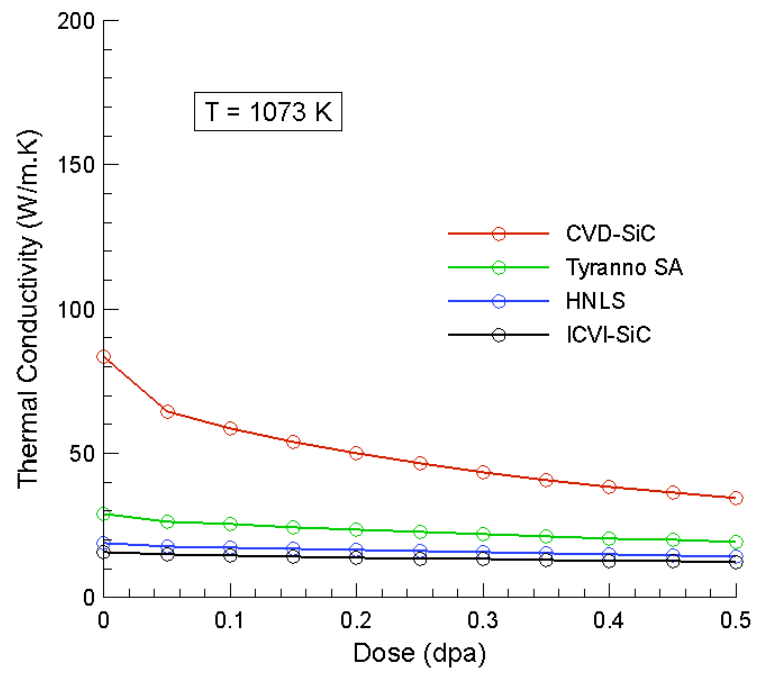

(b)

Figure 27. Thermal conductivities vs. irradiation dose predicted for $\mathrm{SiC}$ constituents at $473 \mathrm{~K}$ in (a) and $1073 \mathrm{~K}$ in (b) using the computed thermal resistance results at this temperature.

\subsubsection{Prediction of Thermal Conductivity for Irradiated SiC/SiC Composites}

The thermal conductivities predicted for unirradiated and irradiated $\mathrm{SiC}$ constituents are used as inputs for EMTA computations to predict the thermal conductivities of unirradiated and irradiated woven $\mathrm{SiC} / \mathrm{ICVI}-\mathrm{SiC}$ composites. For illustration, we consider composites processed from 2D woven preforms of Tyranno-SA or Hi-Nicalon Type-S fibers with an ICVI-SiC matrix. Both fibers were assumed to have 10-micron diameter and $200 \mathrm{~nm}$-thick PyC coating. The fiber volume fraction in both composite systems 
is $33 \%$, and the porosity was assumed to be $12 \%$. These microstructural features correspond to typical parameter values achieved for $\mathrm{SiC} / \mathrm{SiC}$ composites in practice.

The model predicts an increase in irradiated thermal conductivity with temperature at defect saturation, and this finding is consistent with the experimental trend as illustrated in Figure 28 for the Tyranno-SA composite. Fig. 28 reports the predicted irradiation temperature (IT) thermal conductivity for the studied Tyranno-SA/ICVI-SiC composite at $0.1 \mathrm{dpa}$ and $473 \mathrm{~K}$, and at $0.5 \mathrm{dpa}$ and $1073 \mathrm{~K}$. MD data converted to defect thermal resistance vs. vacancy concentration are also applied to compute the thermal conductivities of the Tyranno SA fiber and ICVI-SiC matrix at $473 \mathrm{~K}$ and at $C_{\mathrm{v}}=0.05$. The corresponding results are then used in EMTA to predict the thermal conductivity of the Tyranno$\mathrm{SA} / \mathrm{ICVI}-\mathrm{SiC}$ composite that is also presented in Fig. 28. The experimental room temperature (RT) thermal conductivity data for the Tyranno-SA3/ICVI-SiC studied by Katoh et al. [96] are presented on Fig. 28 for a qualitative comparison with the predictions.

It is noted that the comparison of results on Fig. 28 can only be qualitative because the MD combined with EMTA results are determined at irradiation temperatures while Katoh et al.'s data for the TyrannoSA3 composite were obtained at room temperature. In addition, the computation in this paper applies the same defect thermal resistance vs. dose relationship to different SiC constituents, and future work is needed to investigate grain size effects that underlie such an assumption. Finally, there are microstructural differences between the Tyranno-SA3 composite examined by Katoh et al. and the Tyranno-SA composite example considered in this paper. Tyranno-SA3 composites in [96] possessed a complex multilayer PyC/SiC coating and impurities while our Tyranno-SA/ICVI-SiC model contains a simple PyC coating.

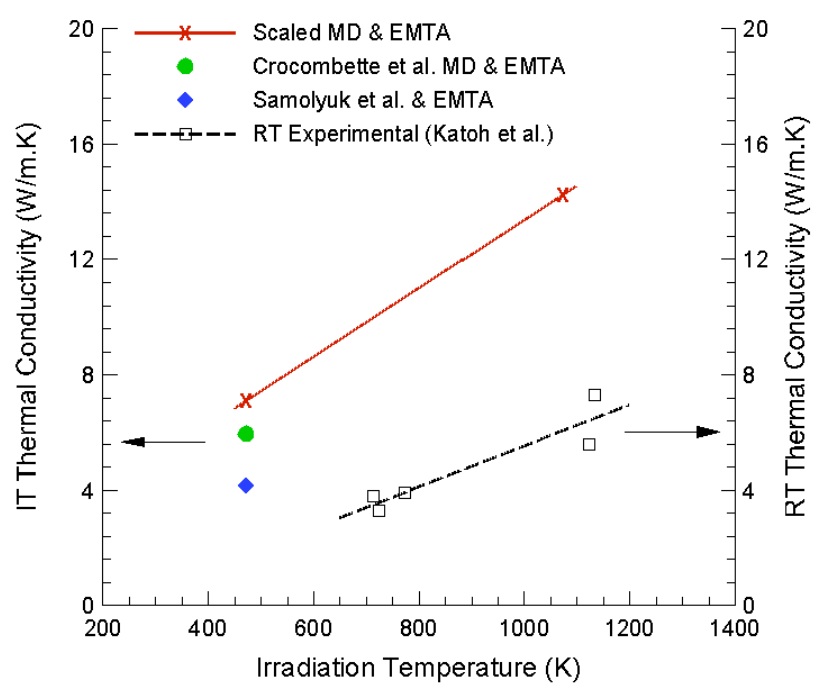

Figure 28. Irradiation temperature (IT) thermal conductivity vs. irradiation temperature predicted by MD/EMTA for the example Tyranno-SA/ICVI-SiC composite compared to room temperature (RT) thermal conductivity vs. irradiation temperature measured by Katoh et al. [96] for a Tyranno-SA3/ICVI$\mathrm{SiC}$ composite. Crocombette et al.'s as well as Samolyuk et al.'s MD data used in the computations are from Refs. [93, 94]. 


\subsection{Conclusions}

\subsection{Thermal and Mechanical Properties with Microstructural Characterization}

This report documents the synthesis of SiC-based alloys having a general structure of $\mathrm{SiC} / \mathrm{Ti}_{3} \mathrm{SiC}_{2}$ dual phase composites formed by simultaneous polycarbosilane pyrolysis and $\mathrm{Si}+\mathrm{TiC}$ displacement reactions. To the best of our knowledge these are the first such dual phase composites made by combining these two methods. Data for thermal conductivity and fracture toughness indicate that properties of these composites are in agreement with what others have measured for similar materials that have been synthesized by different methods, such as spark plasma sintering, for example. This is a positive result and indicates that the polymer pyrolysis methods can be used to combine in situ displacement reactions with $\mathrm{CNT}$ mats to make tougher composites than can be synthesized by combining $\mathrm{SiC}$ and $\mathrm{Ti}_{3} \mathrm{SiC}_{2}$ materials alone.

However, it must be noted that the synthesis methods used here have not yet been optimized and that some of the correlations that were expected to be helpful in guiding these synthesis efforts are lacking. For example, the porosity of the hot-pressed materials developed here continues to be significant even at $1800^{\circ} \mathrm{C}(2073 \mathrm{~K})$ and $20 \mathrm{MPa}$ pressure. This result is unexpected and may further limit achievable properties unless fully dense materials can be synthesized. The porosity adds to the inhomogeneity of the materials and increases the variability in measured properties.

For example, as shown in Figure 29, there is a noted lack of correlation between measured density and thermal conductivity, which is unexpected given the known effects of porosity on thermal conduction. The variability in thermal conductivity seen in Fig. 29 indicates that some other material variable, perhaps percolation through one of the phases, is determining the thermal properties. If there were a strong correlation between density and thermal conductivity then the phase volume fractions could be adjusted to tune the conductivity and fracture toughness to optimum values.

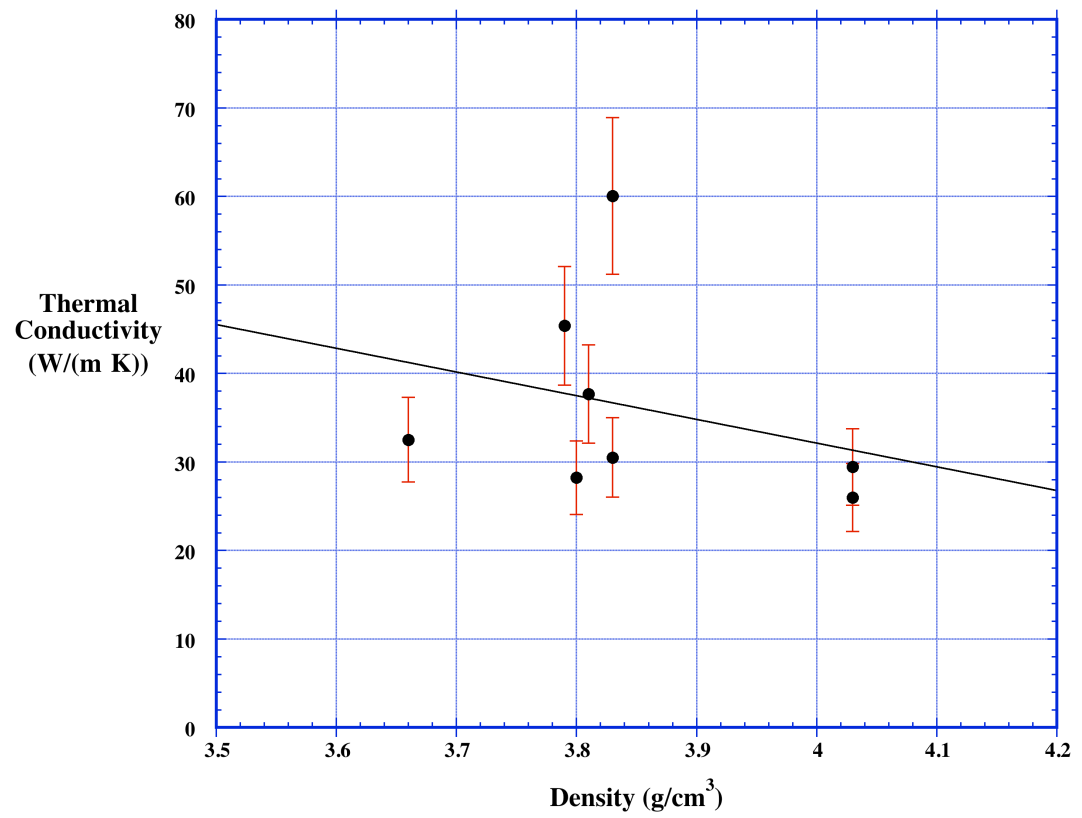

Figure 29. Plot of thermal conductivity as a function of sample density. There is a slight negative correlation between density and conductivity that is unexpected. For the most part, however, this plot shows a lack of a strong correlation since the fitted line has a correlation factor less than 0.3. 


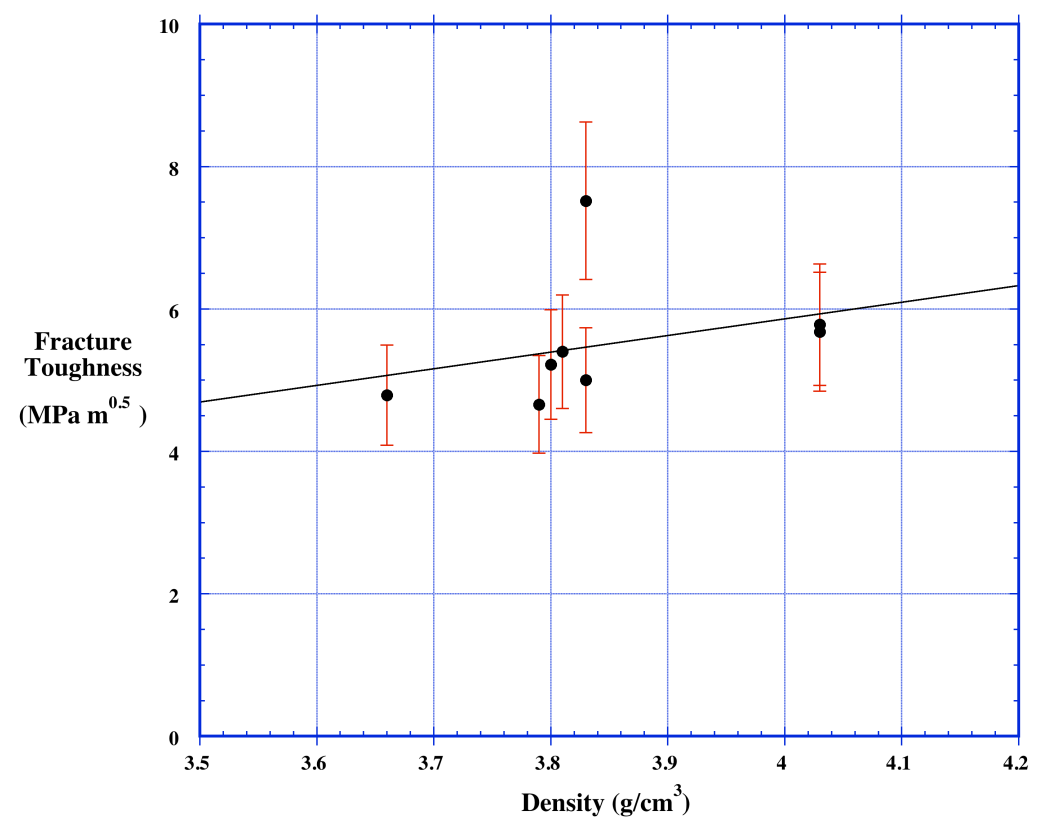

Figure 30. Plot of fracture toughness (indentation method) as a function of sample density. Compared to the lack of correlation for the thermal data this dataset does indicate a general improvement of toughness with increasing density, which would be expected as porosity is decreased.

As is shown in Figure 30, fracture toughness data does show a better correlation with density as increased sample density is positively correlated with an improvement in fracture toughness, which is expected. As porosity is decreased mechanical properties will improve. The fracture toughness data presented here, along with a model data for CNT toughening [97], also suggests that appreciable increases in fracture toughness cannot be achieved using either compositing fabrication as shown in this report or by homogeneously adding CNTs to such a dual phase composite. Rather, this research demonstrates that additional toughening is required and that the development of CNT textured mats must be pursued.

\subsection{Ion Implantation and Fission Product Surrogate Diffusion}

Implantation of $400 \mathrm{keV} \mathrm{Ag}{ }^{2+}, 2 \mathrm{MeV} \mathrm{Au}^{2+}$ and $1 \mathrm{MeV} \mathrm{Cs}^{13+}$ ions were performed to ion fluences of $2.8 \times 10^{16} \mathrm{Ag}^{2+} / \mathrm{cm}^{2}$ (110 dpa for $\mathrm{Ti}_{3} \mathrm{SiC}_{2}$ and $84 \mathrm{dpa}$ for $\mathrm{SiC}$ ) in a dual-phase nanocomposite of $\mathrm{Ti}_{3} \mathrm{SiC}_{2} / 3 \mathrm{C}-\mathrm{SiC}$, polycrystalline CVD $3 \mathrm{C}-\mathrm{SiC}$, and single crystal $6 \mathrm{H}-\mathrm{SiC}$ at $873 \mathrm{~K}, 1.0 \times 10^{16} \mathrm{Au}^{2+} / \mathrm{cm}^{2}(60$ dpa) in polycrystalline $\mathrm{Ti}_{3} \mathrm{SiC}_{2}$ from 230 to $873 \mathrm{~K}$, and $5.7 \times 10^{16} \mathrm{Cs}^{13+} / \mathrm{cm}^{2}$ ( $239 \mathrm{dpa}$ ) in polycrystalline $\mathrm{Ti}_{3} \mathrm{SiC}_{2}$ at $673 \mathrm{~K}$, respectively. The $\mathrm{Ag}^{2+}$ ion implanted nanocomposite and $\mathrm{SiC}$ were furnace annealed at 1073 and $1273 \mathrm{~K}$ for $120 \mathrm{~min}$ at each temperature in flowing Ar gas environment. Both isochronal and isothermal annealing experiments were performed for the $\mathrm{Cs}^{13+}$ implanted $\mathrm{Ti}_{3} \mathrm{SiC}_{2}$ up to $1073 \mathrm{~K}$ and duration of $120 \mathrm{~min}$. Additional furnace annealing was conducted at $1173 \mathrm{~K}$ for $30 \mathrm{~min}$. The implanted and annealed samples were characterized using RBS at room temperature. In-situ RBS measurements near room temperature were made for $\mathrm{Ti}_{3} \mathrm{SiC}_{2}$ implanted with $\mathrm{Au}^{2+}$ ions at temperatures ranging from 230 to $873 \mathrm{~K}$. In addition, HIM and micro-XRD were also used to study the microstructures, phases and implantation damage in $\mathrm{Au}^{2+}$ ion implanted samples. The experimental results from this study are summarized below: 


\subsection{1 $\mathrm{Ag}^{2+}$ ion implanted $\mathrm{Ti}_{3} \mathrm{SiC}_{2} / 3 \mathrm{C}$-SiC dual-phase nanocomposite}

- $\mathrm{Ag}$ is immobile in $\mathrm{SiC}$ up to the highest temperature $(1273 \mathrm{~K})$ applied in this study. However, there is a significant outward diffusion of $\mathrm{Ag}$ in the MAX phase $\mathrm{Ti}_{3} \mathrm{SiC}_{2}$ within the dual-phase nanocomposite of $\mathrm{Ti}_{3} \mathrm{SiC}_{2} / 3 \mathrm{C}-\mathrm{SiC}$ during $\mathrm{Ag}^{2+}$ ion implantation at $873 \mathrm{~K}$. Accumulation of the diffusive Ag on the surface is observed.

- Post-irradiation furnace annealing at $1073 \mathrm{~K}$ in $\mathrm{Ar}$ for $120 \mathrm{~min}$ led to further $\mathrm{Ag}$ outward diffusion; at $1273 \mathrm{~K}$, more extensive Ag out-diffusion and release were observed.

\subsection{2 $\mathrm{Au}^{2+}$ ion implanted polycrystalline $\mathrm{Ti}_{3} \mathrm{SiC}_{2}$}

- The $\mathrm{Au}$ atoms appear to start diffusing in $\mathrm{Ti}_{3} \mathrm{SiC}_{2}$ during implantation at $773 \mathrm{~K}$. There is an extensive $\mathrm{Au}$ out-diffusion in $\mathrm{Ti}_{3} \mathrm{SiC}_{2}$ during implantation at $873 \mathrm{~K}$. Au accumulation on the surface at $873 \mathrm{~K}$ is observed.

- The $230 \mathrm{~K}$ implanted sample appears to exhibit different volume swelling between $\mathrm{Ti}_{3} \mathrm{SiC}_{2}$ and residual TiC. The swelling effect is still visible at $300 \mathrm{~K}$, but becomes less pronounced. The contrast gradually fades out with increasing temperature.

- A secondary $\mathrm{SiC}$ phase is present at $873 \mathrm{~K}$. There is less residual damage produced at higher temperatures during ion irradiation. A highly disordered lattice or an amorphized state near the $\mathrm{Ti}_{3} \mathrm{SiC}_{2}$ surface is likely resulted from $\mathrm{Au}^{2+}$ ion implantation of $\mathrm{Ti}_{3} \mathrm{SiC}_{2}$ at $230 \mathrm{~K}$.

\subsection{3 $\mathrm{Cs}^{13+}$ ion implanted polycrystalline $\mathrm{Ti}_{3} \mathrm{SiC}_{2}$}

- Cs appears to be not very mobile in $\mathrm{Ti}_{3} \mathrm{SiC}_{2}$ during implantation at $673 \mathrm{~K}$ and during postimplantation thermal annealing up to $923 \mathrm{~K}$.

- There is significant Cs diffusion towards the surface at $973 \mathrm{~K}$ with $\sim 36 \%$ Cs released to vacuum $\left(10^{-6}\right.$ Torr) after $30 \mathrm{~min}$ annealing; no evidence of Cs accumulation on the surface at $973 \mathrm{~K}$ is found.

- Further annealing at 1023 and $1073 \mathrm{~K}$ resulted in diminishing diffusion and loss of Cs. About $50 \% \mathrm{Cs}$ was released from the implanted $\mathrm{Ti}_{3} \mathrm{SiC}_{2}$ at $1073 \mathrm{~K}$ for $30 \mathrm{~min}$.

- After first 5 min annealing at $1073 \mathrm{~K}$, Cs tends to diffuse towards the surface, but accumulation of Cs on the surface is not observed. The overall Cs loss is $\sim 10 \%$.

- A more significant Cs loss of $\sim 30 \%$ occurred at $15 \mathrm{~min}$, followed by a total Cs loss of $\sim 40 \%$ at 30 min. Further annealing for longer durations up to $120 \mathrm{~min}$ did not lead to a significant change in the Cs depth profile in $\mathrm{Ti}_{3} \mathrm{SiC}_{2}$.

- MAX phase $\mathrm{Ti}_{3} \mathrm{SiC}_{2}$ is susceptible to oxidation and decomposition at $1173 \mathrm{~K}$.

- After furnace annealing at $1173 \mathrm{~K}$ for $30 \mathrm{~min}$ in flowing $\mathrm{Ar}$ gas, the $\mathrm{Ti}_{3} \mathrm{SiC}_{2}$ surface turned to be mainly titanium oxide. The observation is consistent with a previous report that showed an outer pure $\mathrm{TiO}_{2}$ (rutile) layer and an inner layer comprising $\mathrm{TiO}_{2}$ and $\mathrm{SiO}_{2}$ (silica) after annealing in air at $1373 \mathrm{~K}$ for $360 \mathrm{hrs}$.

The results from this study indicate that diffusion of $\mathrm{Ag}, \mathrm{Au}$ and $\mathrm{Cs}$ in MAX phase $\mathrm{Ti}_{3} \mathrm{SiC}_{2}$ occurs at relatively low temperatures $(773-973 \mathrm{~K})$. Surface oxidation of $\mathrm{Ti}_{3} \mathrm{SiC}_{2}$ takes place at slightly higher temperatures $(1073-1173 \mathrm{~K})$. Because these temperatures are still low for the advanced hightemperature reactor designs, this study may suggest caution in using $\mathrm{Ti}_{3} \mathrm{SiC}_{2}$ as a fuel cladding material for advanced nuclear reactors operating at very high temperatures. Further studies of impurity transport in the related materials may be warranted based on the results of this study. 


\subsection{Modeling and Simulation}

\subsubsection{Mechanical Properties}

Models for elastic properties and damage by matrix cracking were developed and implemented in PNNL's EMTA and EMTA-NLA predictive tools [71, 76]. The damage model associated with a modified boundary layer modeling approach [75] using ABAQUS has allowed us to efficiently predict the composite toughness and crack resistance behavior. Predictions of elastic properties and fracture toughness agree well with Mazaheri et al.'s experimental results [74]. The modeling results show that homogeneously dispersing low to moderate contents of MWCNTs in a ceramic matrix leads to significant increases in the mechanical properties of the as-formed composite, which has a 3D MWCNT orientation distribution. However, the increase in strength and toughness saturates at high MWCNT contents and, therefore, it is not possible to achieve the levels of fracture toughness needed for nuclear reactor applications. Currently, we are working on remedying this limitation by making MWCNT mats with very high volume fractions of MWCNTs. The MWCNT mats will be used in a lay-up similar to a laminated composite. Such a microstructure would achieve higher Mode I fracture toughness, as the composite would better sustain the crack opening stresses.

\subsubsection{Thermal Properties}

An Eshelby-Mori-Tanaka approach implemented in the PNNL-developed EMTA software was used to predict thermal conductivities of $\mathrm{SiC} / \mathrm{SiC}$ composites. The results show that, when perfectly bonded to the fibers, thicker fiber coating layers with higher thermal conductivities than that of the fibers leads to increased thermal conductivities for the composite. EMTA can be effectively used to identify the interfacial thermal conductance by correlating predicted thermal conductivities with measured values for a given composite. A reverse engineering procedure using EMTA is useful to determine the thermal conductivities of the matrix material and of the fiber coating if the actual measured values are not available or are unknown. A sensitivity analysis using EMTA to determine the fiber/matrix interfacial thermal conductance effect indicates that increased thermal conductivities of the composite can be achieved with increasing fiber volume fraction and interfacial thermal conductance. The results show that EMTA is an efficient tool to tailor and optimize thermal conductivities of $\mathrm{SiC} / \mathrm{SiC}$ composites for reactor applications.

A combined MD-EMTA approach demonstrates that under certain regimes these disparate methods can be efficiently applied to predict thermal conductivities as a function of radiation damage and temperature. This was achieved here for the linear point defect swelling regime using vacancy concentrations and irradiation doses for two typical SiC/ICVI-SiC systems made of Tyranno-SA and HiNicalon Type-S fibers. Future work will include the study of grain size effects and temperature on the defect thermal resistance to further develop the MD method. The power of the method is that the computed thermal defect resistance from MD data, Collins et al. thermal conductivity as a function of grain size, and Snead's definition of defect thermal resistance can be used to compute the thermal conductivities of polycrystalline $\mathrm{SiC}$, including CVD-SiC, ICVI-SiC and nearly-stoichiometric SiC fibers in both unirradiated and irradiated conditions. The as-obtained thermal conductivities for $\mathrm{SiC}$ constituents, which are essential to EMTA for predicting thermal conductivity of $\mathrm{SiC} / \mathrm{SiC}$ composites, are accurately predicted in the unirradiated state using the CVD-SiC data and grain size effects. This is a promising result for future predictive work in $\mathrm{SiC}$ and $\mathrm{SiC} / \mathrm{SiC}$ composites under irradiation. 


\subsection{References}

1. Nozawa, T., T. Hinoki, A. Hasegawa, A. Kohyama, Y. Katoh, L.L. Snead, C.H. Henager Jr, and J.B.J. Hegeman, "Recent advances and issues in development of silicon carbide composites for fusion applications," Journal of Nuclear Materials, 2009, 386-388(C), 622-627.

2. Katoh, Y., L.L. Snead, C.H. Henager Jr, A. Hasegawa, A. Kohyama, B. Riccardi, and H. Hegeman, "Current status and critical issues for development of $\mathrm{SiC}$ composites for fusion applications," Journal of Nuclear Materials, 2007, 367-370 A(SPEC ISS), 659-671.

3. Zinkle, S.J., "Advanced materials for fusion technology," Fusion Engineering and Design, 2005, 74(1-4), 31-40.

4. Jones, R.H., L. Giancarli, A. Hasegawa, Y. Katoh, A. Kohyama, B. Riccardi, L.L. Snead, and W.J. Weber, "Promise and challenges of $\mathrm{SiC}_{\mathrm{f}} / \mathrm{SiC}$ composites for fusion energy applications," Journal of Nuclear Materials, 2002, 307-311(2 SUPPL), 1057-1072.

5. Riccardi, B., P. Fenici, A. Frias Rebelo, L. Giancarli, G. Le Marois, and E. Philippe, "Status of the European $\mathrm{RD}$ activities on $\mathrm{SiCf} / \mathrm{SiC}$ composites for fusion reactors," Fusion Engineering and Design, 2000, 51-52, 11-22.

6. Kurtz, R.J., R.H. Jones, E.E. Bloom, A.F. Rowcliffe, D.L. Smith, G.R. Odette, and F.W. Wiffen, "Progress in the United States programme to develop low activation structural materials for fusion," Nuclear Fusion, 1999, 39(Special Issu), 2055-2061.

7. Jones, R.H., L.L. Snead, A. Kohyama, and P. Fenici, "Recent advances in the development of $\mathrm{SiC} / \mathrm{SiC}$ as a fusion structural material," Fusion Engineering and Design, 1998, 41(Pt B), 15-24.

8. Rowcliffe, A.F., E.E. Bloom, R.H. Jones, D.J. Smith, F.W. Wiffen, and W.R. Johnson, "The U.S. program to develop structural materials for near- and long-term fusion systems," Fusion Energy, 1997, 3.

9. Snead, L.L., R.H. Jones, A. Kohyama, and P. Fenici, "Status of silicon carbide composites for fusion," J. Nucl. Mater., 1996, 233-237(Pt. A), 26-36.

10. Sharafat, S., R.H. Jones, A. Kohyama, and P. Fenici, "Status and prospects for SiC-SiC composite materials development for fusion applications," Fusion Engineering and Design, 1995, 29(pt C), 411-420.

11. Hollenberg, G.W., C.H. Henager, G.E. Youngblood, D.J. Trimble, S.A. Simonson, G.A. Newsome, and E. Lewis, "The effect of irradiation on the stability and properties of monolithic silicon carbide and $\mathrm{SiC}_{\mathrm{f}} / \mathrm{SiC}$ composites up to $25 \mathrm{dpa}$," Journal of Nuclear Materials, 1995, 219, 70-86.

12. Henager Jr, C.H. and R.J. Kurtz, "Compatibility of interfaces and fibers for SiC-composites in fusion environments," Journal of Nuclear Materials, 2009, 386-388(C), 670-674.

13. Snead, L.L., T. Nozawa, Y. Katoh, T.-S. Byun, S. Kondo, and D.A. Petti, "Handbook of SiC properties for fuel performance modeling," Journal of Nuclear Materials, 2007, 371(1-3), 329377.

14. Katoh, Y. and L. Snead, "Operating temperature window for SiC ceramics and composites for fusion energy applications," Fusion Science and Technology, 2009, 56(2), 1045-1052.

15. Villmow, T., S. Pegel, A. John, R. Rentenberger, and P. Pötschke, "Liquid sensing: Smart polymer/CNT composites," Materials Today, 2011, 14(7-8), 340-345.

16. Henager Jr, C.H., Y. Shin, Y. Blum, L.A. Giannuzzi, B.W. Kempshall, and S.M. Schwarz, "Coatings and joining for $\mathrm{SiC}$ and $\mathrm{SiC}$-composites for nuclear energy systems," Journal of Nuclear Materials, 2007, 367-370(Part 2), 1139-1143.

17. Radhakrishnan, R., C.H. Henager Jr, J.L. Brimhall, and S.B. Bhaduri, "Synthesis of $\mathrm{Ti}_{3} \mathrm{SiC}_{2} / \mathrm{SiC}$ and $\mathrm{TiSi}_{2} / \mathrm{SiC}$ composites using displacement reactions in the Ti-Si-C system," Scripta Materialia, 1996, 34(12), 1809-1814.

18. Li, J.-F., W. Pan, F. Sato, and R. Watanabe, "Mechanical Properties of Polycrystalline $\mathrm{Ti}_{3} \mathrm{SiC}_{2}$ at Ambient And Elevated Temperatures," Acta Materialia, 2001, 49, 937-945. 
19. Da, C., K. Shirato, M.W. Barsoum, T. El-Raghy, and R.O. Ritchie, "Cyclic fatigue-crack growth and fracture properties in $\mathrm{Ti}_{3} \mathrm{SiC}_{2}$ ceramics at elevated temperatures," Journal of the American Ceramic Society, 2001, 84(12), 2914-20.

20. Zhou, Y., Z. Sun, and B. Yu, "Microstructure of $\mathrm{Ti}_{3} \mathrm{SiC}_{2}$ prepared by the in-situ hot pressing/solidliquid reaction process," Zeitschrift fuer Metallkunde, 2000, 91(11), 937-941.

21. Gilbert, C.J., D.R. Bloyer, M.W. Barsoum, T. El-Raghy, A.P. Tomsia, and R.O. Ritchie, "Fatiguecrack growth and fracture properties of coarse and fine-grained $\mathrm{Ti}_{3} \mathrm{SiC}_{2}$," Scripta Materialia, 2000, 42(8), 761-767.

22. Farber, L., M.W. Barsoum, A. Zavaliangos, and T. El-Raghy, "Dislocations and stacking faults in $\mathrm{Ti}_{3} \mathrm{SiC}_{2}$," Journal of the American Ceramic Society, 1998, 81(6), 1677-1681.

23. Yu, H., X. Zhou, W. Zhang, H. Peng, C. Zhang, and K. Sun, "Properties of carbon nano-tubes-Cf/SiC composite by precursor infiltration and pyrolysis process," Materials and Design, 2011, 32(6), 3516-3520.

24. Zhou, T., X. Wang, X. Liu, and D. Xiong, "Improved thermal conductivity of epoxy composites using a hybrid multi-walled carbon nanotube/micro-SiC filler," Carbon, 2010, 48(4), 1171-1176.

25. Yang, K. and M. Gu, "Enhanced thermal conductivity of epoxy nanocomposites filled with hybrid filler system of triethylenetetramine-functionalized multi-walled carbon nanotube/silane-modified nano-sized silicon carbide," Composites Part A: Applied Science and Manufacturing, 2010, 41(2), 215-221.

26. Thostenson, E.T., R. Zhifeng, and C. Tsu-Wei, "Advances in the science and technology of carbon nanotubes and their composites: a review," Composites Science and Technology, 2001, 61(13), 1899-912.

27. Jiang, W., H. Wang, I. Kim, I.T. Bae, G. Li, P. Nachimuthu, Z. Zhu, Y. Zhang, and W.J. Weber, "Response of nanocrystalline 3C silicon carbide to heavy-ion irradiation," Physical Review B, 2009, 80(16), 161301 (4 pp.).

28. Jiang, W., H. Wang, I. Kim, Y. Zhang, and W.J. Weber, "Amorphization of nanocrystalline 3C-SiC irradiated with Si+ ions," Journal of Materials Research, 2010, 25(12), 2341-2348.

29. Jiang, W., L. Jiao, and H. Wang, "Transition from irradiation-induced amorphization to crystallization in nanocrystalline silicon carbide," Journal of the American Ceramic Society, 2011, 94(12), 4127-4130.

30. Minato, K., H. Kikuchi, K. Fukuda, N. Suzuki, H. Tomimoto, N. Kitamura, and M. Kaneko, "Failure mechanisms of fuel particle coating for high-temperature gas-cooled reactors during the coating processes," Nuclear Technology, 1995, 111(2), 260-274.

31. Minato, K., H. Kikuchi, K. Fukuda, N. Suzuki, H. Tomimoto, N. Kitamura, and M. Kaneko, "Internal flaws in the silicon carbide coating of fuel particles for high-temperature gas-cooled reactors," Nuclear Technology, 1994, 106(3), 342-349.

32. Barrachin, M., R. Dubourg, S. De Groot, M.P. Kissane, and K. Bakker, "Fission-product behaviour in irradiated TRISO-coated particles: Results of the HFR-EU1bis experiment and their interpretation," Journal of Nuclear Materials, 2011, 415(1), 104-116.

33. Minato, K., K. Sawa, T. Koya, T. Tomita, A. Ishikawa, C.A. Baldwin, W.A. Gabbard, and C.M. Malone, "Fission product release behavior of individual coated fuel particles for high-temperature gas-cooled reactors," Nuclear Technology, 2000, 131(1), 36-47.

34. Jiang, W., W.J. Weber, V. Shutthanandan, L. Li, and S. Thevuthasan, "Thermal and dynamic responses of Ag implants in silicon carbide," Nuclear Instruments and Methods in Physics Research, B, 2004, 219-220, 642-646.

35. Friedland, E., N.G. Van Der Berg, J.B. Malherbe, J.J. Hancke, J. Barry, E. Wendler, and W. Wesch, "Investigation of silver and iodine transport through silicon carbide layers prepared for nuclear fuel element cladding," Journal of Nuclear Materials, 2011, 410(1-3), 24-31.

36. Friedland, E., J.B. Malherbe, N.G. van der Berg, T. Hlatshwayo, A.J. Botha, E. Wendler, and W. Wesch, "Study of silver diffusion in silicon carbide," Journal of Nuclear Materials, 2009, 389(2), 326-331. 
37. Xiao, H.Y., Y. Zhang, L.L. Snead, V. Shutthanandan, H.Z. Xue, and W.J. Weber, "Near-surface and bulk behavior of Ag in SiC," Journal of Nuclear Materials, 2012, 420(1-3), 123-130.

38. Barsoum, M.W., "Mechanical Properties: Ambient Temperature," in MAX Phases, 2013, Wiley-VCH Verlag GmbH \& Co. KGaA, p. 307-361.

39. Nappe, J.C., I. Monnet, F. Audubert, P. Grosseau, M. Beauvy, and M. Benabdesselam, "Formation of nanosized hills on Ti3SiC2 oxide layer irradiated with swift heavy ions," Nuclear Instruments and Methods in Physics Research, Section B: Beam Interactions with Materials and Atoms, 2012, 270(1), 36-43.

40. Nappe, J.C., I. Monnet, P. Grosseau, F. Audubert, B. Guilhot, M. Beauvy, M. Benabdesselam, and L. Thome, "Structural changes induced by heavy ion irradiation in titanium silicon carbide," Journal of Nuclear Materials, 2011, 409(1), 53-61.

41. Nappe, J.C., C. Maurice, P. Grosseau, F. Audubert, L. Thome, B. Guilhot, M. Beauvy, and M. Benabdesselam, "Microstructural changes induced by low energy heavy ion irradiation in titanium silicon carbide," Journal of the European Ceramic Society, 2011, 31(8), 1503-1511.

42. Barsoum, M.W., "Introduction," in MAX Phases, 2013, Wiley-VCH Verlag GmbH \& Co. KGaA, p. $1-12$.

43. Kisi, E.H., J.A.A. Crossley, S. Myhra, and M.W. Barsoum, "Structure and crystal chemistry of Ti3SiC2," Journal of the Physics and Chemistry of Solids, 1998, 59(9), 1437-43.

44. Barsoum, M.W., "Dislocations, Kinking Nonlinear Elasticity, and Damping," in MAX Phases, 2013, Wiley-VCH Verlag GmbH \& Co. KGaA, p. 271-305.

45. Barsoum, M.W., T. El-Raghy, C.J. Rawn, W.D. Porter, H. Wang, E.A. Payzant, and C.R. Hubbard, "Thermal properties of $\mathrm{Ti}_{3} \mathrm{SiC}_{2}$," Journal of the Physics and Chemistry of Solids, 1999, 60(4), 429-39.

46. Barsoum, M.W., "Thermal Properties," in MAX Phases, 2013, Wiley-VCH Verlag GmbH \& Co. KGaA, p. 107-153.

47. Emmerlich, J., D. Music, P. Eklund, O. Wilhelmsson, U. Jansson, J.M. Schneider, H. Hogberg, and L. Hultman, "Thermal stability of Ti3SiC2 thin films," Acta Materialia, 2007, 55(4), 1479-88.

48. Barsoum, M.W., T. El-Raghy, and L.U.J.T. Ogbuji, "Oxidation of Ti3SiC2 in air," Journal of the Electrochemical Society, 1997, 144(7), 2508-16.

49. Travaglini, J., M.W. Barsoum, V. Jovic, and T. El-Raghy, "The corrosion behavior of Ti3SiC2 in common acids and dilute $\mathrm{NaOH}$," Corrosion Science, 2003, 45(6), 1313-27.

50. Barsoum, M.W. and T. El-Raghy, "Synthesis and characterization of a remarkable ceramic: Ti3SiC2," Journal of the American Ceramic Society, 1996, 79(7), 1953-6.

51. El-Raghy, T., M.W. Barsoum, A. Zavaliangos, and S.R. Kalidindi, "Processing and mechanical properties of Ti3SiC2: II, Effect of grain size and deformation temperature," Journal of the American Ceramic Society, 1999, 82(10), 2855-2860.

52. Zhen, T., M.W. Barsoum, S.R. Kalidindi, M. Radovic, Z.M. Sun, and T. El-Raghy, "Compressive creep of fine and coarse-grained $\mathrm{T} 3 \mathrm{SiC} 2$ in air in the 1100-1300 c temperature range," Acta Materialia, 2005, 53(19), 4963-4973.

53. Radovic, M., M.W. Barsoum, T. El-Raghy, and S.M. Wiederhorn, "Tensile creep of coarse-grained Ti3SiC2 in the 1000-1200C temperature range," Journal of Alloys and Compounds, 2003, 361, 299-312.

54. Liu, X.M., M. Le Flem, J.L. Bechade, F. Onimus, T. Cozzika, and I. Monnet, "XRD investigation of ion irradiated Ti3Si0.90A10.10C2," Nuclear Instruments \&amp; Methods in Physics Research, Section B (Beam Interactions with Materials and Atoms), 2010, 268(5), 506-12.

55. Le Flem, M., X. Liu, S. Doriot, T. Cozzika, and I. Monnet, "Irradiation damage in Ti3(Si,Al)C2: A TEM investigation," International Journal of Applied Ceramic Technology, 2010, 7(6), 766-775.

56. Henager Jr, C.H., J.L. Brimhall, and J.P. Hirth, "Synthesis of a MoSi2/SiC composite in situ using a solid state displacement reaction between Mo2C and Si," Scripta Metallurgica et Materialia, 1992, 26(4), 585-589. 
57. Katoh, Y., L.L. Snead, T. Cheng, C. Shih, W.D. Lewis, T. Koyanagi, T. Hinoki, C.H. Henager Jr, and M. Ferraris, "Radiation-tolerant joining technologies for silicon carbide ceramics and composites," Journal of Nuclear Materials, 2014, 448(1-3), 497-511.

58. Katoh, Y., L.L. Snead, C.H. Henager, Jr., T. Hinoki, M. Ferraris, and S.T. Gonczy, "Joining Silicon Carbide for Advanced LWR Fuel Cladding," in 2012 Winter Meeting, 11-15 Nov. 2012, 2012, USA: American Nuclear Society.

59. Henager, J., Charles H. and R.J. Kurtz, "Low-activation joining of $\mathrm{SiC} / \mathrm{SiC}$ composites for fusion applications," Journal of Nuclear Materials, 2011, 417(1-3), 375-378.

60. Henager Jr, C.H., Y. Shin, Y. Blum, L.A. Giannuzzi, B.W. Kempshall, and S.M. Schwarz, "Coatings and joining for $\mathrm{SiC}$ and $\mathrm{SiC}$-composites for nuclear energy systems," Journal of Nuclear Materials, 2007, 367-370 B(SPEC ISS), 1139-1143.

61. Henager, C.H., Jr. and R.H. Jones, "Joining SiC ceramics using displacement reactions," in Ceramics Transactions, 1996, Indianapolis, IN: The American Ceramic Society.

62. Henager, C.H., Jr., J.L. Brimhall, and L.N. Brush, "Tailoring structure and properties of composites synthesized in situ using displacement reactions," Materials Science \& Engineering A: Structural Materials: Properties, Microstructure and Processing, 1995, A195(1-2), 65.

63. Williford, R.E., C.H. Henager Jr, and J.P. Hirth, "Matrix creep accommodation in diffusion controlled phase transformations," Acta Materialia, 1996, 44(Compendex), 763-773.

64. Jianfeng, Z., W. Ting, W. Lianjun, J. Wan, and C. Lidong, "Microstructure and properties of $\mathrm{Ti}_{3} \mathrm{SiC}_{2} / \mathrm{SiC}$ nanocomposites fabricated by spark plasma sintering," Composites Science and Technology, 2008, 68(2), 499-505.

65. Anstis, G.R., P. Chantikul, B.R. Lawn, and D.B. Marshall, "A critical evaluation of indentation techniques for measuring fracture toughness. I. Direct crack measurements," Journal of the American Ceramic Society, 1981, 64(9), 533-8.

66. Ziegler, J.F., M.D. Ziegler, and J.P. Biersack, "SRIM - The stopping and range of ions in matter (2010)," Nuclear Instruments and Methods in Physics Research, B, 2010, 268(11-12), 1818-1823.

67. Audren, A., A. Benyagoub, L. Thome, and F. Garrido, "Ion implantation of Cs into silicon carbide: Damage production and diffusion behaviour," Nuclear Instruments and Methods in Physics Research, B, 2007, 257(1-2 SPEC. ISS.), 227-230.

68. Friedland, E., N.G. Van Der Berg, T.T. Hlatshwayo, R.J. Kuhudzai, J.B. Malherbe, E. Wendler, and W. Wesch, "Diffusion behavior of cesium in silicon carbide at T $>1000 \mathrm{C}$," Nuclear Instruments and Methods in Physics Research, B, 2012, 286, 102-107.

69. Nguyen, B.N. and C.H. Henager Jr, "Fiber/matrix interfacial thermal conductance effect on the thermal conductivity of $\mathrm{SiC} / \mathrm{SiC}$ composites," Journal of Nuclear Materials, 2013, 440(1-3), 1120.

70. C. H. Henager, J. and B.N. Nguyen, "Thermal Conductivity of SiC/SiC Composites: Porting PNNL EMTA code for Fusion Analyses," in Fusion Reactor Materials Program Semiannual Progress Reports, Vol. 53, F. Wiffen, R. Godfrey, and B. Waddell, Editors, 2012, ORNL: Oak Ridge, TN, p. $118-121$.

71. Nguyen, B.N., "EMTA User's Guide," PNNL-19997, 2010, PNNL, Richland, WA.

72. Ba Nghiep, N. and V. Kunc, "An Elastic-plastic Damage Model for Long-fiber Thermoplastics," International Journal of Damage Mechanics, 2010, 19(6), 691-725.

73. Advani, S.G. and C.L. Tucker Iii, "The Use of Tensors to Describe and Predict Fiber Orientation in Short Fiber Composites," Journal of Rheology, 1987, 31(8), 751-784.

74. Mazaheri, M., D. Mari, Z.R. Hesabi, R. Schaller, and G. Fantozzi, "Multi-walled carbon nanotube/nanostructured zirconia composites: Outstanding mechanical properties in a wide range of temperature," Composites Science and Technology, 2011, 71(7), 939-45.

75. Nguyen, B.N., B.J. Koeppel, S. Ahzi, M.A. Khaleel, and P. Singh, "Crack Growth in Solid Oxide Fuel Cell Materials: From Discrete to Continuum Damage Modeling," Journal of the American Ceramic Society, 2006, 89(4), 1358-1368.

76. Nguyen, B.N., "EMTA-NLA User's Guide," PNNL-20013, 2010, PNNL, Richland, Washington. 
77. Krause Jr., R.F., "Rising Fracture Toughness from the Bending Strength of Indented Alumina Beams," Journal of the American Ceramic Society, 1988, 71(5), 338-343.

78. Ramachadran, N. and D.K. Shetty, "Rising Crack-Growth-Resistance (R-curve) Behavior of Toughened Alumina and Silicon Nitride," Journal of the American Ceramic Society, 1991, 74(10), 2634-2641.

79. Sarka, S. and P.K. Das, "Temperature and Load Dependent Mechanical Properties of Pressureless Sintered Carbon Nanotube/Alumina Nanocomposites," Materials Sciences and Engineering A, 2012, 531, 61-69.

80. Hatta, H. and M. Taya, "Equivalent inclusion method for steady state heat conduction in composites," International Journal of Engineering Science, 1986, 24(7), 1159-72.

81. Mori, T. and K. Tanaka, "Average stress in matrix and average elastic energy of materials with misfitting inclusions," Acta Metallurgica, 1973, 21(5), 571-4.

82. Eshelby, J.D., "The Determination of the Elastic Field of an Ellipsoidal Inclusion and Related Problems," Proceedings of the Royal Society London, 1957, A241, 376-396.

83. Benveniste, Y., "A New Approach to the Application of Mori-Tanaka's Theory in Composite Materials," Mechanics of Materials, 1987, 6(2), 147-157.

84. Youngblood, G.E., D.J. Senor, R.H. Jones, and W. Kowbel, "Optimizing the transverse thermal conductivity of 2D-SiCf/ SiC composites , II. Experimental," Journal of Nuclear Materials, 2002, 307-311(Pt. B), 1120-1125.

85. Youngblood, G.E., D.J. Senor, and R.H. Jones, "Optimizing the transverse thermal conductivity of 2D-SiCf/ SiC composites . I. Modeling," Journal of Nuclear Materials, 2002, 307-311(Pt. B), $1112-1119$

86. Youngblood, G.E., D.J. Senor, R.H. Jones, and S. Graham, "The transverse thermal conductivity of 2D-SiCf/ SiC composites," Composites Science and Technology, 2002, 62(9), 1127-1139.

87. Youngblood, G.E., D.J. Senor, and R.H. Jones, "Modeling the transverse thermal conductivity of 2-D $\mathrm{SiCf} / \mathrm{SiC}$ composites made with woven fabric," Fusion Science and Technology, 2004, 45(4), 583-591.

88. Collins, A.K., M.A. Pickering, and R.L. Taylor, "Grain size dependence of the thermal conductivity of polycrystalline chemical vapor deposited $\beta$-SiC at low temperatures," Journal of Applied Physics, , 1990, 68, 6510-6512.

89. Youngblood, G.E., R.H. Jones, and R. Yamada, "Modeling the transverse thermal conductivity of 3D$\mathrm{SiCf} / \mathrm{SiC}$ composites," in Fusion Reactor Materials Semiannual Progress Report, Vol. 36, F. Wiffen, R. Godfrey, and B. Waddell, Editors, 2004, ORNL: Oak Ridge, TN, p. 44-51.

90. Snead, L.L., "Limits on irradiation-induced thermal conductivity and electrical resistivity in silicon carbide materials," in Proceedings of the 11th Conference on Fusion Research, December 7, 2003 - December 12, 2003, 2004, Kyoto, Japan: Elsevier.

91. Senor, D.J., G.E. Youngblood, L.R. Greenwood, D.V. Archer, D.L. Alexander, M.C. Chen, and G.A. Newsome, "Defect structure and evolution in silicon carbide irradiated to $1 \mathrm{dpa}-\mathrm{SiC}$ at $1100 \mathrm{C}$," Journal of Nuclear Materials, 2003, 317(2-3), 145-159.

92. Crocombette, J.-P. and L. Gelebart, "Multiscale modeling of the thermal conductivity of polycrystalline silicon carbide," Journal of Applied Physics, 2009, 106(8).

93. Crocombette, J.-P. and L. Proville, "Thermal conductivity degradation induced by point defects in irradiated silicon carbide," Applied Physics Letters, 2011, 98(19).

94. Samolyuk, G.D., S.I. Golubov, Y.N. Osetsky, and R.E. Stoller, "Molecular dynamics study of influence of vacancy types defects on thermal conductivity of -SiC," Journal of Nuclear Materials, 2011, 418(1-3), 174-181.

95. Gao, F. and W.J. Weber, "Cascade overlap and amorphization in 3C-SiC: Defect accumulation, topological features, and disordering," Physical Review B (Condensed Matter and Materials Physics), 2002, 66(2), 024106-1. 
96. Katoh, Y., L.L. Snead, T. Nozawa, S. Kondo, and J.T. Busby, "Thermophysical and mechanical properties of near-stoichiometric fiber $\mathrm{CVI} \mathrm{SiC} / \mathrm{SiC}$ composites after neutron irradiation at elevated temperatures," Journal of Nuclear Materials, 2010, 403(1-3), 48-61.

97. Nguyen, B.N. and J. Henager C.H, "Mode I Fracture Toughness Prediction for Multiwalled-CarbonNanotube Reinforced Ceramics," Journal of the American Ceramics Society, 2014, submitted for publication (in review). 



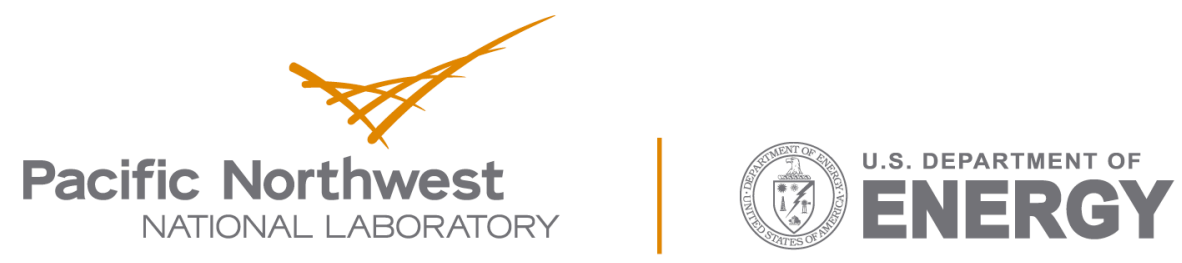

Proudly Operated by Battelle Since 1965

902 Battelle Boulevard

P.O. Box 999

Richland, WA 99352

1-888-375-PNNL (7665)

www.pnnl.gov 